\title{
A method for three-dimensional stem analysis and its application in a study on the occurrence of resin pockets in Pinus patula
}

by

Frederik Johannes Lerm

Thesis presented in partial fulfilment of the requirements for the degree of Master of Science in Forestry (Wood Products Science) at Stellenbosch University

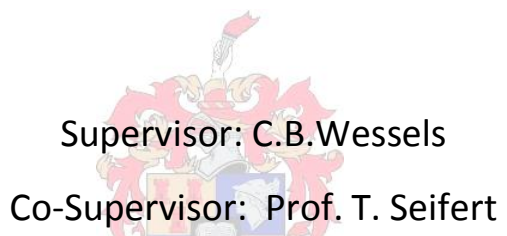

March 2013 


\section{Declaration}

By submitting this thesis electronically, I declare that the entirety of the work contained therein is my own, original work, that I am the sole author thereof (save to the extent explicitly otherwise stated), that reproduction and publication thereof by Stellenbosch University will not infringe any third party rights and that I have not previously in its entirety or in part submitted it for obtaining any qualification.

March 2013

Copyright (C) 2013 Stellenbosch University

All rights reserved 


\section{Summary}

Information on the external shape and internal properties of a tree such as the branch structure, tree ring widths and formation, and defects such as resin pockets is important for many forest -and wood science researchers as well as for the forest and wood processing industries. Resin pockets are internal defects associated with some softwood species, and are undesirable in some wood applications such as furniture and veneer. A tool that is often used in research to obtain this information is the Computed Tomography scanner. The high cost of the scanner, as well as the cost of transporting logs to the scanner, limits the application range of this equipment. An alternative, lower cost method would be beneficial for many researchers interested in tree shape and macroscopic internal tree characteristics. The objectives of this study were to:

- Design, construct and test a mobile system that can be used in field to obtain a three-dimensional model of a log or tree stem indicating selected macroscopic internal characteristics and,

- Interpret results to explain the occurrence and causes of resin pockets in Pinus patula from the Mpumalanga escarpment, South Africa.

A system for dissecting and measuring trees in field was designed, constructed and tested. The metal frame was used to cut a stationary, fixed log into discs and obtain digital images of crosssections along the stem axis. The frame was capable of processing logs with maximum dimensions of $3 \mathrm{~m}$ in length and $45 \mathrm{~cm}$ in diameter. Software was developed to convert the digital images into three-dimensional models of logs and trees to demonstrate properties such as the external shape of the trees, branch structure and pith location. Properties such as ring width were measured from the images obtained.

The study was conducted in the Mpumalanga escarpment to obtain three-dimensional models of Pinus patula trees and to establish the reason for formation of resin pockets in these trees. 
Four $3 \mathrm{~m}$ logs from twenty-four trees from three compartments were dissected and digitally reconstructed into three-dimensional models.

A total of 61 cross sections with resin pockets were identified from the 2750 cross cut images taken $20 \mathrm{~cm}$ apart along the longitudinal axis of the log. It was not possible to accept or reject conclusively any of the existing hypotheses for the cause of resin pocket formation. The formation of Type 2 resin pockets was most probably due to felling damage during thinning operations. It seems likely that wind damage and possibly insects might be responsible for the formation of Type 1 resin pockets. 


\section{Opsomming:}

Kennis in verband met die interne eienskappe van 'n boom soos takeienskappe, jaarringwydte en vorm, en harsholtes is belangrik vir sommige bos -en houtkundige navorsers. Die toerusting wat huidiglik algemeen gebruik word om inligting van hierdie aard te bekom is ' $n$ CTskandeerder. Die metode is egter duur as gevolg van hoë kapitale koste van die toerusting sowel as die vervoerkoste van stompe na die CT-fasiliteit. ' $\mathrm{n}$ Meer ekonomiese alternatief sal vir baie navorsers van waarde wees. Harsholtes in hout lei tot afgradering van hout en fineer.

Die doel van die studie was twee-sydig:

- Om 'n stelsel te ontwerp en bou wat ' $\mathrm{n}$ drie-dimensionele model van 'n boom kan skep wat sommige makroskopiese, interne eienskappe weergee, en

- Om die voorkoms en oorsaak van harsholtes in Pinus Patula van die Mpumalanga platorand te ondersoek.

'n Raam is ontwerp en vervaardig wat in die plantasie gebruik word. Die raam kan stompe van tot drie meter lengte met ' $\mathrm{n}$ maksimale diameter van $45 \mathrm{~cm}$ hanteer. Die raam is gebruik om snitte deur die stompe te maak, 'n afstandmeting tot by die gesaagde oppervlak word deur ' $n$ lasermeter geneem en 'n kamera neem 'n foto. Sagteware word dan gebruik vir die uitkenning van sekere dele in elke beeld sowel as die samestelling van 'n drie-dimensionele model.

Data-insameling met die raam is in Mpumalanga gedoen. Die raam is in die tydperk getoets en het goed gefunksioneer. Vier stompe elk vanaf vier-en-twintig bome vanuit drie afsonderlike kompartemente is verwerk op die raam en volledige drie-dimensionele modelle geskep vir hierdie bome insluitend hul eksterne vorm, takeienskappe en pitvorm ("pith location"). 
Ongeveer 2750 foto's van dwarssnitte is tydens data-insameling geneem. Net 61 van die foto's het harsholtes bevat. Geen definitiewe oorsaak van harsholtes kon bepaal word nie. Tipe 2 harsholtes word waarskynlik as gevolg van skade tydens uitdunning van bome gevorm. Wind en insekte lyk na die mees waarskynlike oorsake van Tipe 1 harsholtes. 


\section{Acknowledgements}

I would like to thank the following people for the contribution and assistance they made towards the successful completion of this study.

Brand Wessels: Assistance

Dr. Ben du Toit and Prof. Thomas Seifert: Assistance with study on resin pocket formation

Willie Brink: Developing a part of the software for reconstructing a 3D-model of trees

Anton Kunneke: Assistance with programming 


\section{Contents}

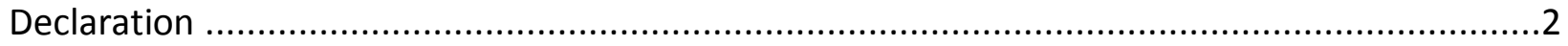

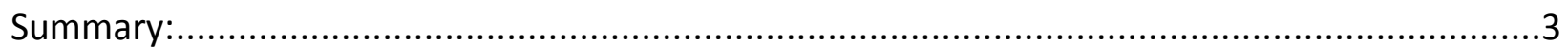

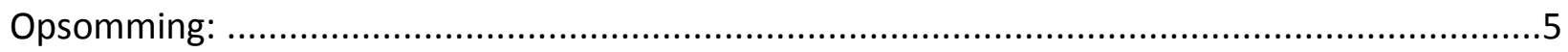

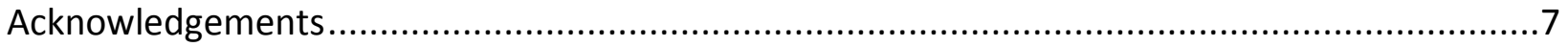

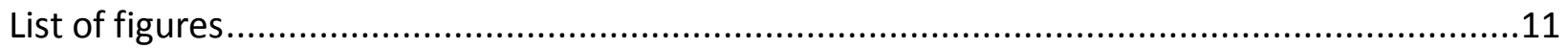

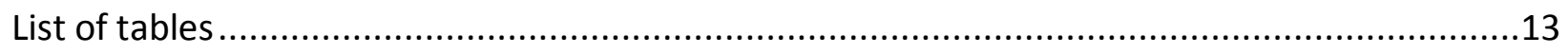

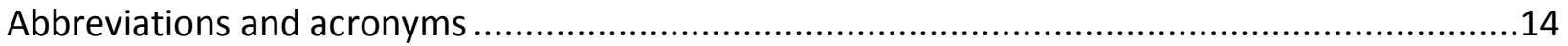

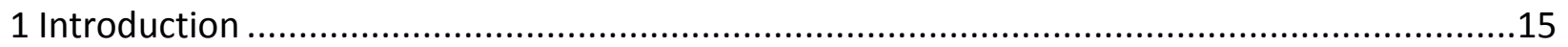

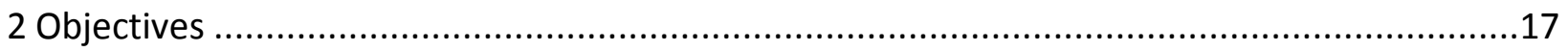

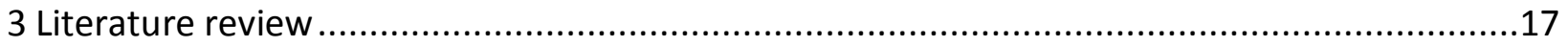

3.1 Sawmill recovery and latest CT scanning technology........................................17

3.2 Other devices for stem analysis ...................................................................... 19

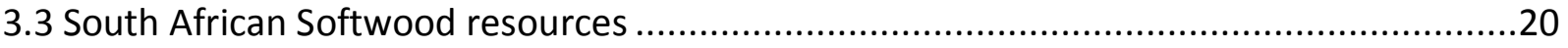

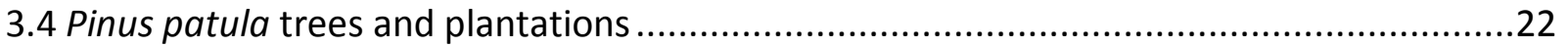

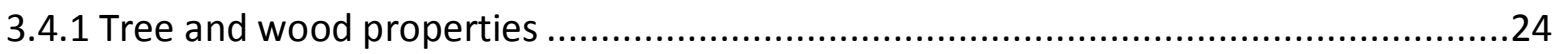

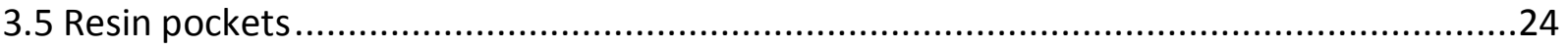

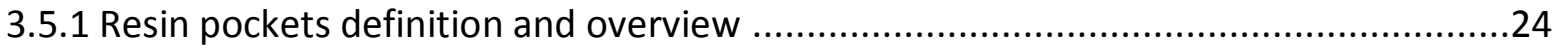

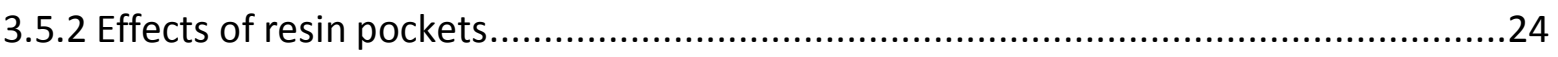

3.5.3 Economic influence of resin pockets in South African grown Pinus Patula ................25

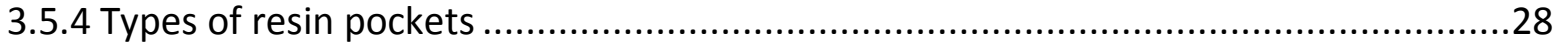

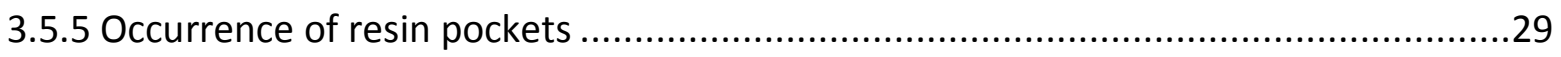

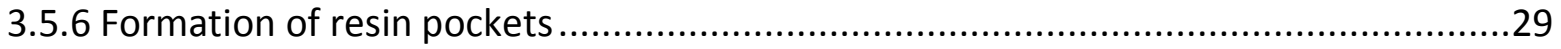

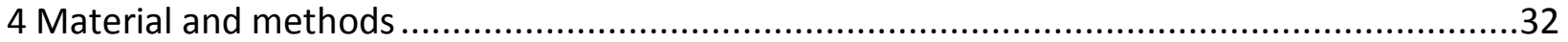


4.1 Part 1: Development of log analysis system .......................................................33

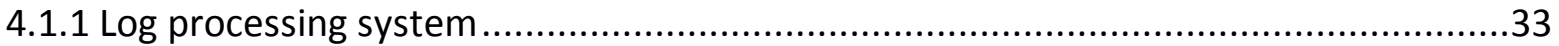

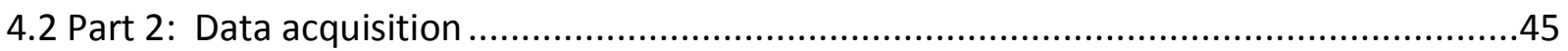

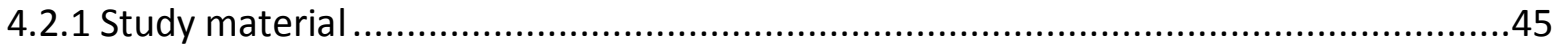

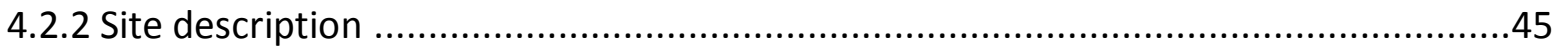

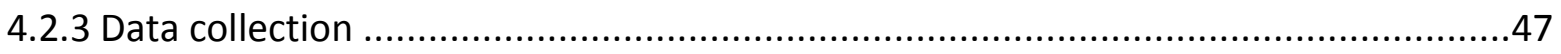

4.3 Software for image analysis and log reconstruction ...........................................47

4.3.1 Plug-in for identifying outline, pith and knots ............................................48

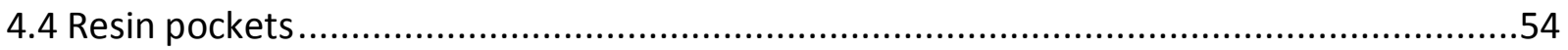

4.4.1 Testing of resin pocket formation hypotheses ….............................................5

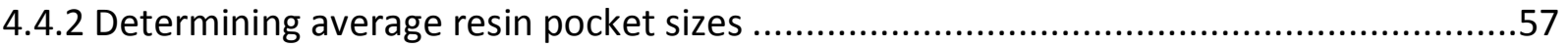

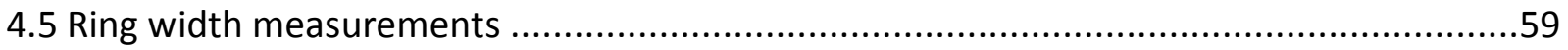

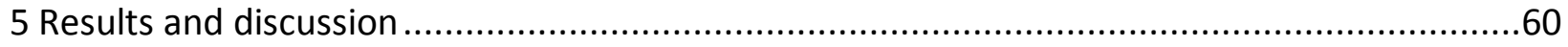

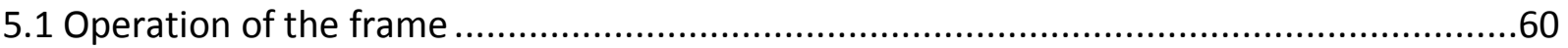

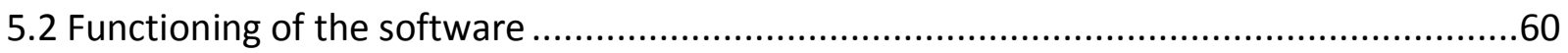

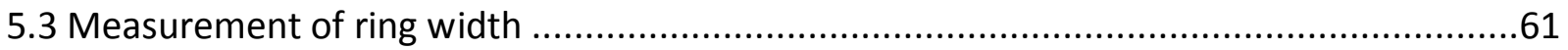

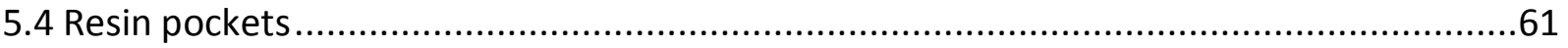

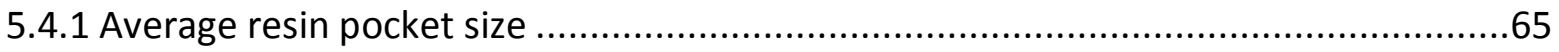

5.4.2 Statistical method for determining number of resin pockets in material ................67

5.4 .3 Indications of possible reasons for resin pocket formation ..................................70

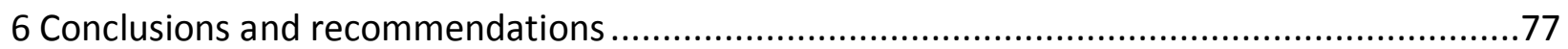

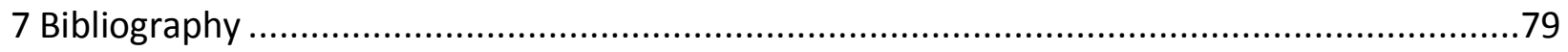

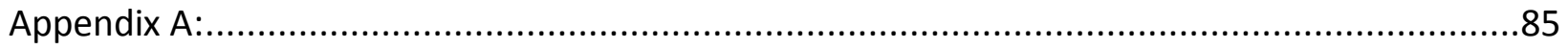

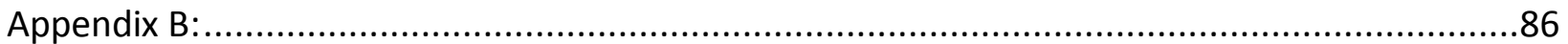




\section{List of figures}

Figure 1: $(A)$ : Device used for measuring sweep. The device consists of a main structure (1), two bubble levels, three nails, a metallic arm (2), and a levelling system composed of four thin bolts.

(B): Coordinate system explained (Cominetti et al., 2002) ....................................................20

Figure 2: Plantation area by species 2009 (Adapted from DAFF, 2011)...............................21

Figure 3: Changing markets: South African softwood sawn timber by end-use from 2000-2010 (adapted from Crickmay and Associates Lumber Index) ......................................................27

Figure 4: Type 1 resin pocket (Watt et al, 2011).................................................................28

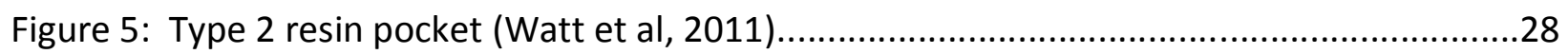

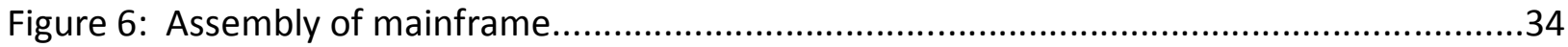

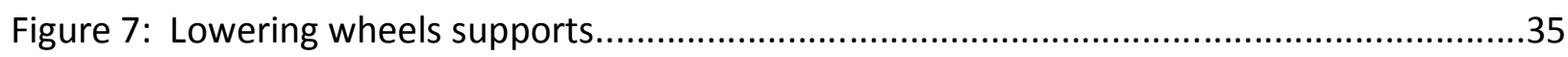

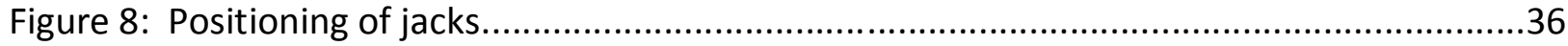

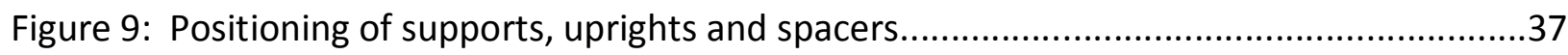

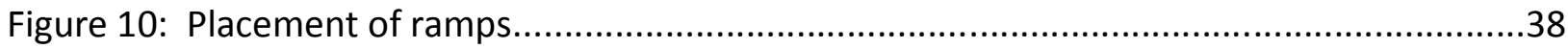

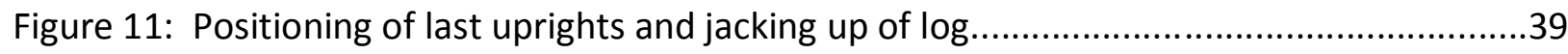

Figure 12: Position of sharpened bolt and placement of chainsaw.....................................40

Figure 13: Assembly and position of camera frame .....................................................41

Figure 14: Position of lasermeter and camera...................................................................41

Figure 15: Completely assembled frame infield........................................................42

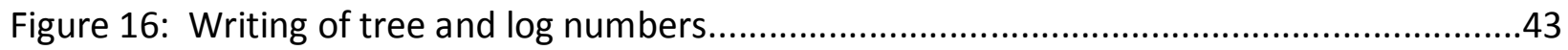

Figure 17: Area of interest in Mpumalanga (Google earth)...............................................46

Figure 18: Zoomed in image indicating locations of sites (Google earth)..............................46

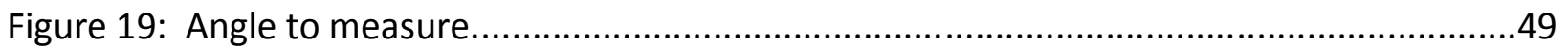

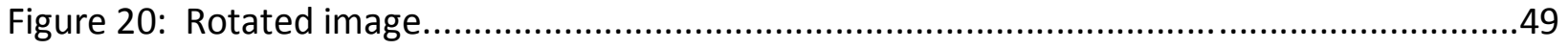


Figure 21: Rotated image...................................................................................................

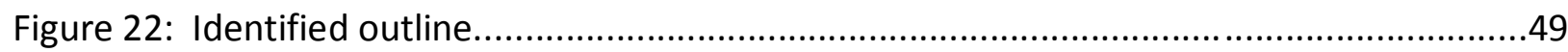

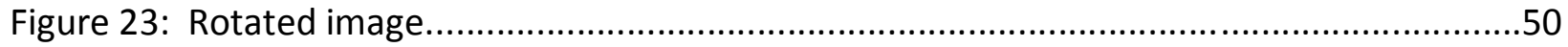

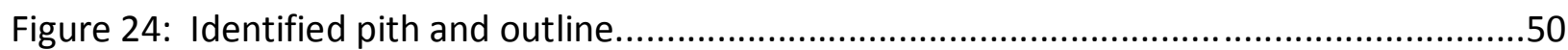

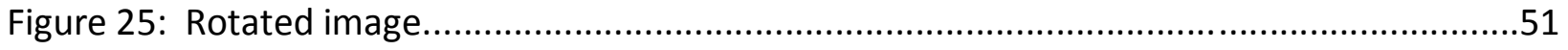

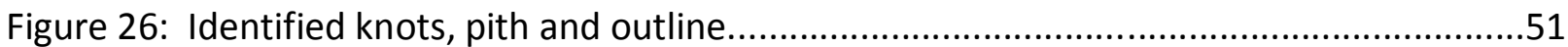

Figure 27: Example of 3D-model..........................................................................................5

Figure 28: CAF CT scanner at Stellenbosch University........................................................58

Figure 29: Scanned disk with resin pocket identified................................................................59

Figure 30: Comparison of ring width measurements..........................................................61

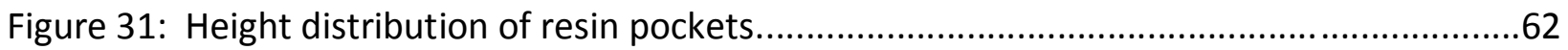

Figure 32: Frequency of resin pockets per year................................................................63

Figure 33: Frequency of resin pockets per cambial age............................................................63

Figure 34: Resin pocket occurrence per compartment..............................................................

Figure 35: Resin pocket occurrence per tree.........................................................................65

Figure 36: Reference evaporation and median rainfall compared to actual rainfall for site Blyde C22 for a high rainfall year, an average rainfall year and a low rainfall year................................73

Figure 37: Annual rainfall compared to mean annual rainfall for site Blyde C22......................74

Figure 38: Reference evaporation and median rainfall compared to actual rainfall for site Morgenzon E3 for a high rainfall year, an average rainfall year and a low rainfall year...............75

Figure 39: Annual rainfall versus number of resin pockets formed.............................................75 


\section{List of tables}

Table 1: Yield increase through optimization (Rinnhofer et al., 2003)

Table 2: Roundwood sales by product and zone (Adapted from DAFF, 2011).

Table 3: Optimum site conditions for growing Pinus patula in South Africa (Adapted from Vermaak, 2007).

Table 4: Permissible defects, other than decay, insect damage, cross-fracture, mechanical

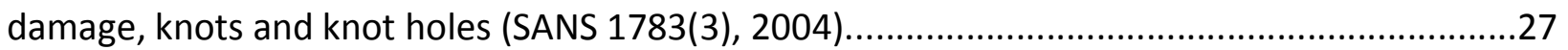

Table 5: Plywood standards from York-timbers...........................................................27

Table 6: Site descriptors including age, height, mean annual precipitation and mean annual

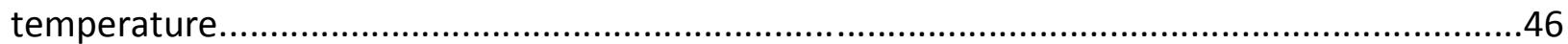

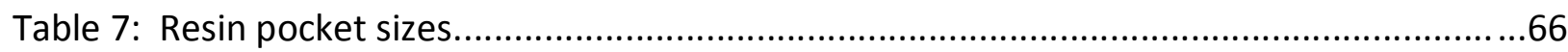

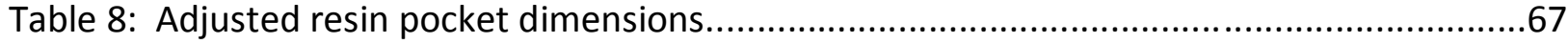




\section{Abbreviations and acronyms}

DBH: Diameter at breast height

CT: Computed tomography

3D: Three dimensional

SANS: South African National Standards 


\section{Introduction}

There is often a need to analyse tree stems three-dimensionally for properties such as stem form, ring structure, branch properties and various other characteristics. Wei et al. (2009) stated: "...a common method for the human eye to observe an object is always through the three-dimensional (3D) form of the object". This statement clearly explains the importance or the potential value of three dimensional models of tree stems. Makela and Makinen (2002) suggested a model for prediction of stem structure, in particular the three dimensional geometry of the stem and its internal knots. Three-dimensional models can also be used for simulation, such as log breakdown simulation (Bhandarkar et al. 1999). During this procedure the model is used as input into sawing simulation software such as Simsaw 6 developed by the CSIR. Simsaw can be used to determine recovery from different sawing patterns, given certain inputs.

The system most often used to obtain such a three-dimensional model is a CT-scanner with specialised software to combine the set of cross-sectional images from the scanner into a three-dimensional model of the object. One of the main advantages to this system is that it is non-destructive. While proven a versatile method in tree and wood research (e.g. Nikolova et al. 2009, Seifert et al. 2010) the disadvantage of CT-scanning is that it is very expensive. CT scanning systems are usually also located in a laboratory not necessarily close to forests (although portable CT scanners have been developed in the past i.e. Onoe et al. 1984, Habermehl and Ridder. 1999). In most countries around the world no CT scanning facilities are available for forest and tree related work. Removing and transporting tree stems to a CT scanning facility add further costs to these systems. For research purposes these high costs limit the potential application of CT scanning. Thus, a more cost effective, in field system, for obtaining a 3-dimensional model from a tree would be beneficial. 
Occena et al. (2001) stated that 'Trends of increased log costs and limited availability are forcing wood processors to become more efficient in their operations'. Other than making sure that sawmills are operating at full capacity the only way of becoming more efficient is to make optimum use of the log.

In this study a relatively low-cost system for the three-dimensional reconstruction of full tree stems was developed to provide some of the data typically generated by CT-scanning. This system was used in the field by two persons so that no transport of logs was required. The three-dimensional tree stem models from this system can be used for wood property assessment and sawing simulation. In this study the system was applied to analyse the occurrence of resin pockets in Pinus patula trees from Mpumalanga, South Africa. Information obtained in this study regarding branches, will be used in another study.

Temnerud et al. (1999) and Seifert et al. (2010), in accordance with Larson (1994), chose to define resin pockets as: "...an intercellular circumferentially elongated pocket in the xylem with resin and wound tissue, which is usually occluded the same year as it is formed." A resin pocket is considered as a defect in some wood products as it decreases the value of timber and veneer and there is a need to understand the occurrence and causes of formation better. According to a local experts' opinion Pinus patula is probably the one pine species in South Africa where resin pockets are found the most often (Malan, 2011). After a recent visual inspection (done by the author) of Pinus patula timber from the Mpumalanga escarpment it was found that resin pockets were present to a significant extent. 


\section{Objectives}

The objectives of this study were as follows:

- To develop an in-field system that can be used to obtain a three-dimensional model of a tree, including selected internal characteristics.

- To analyse resin pocket occurrence and identify the main cause of resin pocket formation in Pinus patula from Mpumalanga, South Africa.

\section{Literature review}

\subsection{Sawmill recovery and latest CT scanning technology}

By increasing volume recovery by about five percent, which is possible according to previous studies (Bhandarkar 1999, Rinnhofer 2003), large sawmills in South Africa with an annual log intake of $200000 \mathrm{~m}^{3}$ can increase their revenue by about R24 190000 per annum (based on the price for structural timber in August 2012). To optimize value recovery, more information is needed on the log that will enable sawmills to break it down for optimal value.

Information that is needed to optimize sawing patterns and thus, ultimately, recovery includes the outer shape of the log as well as some internal properties. If we have accurate information on both these aspects it is safe to say that we can devise better possible breakdown methods for each log. Optimal cutting, based on inner quality evaluation of Nordic softwoods, can theoretically increase the economic yield of lumber products by $10 \%$ or more (Birkeland, 1985). According to Bhandarkar (1999), information on internal defects prior to first cut is estimated to lead to potential gains of about $15-18 \%$ in lumber value. Rinnhofer (2003) investigated yield increases resulting from the use of a CT-scanner and obtained the results that can be seen in Table 1. 
Table 1: Yield increase through optimization by using information from CT-scanner (Rinnhofer et al., 2003).

\begin{tabular}{lll} 
Test & Number of logs & Yield increase in $\%$ \\
\hline Spruce AB 51 & 30 & 6 \\
Spruce AB 46 & 34 & 9 \\
Spruce C* & 30 & 6 \\
Larch AB46 & 20 & 0 \\
\hline
\end{tabular}

Given the large range of published numbers, a single value for potential improvements cannot be derived. Many factors such as species, growing conditions (geography, rainfall, nutrients etc.), silvicultural operations such as pruning, local grading rules and timber value will influence value recovery. It is clear though that the knowledge of internal macroscopic stem structure can increase recovery significantly and thus warrants the development of methods to obtain more detailed information on logs.

Information on the internal properties of logs can be obtained in several ways; here are just a few of them: X-ray computed tomography, ultrasound, microwaves, infrared waves, gammarays and nuclear magnetic resonance (Thawornwong, 2003). CT-scanning has received the greatest interest for industrial log inspection, because of its internal imaging capability, high penetrating power, efficiency and resolution (Som et al., 1992). Due to development and speed requirements, the implementation of such systems have been possible in theory but not yet implemented in industry. At the end of 2011, Microtec reported that they had developed a CTscanner with a feedspeed acceptable for industrial purposes. Recently in 2012, Microtec implemented the first industrial CT-scanner for commercial use in a log processing facility. The scanner can process logs up to $650 \mathrm{~mm}$ in diameter at speeds of up to $140 \mathrm{~m} / \mathrm{min}$. The system also shows the optimal cutting patterns virtually. According to the supplier the system can also be used to virtually grade boards before the log has been cut. (Microtec, 2012) 
The data obtained from a CT-scanner can be used for several applications. The data obtained from such a scan can be fed into sawmill simulation software such as Simsaw 6 . This software can be used to calculate recovery and thus determine the optimal cutting pattern for the specific log. It can also illustrate the best orientation of the log. Frediksson (2011) proposed a simulation tool for finger jointing that makes use of data obtained from a CT-scanner. Thus CTscanners are not limited to the primary breakdown of logs. The data from CT-scanners can also be used for research purposes. In this field it can be used for analysing branch angles, stem form, knot occlusion (Seifert et al., 2010) and, if weather data is available, the reaction of the tree to certain environmental conditions can even be analysed.

Log size industrial CT scanners cost about two million Euros (Tait 2011). Images of a CT-scanner can be seen in Appendix A. Based on prices by Central Analytical Facility (CAF) for a CT-scan at Stellenbosch University the amount of material that was processed during data gathering will cost R800 000 while processing logs on the designed log processing system, defined in section 4 of this document, was done at a cost of about R50 000.

\subsection{Other devices for stem analysis}

In a study done by Cominetti (2002), a destructive method of determining internal and external log properties in-field was proposed. The system relies on a device they developed "to capture the spatial orientation of a standing tree" (Cominetti et al., 2002). This device can be seen in Figure 1. 


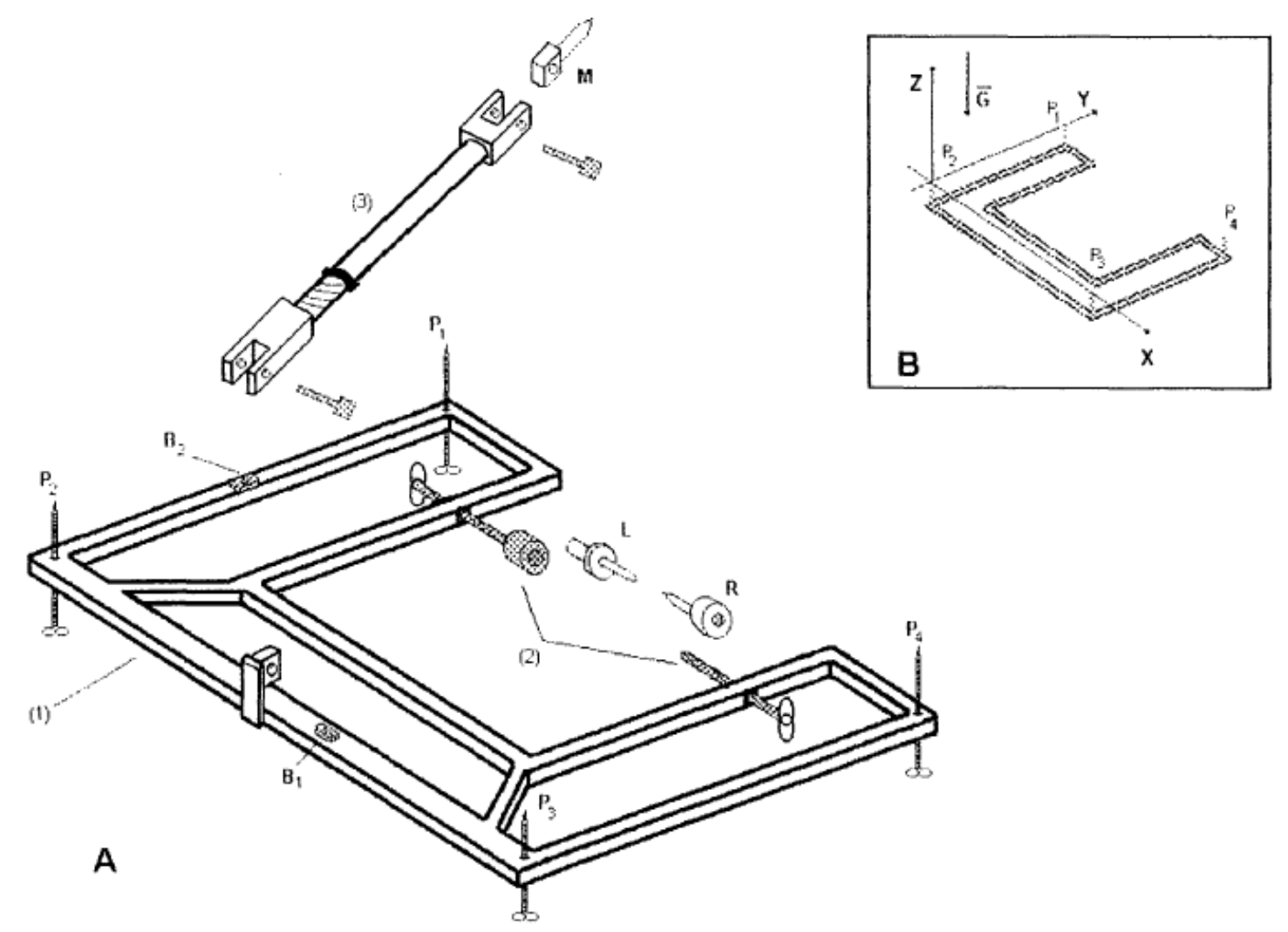

Figure 1: (A): Figure illustrating the device used for measuring sweep. The device consists of a main structure (1), two bubble levels, three nails, a metallic arm (2), and a levelling system composed of four thin bolts. (B): Coordinate system explained (Cominetti et al., 2002).

Cominetti extracted disks from the tree and estimated their real spatial position. The disks were scanned to obtain an image of each and the outline, pith and year rings were identified. They then reconstructed the log spatially, based on this data.

\subsection{South African Softwood resources}

The total commercial timber plantation area in 2008/2009 was 1274869 hectares (2007/2008: 1257341 ha). Private sector ownership accounts for 83\% of this total plantation area (DAFF, 2011). 
In Figure 2 below the plantation area by species that was present in South Africa in 2009 is shown. The figures, as well as the chart, are from the DAFF Report on commercial timber resources and primary round wood processing in South Africa for 2008/2009.

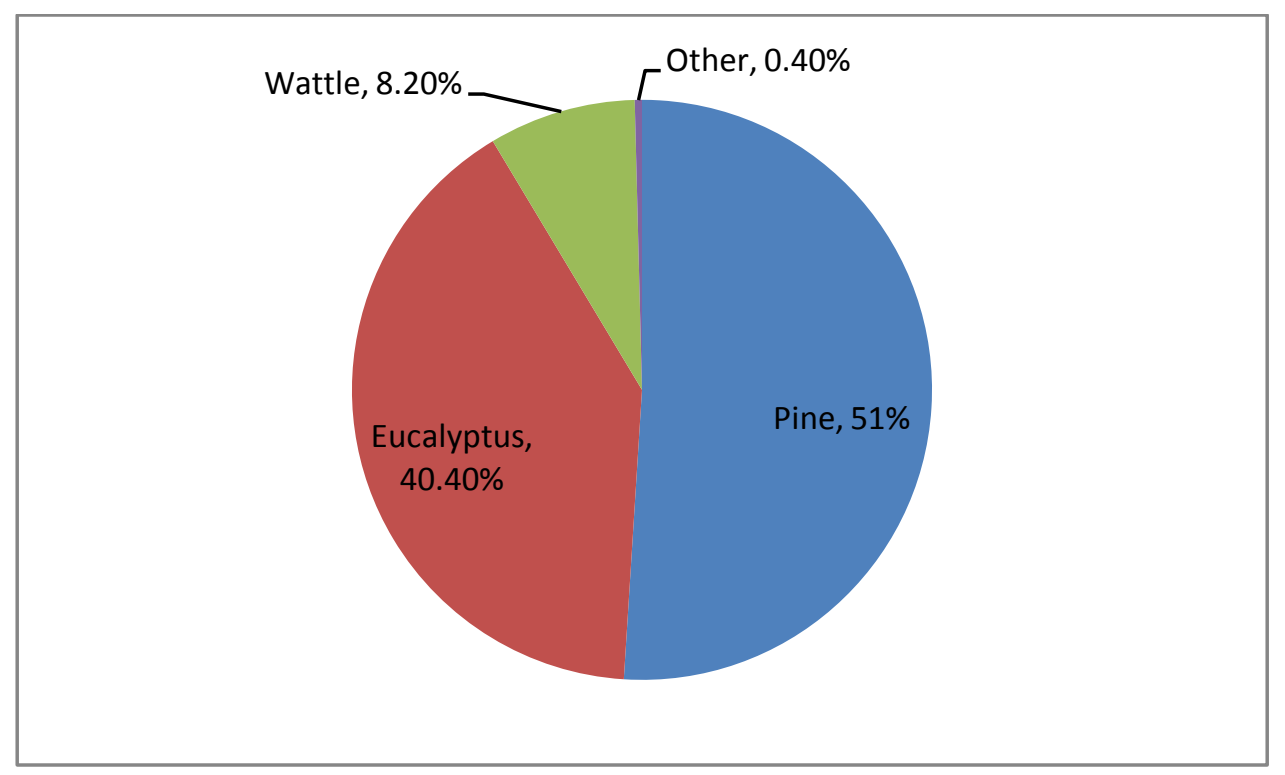

Figure 2: Graph of plantation area by species 2009 (Adapted from DAFF, 2011).

It can be seen in Figure 2 that more than $50 \%$ of the total plantation area in South Africa in 2009 was Pine. Softwoods are used for several purposes in South Africa.

Table 2 indicates the roundwood sales by product and zone. It can be observed in the table that roughly $50 \%$ of roundwood sales from Mpumalanga North are used as saw logs and veneer. 
Table 2: Roundwood sales by product and zone (Adapted from DAFF, 2011).

\begin{tabular}{|l|l|l|l|l|l|l|}
\hline & $\begin{array}{l}\text { Sawlogs } \\
\text { and Veneer } \\
\left(\mathrm{m}^{3}\right)\end{array}$ & $\begin{array}{l}\text { Poles and } \\
\text { droppers } \\
\left(\mathrm{m}^{3}\right)\end{array}$ & $\begin{array}{l}\text { Mining } \\
\text { Timber } \\
\text { (tons) }\end{array}$ & $\begin{array}{l}\text { Pulpwood } \\
\text { (tons) }\end{array}$ & $\begin{array}{l}\text { Charcoal } \\
\text { and } \\
\text { Region/Zone }\end{array}$ & $\begin{array}{l}\text { Other } \\
\text { (tons) } \\
\text { (tons) }\end{array}$ \\
\hline Mpumalanga North & 1389771 & 85379 & 302950 & 949160 & 22019 & 17728 \\
\hline TotalSouthAfrica & 4374799 & 519582 & 430788 & 10396380 & 249992 & 94738 \\
\hline
\end{tabular}

\subsection{Pinus patula trees and plantations}

According to Vermaak (2007) Pinus patula "...is native to Mexico and occurs in a narrow but long distribution between $16^{\circ} \mathrm{N}$ to $24^{\circ} \mathrm{N}$ latitude. It occurs on fertile, deep clay soils across a variety of climatic regions ranging from humid, tropical to temperate, where the mean annual precipitation ranges from $1000-2500 \mathrm{~mm}$, with additional moisture being provided in the form of heavy mists, cloud and fog. Most of the distributions occur between altitudes of 2100 and 2800 meters. This species can withstand both heavy frost and dry periods of up to five months. It is best suited to warm humid conditions though". Pinus patula is the softwood species planted most extensively in South Africa, comprising 332925 hectares or $50.4 \%$ of the total softwood area. The species occurs mainly in Mpumalanga North and South, KwaZulu-Natal and the Eastern Cape (DAFF, 2011). According to reports from DAFF (2011) the planted area of Pinus patula in the Mpumalanga escarpment was 75443 ha in $2008 / 2009$. This is about $23 \%$ of the total area planted with Pinus patula in South Africa and about $11.5 \%$ of the total area planted with softwoods in South Africa.

Table 3 gives the optimum growing conditions for Pinus patula. In the table it can be seen that the species in general prefers cooler temperatures normally associated with higher altitudes. It grows optimally at about $1000 \mathrm{~mm}$ precipitation per year. Due to its thin bark it can easily be damaged by hail or fire (Vermaak, 2007). 
Table 3: Optimum site conditions for growing Pinus patula in South Africa (Adapted from Vermaak, 2007).

\begin{tabular}{|c|c|}
\hline Climatic parameters & \\
\hline $\begin{array}{l}\text { Mean annual } \\
\text { temperature (MAT): }\end{array}$ & $<18^{\circ} \mathrm{C}$ \\
\hline $\begin{array}{l}\text { Mean annual } \\
\text { precipitation (MAP): }\end{array}$ & $\begin{array}{l}>700 \mathrm{~mm} / \text { annum at high altitudes } \\
>950 \mathrm{~mm} / \text { annum at low altitudes } \\
\text { Optimum growth at } 1000 \mathrm{~mm} / \text { annum }\end{array}$ \\
\hline Altitude: & $\begin{array}{l}\text { >800m in Eastern Cape } \\
>1100 \mathrm{~m} \text { in Kwazulu-Natal } \\
>1400 \mathrm{~m} \text { in Northern Transvaal } \\
\text { Altitude not exceeding } 2000 \mathrm{~m}\end{array}$ \\
\hline Hail: & Sensitive due to thin bark \\
\hline Snow: & $\begin{array}{l}\text { Least prone of the commercial pines in SA, especially } \\
\text { at older ages }\end{array}$ \\
\hline Frost: & Shows reasonable resistance to frost damage \\
\hline Soil parameters & \\
\hline $\begin{array}{l}\text { Effective rooting depth } \\
\text { (ERD): }\end{array}$ & $>600 \mathrm{~mm}$ \\
\hline Soil drainage: & $\begin{array}{l}\text { Best growth on well drained, dystrophic soils. Poor } \\
\text { growth on wet soils }\end{array}$ \\
\hline Soil texture: & Best growth on loamy, clayey sub soils with $>35 \%$ clay \\
\hline \multirow[t]{2}{*}{ Insects: } & Attacked by Sirex notilus (woodwasp) \\
\hline & $\begin{array}{l}\text { Attacked by Euproctis terminalis(Emperor moth), } \\
\text { especially on Mpumalanga Highveld }\end{array}$ \\
\hline \multirow[t]{2}{*}{ Diseases: } & Susceptible to Sphaeropsis sapinea after hail \\
\hline & $\begin{array}{l}\text { Susceptible to Fusarium circinatum, especially in } \\
\text { nurseries }\end{array}$ \\
\hline
\end{tabular}




\subsubsection{Tree and wood properties}

Pinus patula trees with measurements of up to $40 \mathrm{~m}$ in length and about $1 \mathrm{~m}$ in diameter have been recorded. P. patula is densely branched with an average spread of branches. Its bark is grey and deeply grooved towards the lower part of the stem. The wood from P. patula is widely used.

In comparison to wood from other pines, wood from $P$. patula is soft and light but yet quite strong. The heartwood and sapwood do not differ much in colour and it is sometimes difficult to detect the boundary between them. Dried Pinus patula has an average density of about $443 \mathrm{~kg} / \mathrm{m}^{3}$ which is slightly less than the average density for most other pines (Vermaak, 2007).

\subsection{Resin pockets}

\subsubsection{Resin pockets definition and overview}

Temnerud et al. (1999) and Seifert et al. (2010), in accordance with Larson (1994) chose to define resin pockets as: "an intercellular, circumferentially elongated pocket in the xylem with resin and wound tissue which is usually occluded the same year as it is formed."

Resin pockets are found in the xylem of those conifers which possess resin ducts, e.g. Pinus species and Picea species. The pocket is always surrounded by abnormal tissue, and tracheids and rays centripetal to the cavity are often distorted, and in some cases collapsed (Temnerud, 1999). This tear in the xylem is in the tangential direction and can reach dimensions of $65 \mathrm{~mm}$

and more in width (tangential direction), $7 \mathrm{~mm}$ thickness (radial direction) and $175 \mathrm{~mm}$ in length (longitudinal direction) in Norway spruce (Oja and Temnerud, 1999).

\subsubsection{Effects of resin pockets}

Since a resin pocket is a disruption of normal wood, it sometimes affects the timber quality or the operations of sawmills. Some of the effects it might have are: 
- "Resin pouring from cut pockets is hampering surface coating in window, door and furniture production" (Seifert et al., 2010).

- Economic losses in high quality joinery wood manufacturing. If a resin pocket is cut into in the joint part, it might prevent proper adhesion (Temnerud et al., 1999). As a result the part will need to be replaced, leading to material loss and thus value loss.

- Resin pockets are unwanted where appearance is important as in veneer and appearance grade timber. The South African National Standards (SANS) allows only certain numbers of resin pockets per grade for appearance grade timber and thus an increase in the number of resin pockets will lead to a decrease in value.

- Free resin in the pocket may leak out and spoil surrounding wood when kiln dried (Temnerud et al., 1999).

- "The influence of resin pockets on the strength properties of round products and framing grade timber is slight, depending on the dimensions and position of the defect" (Cown, 1973)

\subsubsection{Economic influence of resin pockets in South African grown Pinus Patula}

As mentioned earlier, patula comprises about $50 \%$ of all softwood forest areas in South Africa. Due to the high proportion of patula in the South African softwood industry, value losses in this species will decrease the revenue of the whole industry.

Patula in South Africa is used for the following: structural timber, veneer, industrial timber, wooden poles, mining timber, wood-based panel products, wood pulp, paper and matches.

Of the above mentioned products, industrial timber and veneer are the only categories where appearance is of importance and thus the only ones affected by resin pockets.

Despite the fact that resin pockets will have a weakening effect on timber, this is not included in the SANS for structural timber. 
The only SANS grade that includes restrictions on resin pockets is the one for industrial timber. In Table 4 the part of SANS that includes resin pockets is provided. No resin pockets are allowed in clear wood; $5 \mathrm{~mm}$ width and a sum of length of $50 \mathrm{~mm}$ on the worst face is allowed for semi-clear grade. Generally, as appearance is of less importance, more resin pockets are allowed. Unfortunately as appearance becomes of less importance, so does the value.

Table 4: Permissible defects, other than decay, insect damage, cross-fracture, mechanical damage, knots and knot holes (SANS 1783(3), 2004).

\begin{tabular}{|c|c|c|c|c|c|c|}
\hline 1 & 2 & 3 & 4 & 5 & 6 & 7 \\
\hline & \multicolumn{6}{|c|}{ Maximum dimension } \\
\hline Defect & $\begin{array}{l}\text { Clear } \\
\text { grade }\end{array}$ & Semi-clear grade & $\begin{array}{l}\text { Cutting } \\
\text { grade }\end{array}$ & $\begin{array}{l}\text { Appearance } \\
\text { grade }\end{array}$ & $\begin{array}{l}\text { Utility } \\
\text { grade }\end{array}$ & $\begin{array}{l}\text { Packaging } \\
\text { grade }\end{array}$ \\
\hline $\begin{array}{l}\text { Resin pockets(in } \\
\text { any } 1 \mathrm{~m} \text { length of } \\
\text { piece) }\end{array}$ & & & \multirow{3}{*}{$\begin{array}{l}\text { One } \\
\text { per2m } \\
\text { length } \\
\text { or part } \\
\text { thereof }\end{array}$} & & & \\
\hline a) Width & Nil & $5 \mathrm{~mm}$ & & $5 \mathrm{~mm}$ & Unlimited & Unlimited \\
\hline b) Sum of lengths & Nil & $\begin{array}{l}50 \mathrm{~mm} \text { on worst } \\
\text { face only }\end{array}$ & & $\begin{array}{l}50 \mathrm{~mm} \text { on } \\
\text { each face }\end{array}$ & Unlimited & Unlimited \\
\hline
\end{tabular}

According to Malan (2011) a small study was conducted on Pinus patula from the Jessievale area. In a nearby veneer factory about $70 \%$ of the logs were affected by resin pockets. From this information it seems that resin pockets can be a particularly big problem in the veneer industry. In Table 5, an example of the allowance of resin pockets in surface veneers for plywood can be seen. 
Table 5: Plywood standards from the York Timber Sabie veneer mill.

\begin{tabular}{|l|l|l|l|l|}
\hline & \multicolumn{5}{|c|}{ Veneer grade } \\
\hline Characteristic & A & B & C & $\begin{array}{l}\text { D(Utility } \\
\text { grade) }\end{array}$ \\
\hline $\begin{array}{l}\text { Resin Streaks and } \\
\text { pockets }\end{array}$ & None & $\begin{array}{l}\text { W } \leq 25 \mathrm{~mm} \text { Any length, any } \\
\text { quantity }\end{array}$ & Unlimited & Unlimited \\
\hline
\end{tabular}

The part of the market where the presence of resin pockets is of importance is in remanufacturing which accounted for $18 \%$ of the South African sawn timber market in 2010 . It can be seen in Figure 3 that this portion of the market has decreased significantly since the start of the millennium.
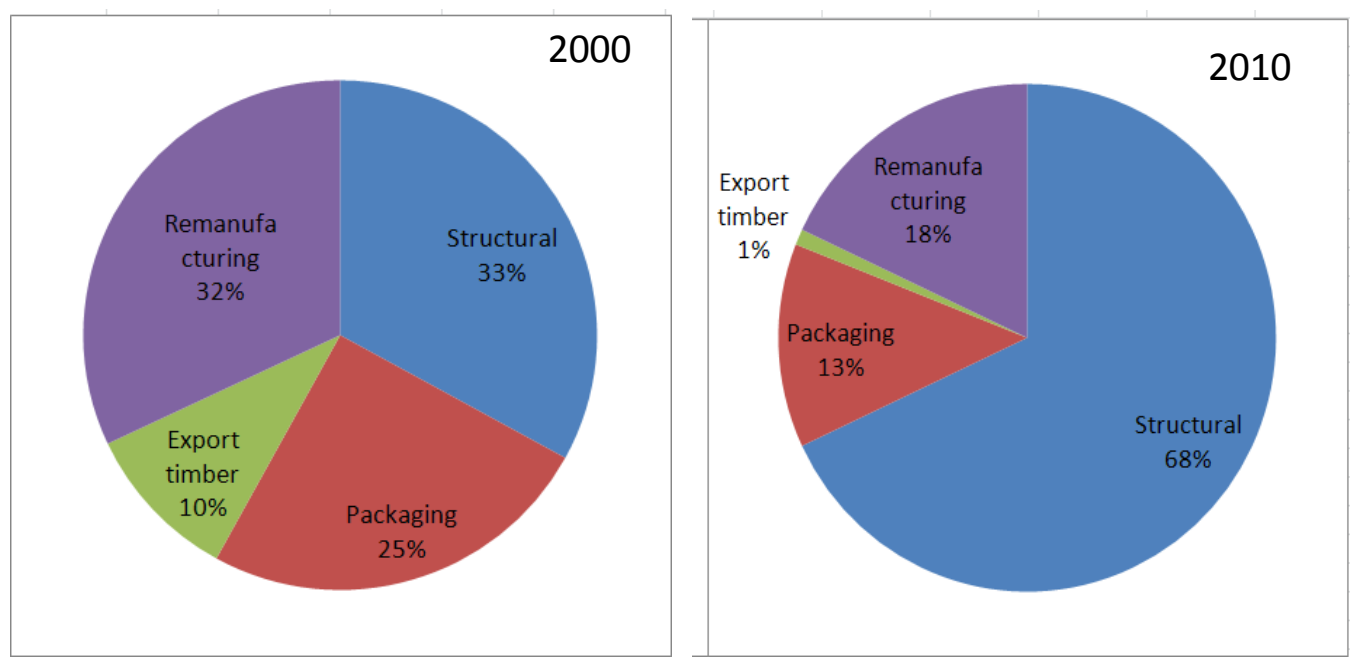

Figure 3: Changing markets: South African softwood sawn timber by end-use from 2000-2010 (adapted from Crickmay and Associates Lumber Index). 


\subsubsection{Types of resin pockets}

Somerville (1980), quoted by Cown et al. (2010), defined three different types of resin pockets:

Type 1: "Most common form. It occurs as a tangentially-oriented lens-shaped cavity filled with callus and liquid resin and is completely enclosed within a growth ring." (Cown et al., 2010). An example can be seen in Figure 4.

Type 2: "It originates as a type 1 pocket but erupts through the cambium to produce visible external resin bleeding. An occlusion scar that may contain resin, callus and bark is formed."(Cown et al., 2010). An example can be seen in Figure 5.

Type 3: "This is a small defect that appears to originate in a cambial lesion. It may cause external resin bleeding." (Cown et al., 2010)

According to Watt et al. (2011) generally no distinction is made between Type 2 and Type 3 resin pockets.

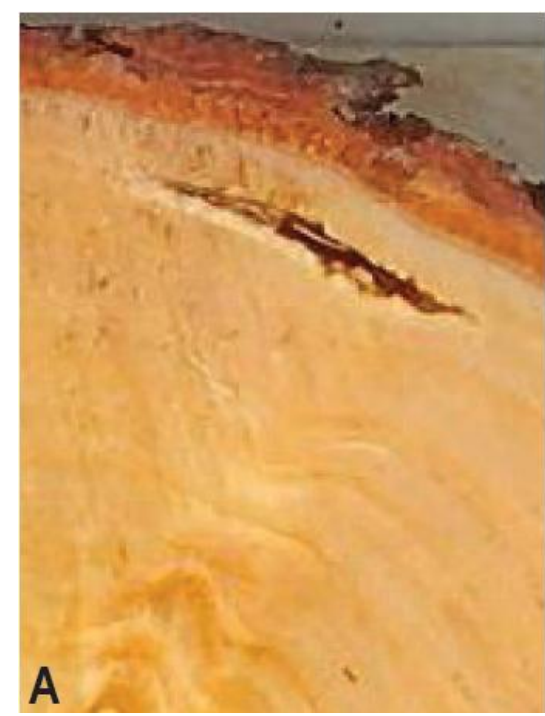

Figure 4: Type 1 resin pocket

(Watt et al, 2011).

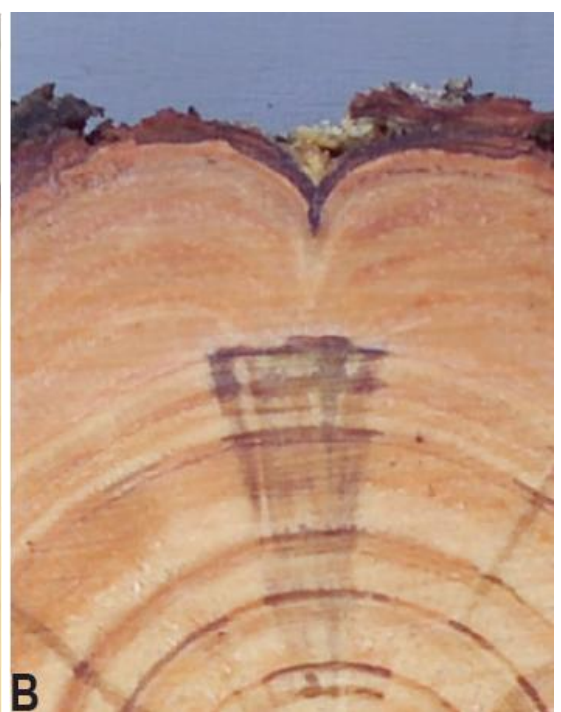

Figure 5: Type 2 resin pocket (Watt et al, 2011). 


\subsubsection{Occurrence of resin pockets}

Temnerud (1999), Seifert et al. (2010) and Watt et al. (2011) found an increasing trend in the occurrence of resin pockets from the bottom to the top of a tree. Watt et al. (2011) also found an increasing trend in Pinus radiata trees with radial distance from the pith with a near absence of resin pockets near the pith.

According to Watt et al. (2011), most resin pockets were found in late wood and some were also found in the early wood, while the least were found in the centre of the year ring. In his study Watt concluded, from this position within the rings, that water stress is the most likely environmental driver. In his study Park (2005) proposed a bark scoring system that could be used to predict the presence of resin pockets. He concluded, however, that this could provide only some indication of dry resin pockets (Type 2 and 3) and/or of resin streaks.

\subsubsection{Formation of resin pockets}

Resin pockets are induced by tangential ruptures in the cambial region and are believed to expand due to pressure created by build-up of resin from neighbouring resin canals (Cown 1973, Larson 1994, Temnerud et al 1999). Temnerud et al. (1999) stated that 'It is conceivable that any factor causing a wound response could be responsible for the formation of resin pockets'.

The cause of resin pocket formation is complex and is dependent on the site, the tree, the climate and some other factors. A number of studies have been done on why resin pockets form. Most of the studies were done on radiata in New-Zeeland and spruce (Picea abies) in Europe.

The three main hypotheses that emerged from these studies were:

- Storm hypothesis

- Drought hypothesis

- Damage hypothesis 


\section{Storm hypothesis}

Strong wind loads induce mechanical bending which sometimes leads to damage or even collapse of cells. This theory is certainly supported by studies on radiata from the New Zealand Canterbury plains. Temnerud (1996) stated that this hypothesis was first proposed by FreyWyssling (1938, 1946). According to Seifert et al (2010), this hypothesis was supported amongst others, by Holzmann (1998), Seifert et al. (2002), Wernsdörfer (2002), and Herb and Becker (2006).

There are a number of factors that will increase the formation of resin pockets. According to Seifert et al. (2010), the following factors are some which will have an influence:

Stand density: In a less dense compartment it is quite obvious that all trees will be more exposed to wind. This is true for all trees except for the trees on the edges of the compartment, which are more exposed and do not have cover against winds.

Crown size: Generally, the bigger the area of the crown against which the wind can press, the higher the bending stresses induced in the tree will become. Thus the occurrence of resin pockets should, under the same wind load, increase with crown size.

Wind load: If data is available on the wind speeds for each different stand and other factors such as stand density and crown size are fairly constant, an increase in wind speed could result in an increasing number of resin pockets.

Seifert et al. (2010) found most resin pockets in the earlywood-latewood transition zone of the latewood of Norway spruce. Since the latewood is predominantly formed in late summer, they concluded that storms, that typically take place outside the vegetation period, do not provide the most likely explanation for resin pocket formation. 


\section{Drought hypothesis}

Water deficiency is the main cause of resin pocket formation, according to this hypothesis. Seifert (2010) pinned the formation of resin pockets on a negative pressure developing in the xylem in short but severe drought periods. Drought has been identified as the main cause of resin pockets in several studies (Woollons et al. 2008, Oja and Temnerud 1999, Seifert et al. 2010).

Cown(1973) linked resin pocket occurrence with false rings and thus illustrated that water stress, rather than strong winds may be the main contributor to resin pocket formation. Watt et al.(2011) proposed that the position within the growth period at which the resin pocket occurs can be used to identify water stress as the main cause of resin pocket formation.

False rings of conifers can usually be distinguished from normal growth rings by examining latewood to earlywood transition (Panshin and de Zeeuw, 1980).

'Normal growth rings are categorized by an abrupt change in cell size and wall thickness from the last formed latewood of one seasonal ring to the earlywood of the next. False rings exhibit a gradual change in cell character between false latewood and subsequently formed earlywoodtype cells.' (Haygreen and Bowyer, 1996).

\section{Damage hypothesis}

Insects and micro-organisms are another possible cause of resin pocket formation (Christiansen and Kucera, 1999; Hood and Gardener, 2002). They cause micro wounds to the phloem and xylem layers and, as a defensive reaction, the tree then creates resin pockets. No conclusive evidence of this hypothesis has been found yet (Seifert et al., 2010). 


\subsection{Study on resin pockets in Pinus patula by Komatiland Forests}

In an internal company study on resin pockets in patula at Komatiland Forestry (Malan 2011) hail was suggested as a possible cause of resin pocket formation because patula has thin bark which provides little protection. It was argued that trees are vulnerable in the tops where new wood is formed and that hail can easily bruise the cambium in these regions. Further it was stated that it can be expected that resin pockets formed by hail will be grouped on one side of the tree and/or at certain heights. After further analysis Malan (2011) concluded, however, that hail was not the main cause of resin pockets for patula from this area. He based his conclusion on the lack of grouping of resin pockets. There were expectations that thinning plays a role in resin pocket formation (Malan, 2011). Since the bark of Pinus patula is relatively thin, the impact from falling branches and trees during this process could easily bruise the cambium and thus lead to the formation of resin pockets.

A correlation can easily be made between occurrences of resin pockets and thinning simply by looking at the years of occurrence. Malan (2011) concluded after further analysis however, that thinning is unlikely to be the main cause of resin pocket formation.

Malan (2011) also found no correlation between false growth rings and resin pockets. He could not find any conclusive proof for any specific cause of resin pockets and proposed that it should be determined whether there are any linkages between environmental factors and incidence of resin pockets.

\section{Material and methods}

In the development of a system to reconstruct logs three-dimensionally a way had to be found to obtain cross-sectional images of the log based on optical methods. A destructive method of making physical cross-cuts and taking photos of them was proposed. Secondly, software had to be developed to identify certain features of the log and reconstruct these images into a 3dimensional model. 


\subsection{Part 1: Development of log analysis system}

\subsubsection{Log processing system}

The development of the system required a mobile frame that could be taken into the forest directly to a log. The log is then loaded onto the frame; cross-cuts were made and photos (with settings as described in section 4.1.4) were taken of the cut surface. A design was proposed that involved a frame with movable parts, such as a chainsaw and a camera, and stationary parts such as the devices holding the log in position during processing. The explanation of the system below can also serve as a user manual and was written as such.

\subsubsection{Design and building of frame}

The frame was designed in Inventor, which is part of the AutoCAD software package. The design was given to a private company specialising in metal construction for manufacture of the frame. During the building of the frame quite a few practical changes were made to the design to make the frame more stable and its application more user friendly. This phase involved several steps of testing and changing the design in order to enable it to better serve its purpose.

\subsubsection{Operation of the frame}

The frame was designed to fit onto the back of a light pick-up truck (also referred to as a bakkie in South Africa). The frame could thus be transported on a bakkie to the desired site. It was important to position the frame correctly. Since logs were heavy and difficult to handle, it was important to position the frame as close to the log as possible. If the compartment has a slope, always position the frame at an angle of $45^{\circ}$ to the slope and on the downhill side of the log. By doing this the process of loading was easier and stability of the frame ensured. Once the site was assessed and the parts positioned, the frame was assembled. Assemble the mainframe as can be seen in Figure 7. 
The mainframe consists of 4 different parts which were simply bolted together to form the structure that can be seen in Figure 6. The total length of the frame is $3.5 \mathrm{~m}$ when assembled.

The next step in the setup procedure was to lower the wheel supports until the wheels are slightly off the ground. This was done simply by rotating them clockwise. The position of these supports is indicated in Figure 7. This is done in order to protect the axle and wheels from the heavy load.

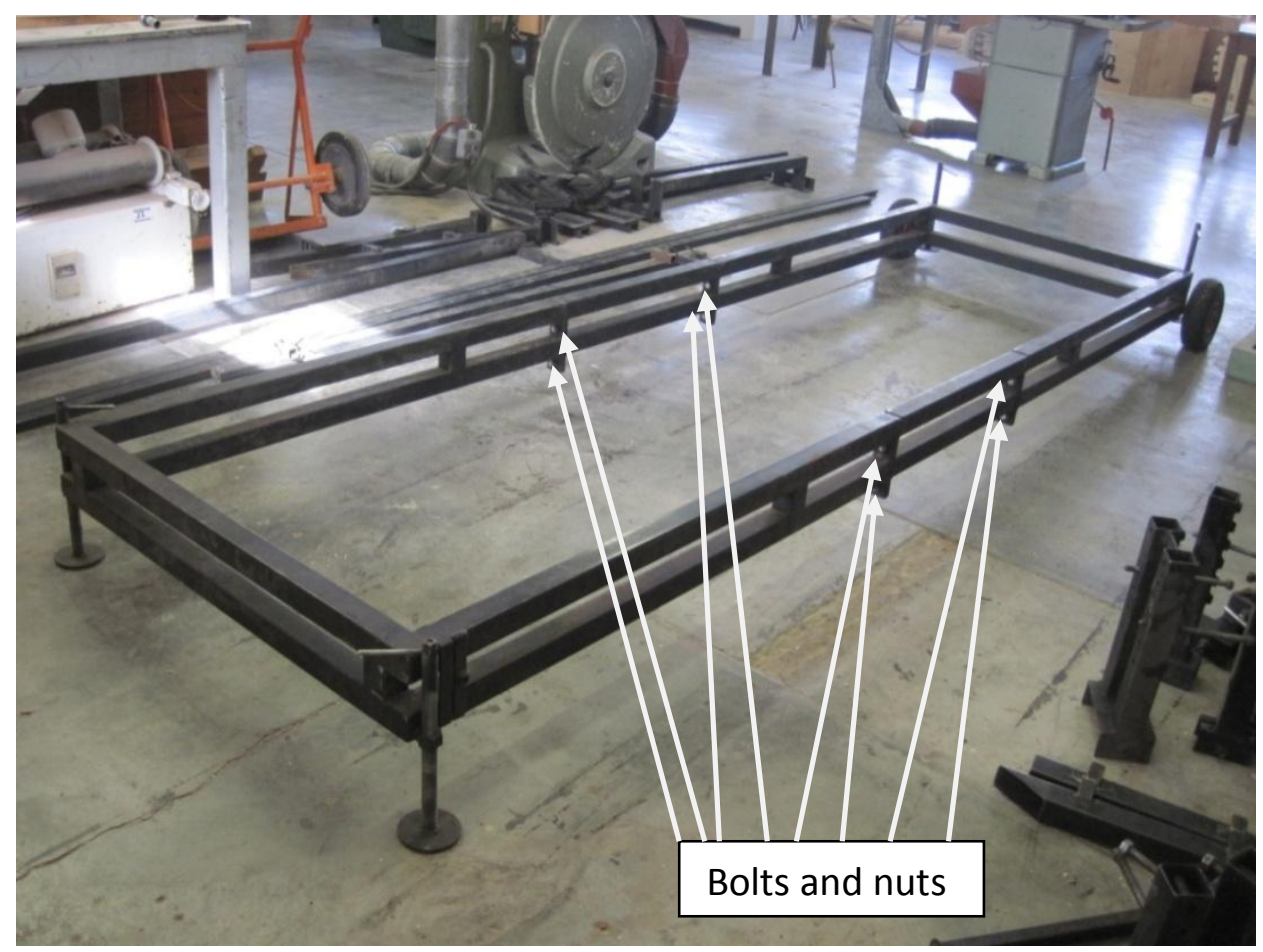

Figure 6: Figure explaining assembly of mainframe. 


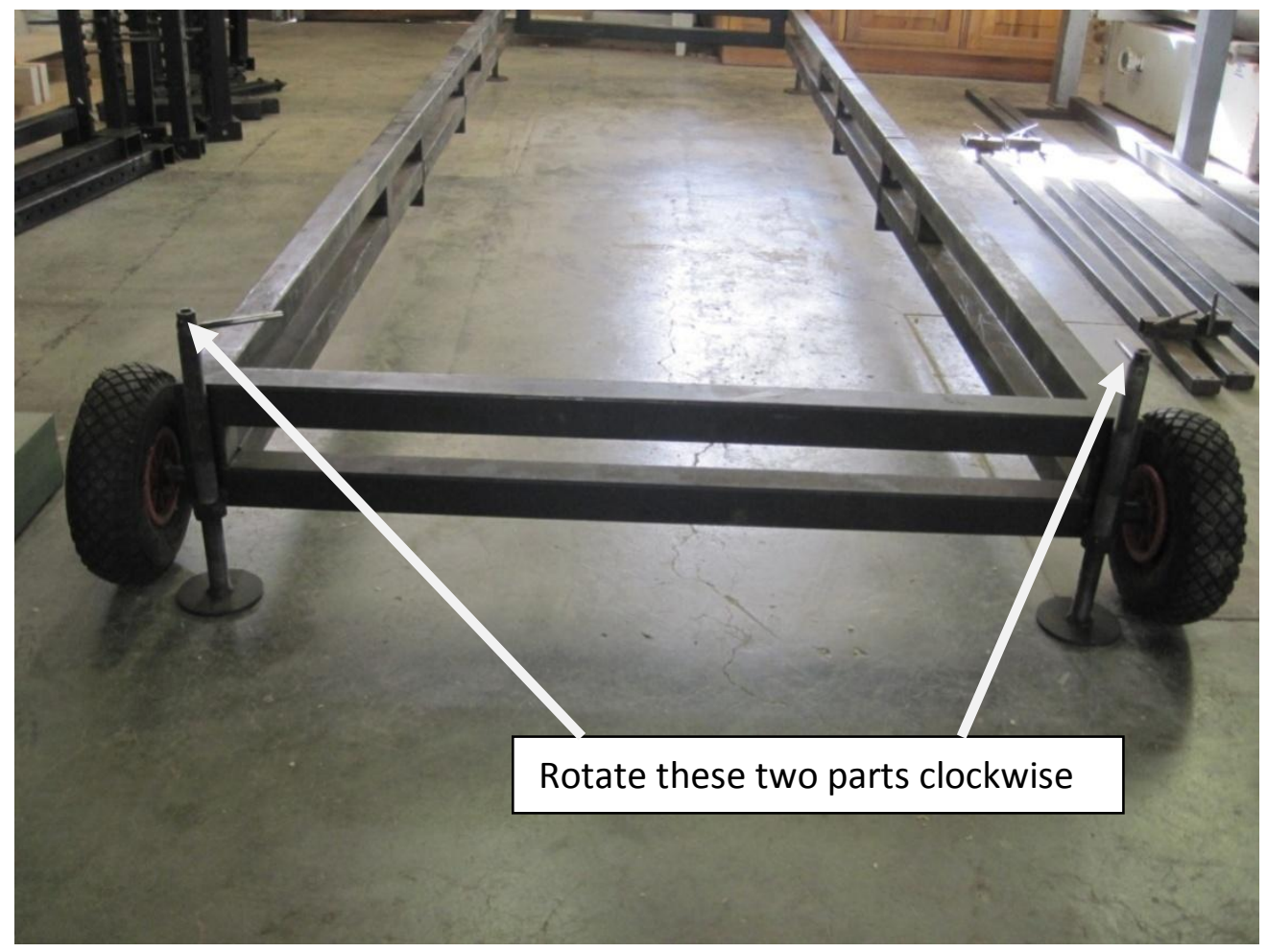

Figure 7: Figure explaining how to lower wheels supports.

Place the two jack-supports on the top rail of the mainframe. One placed $\pm 0.5 \mathrm{~m}$ from the front of the frame and one $\pm 0.5 \mathrm{~m}$ from the back end of the frame. Place a modified car jack on each of the two jack-supports. In Figure 8, a good position of the supports with the jacks can be seen. 


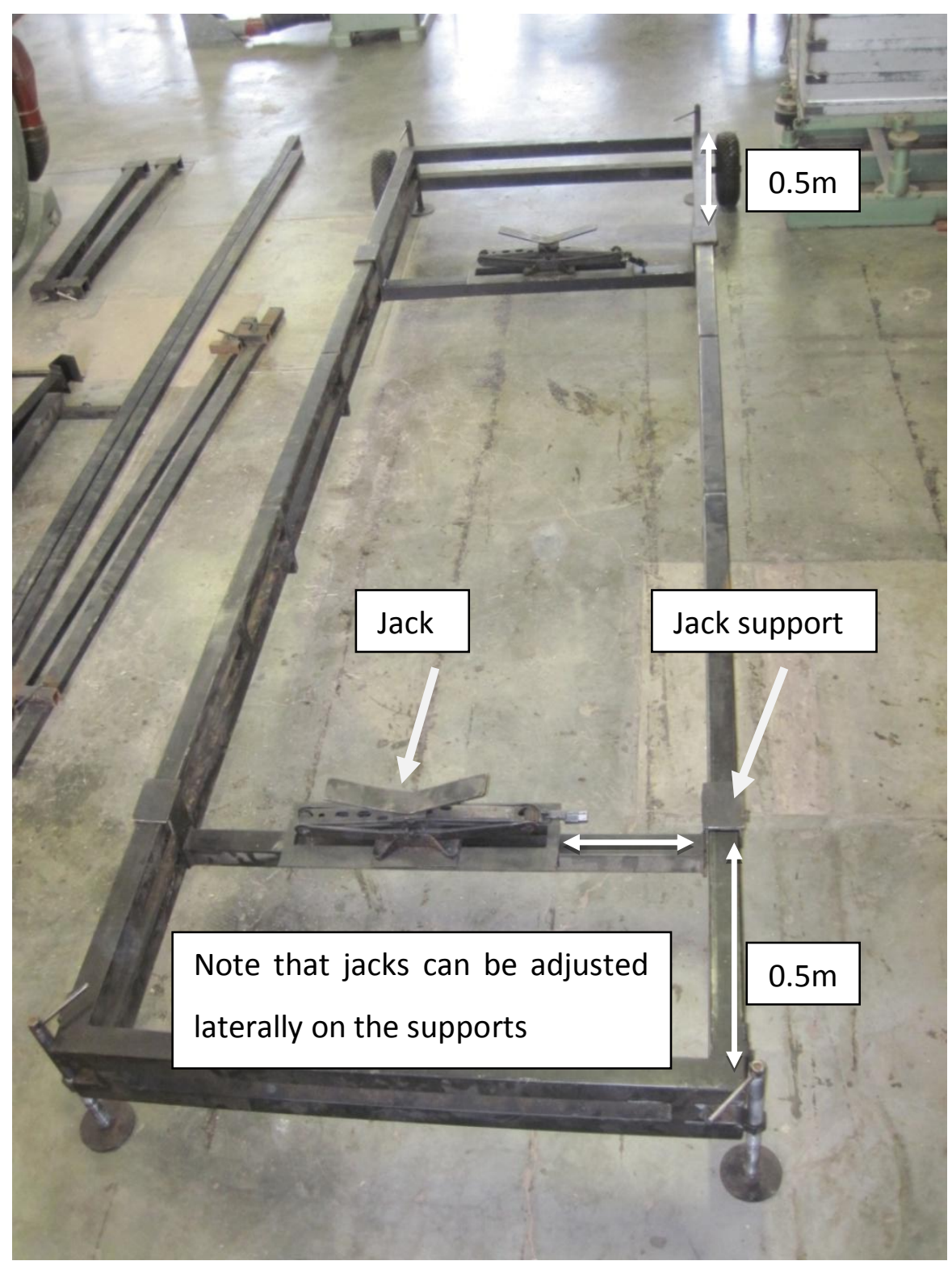

Figure 8: Figure explaining positioning of jacks.

Position the five log supports (one double and four singles) on the top rail. Position them strategically along the length of the frame. Put one upright on each of the supports, on the opposite side from which the log will be rolled on. Figure 9 illustrates good placement of log supports and uprights. Place one of the two spacers on top of the front support and the other one on the support second from the back end. This part lifts the log slightly higher to enable the jacks to be positioned underneath the log. 


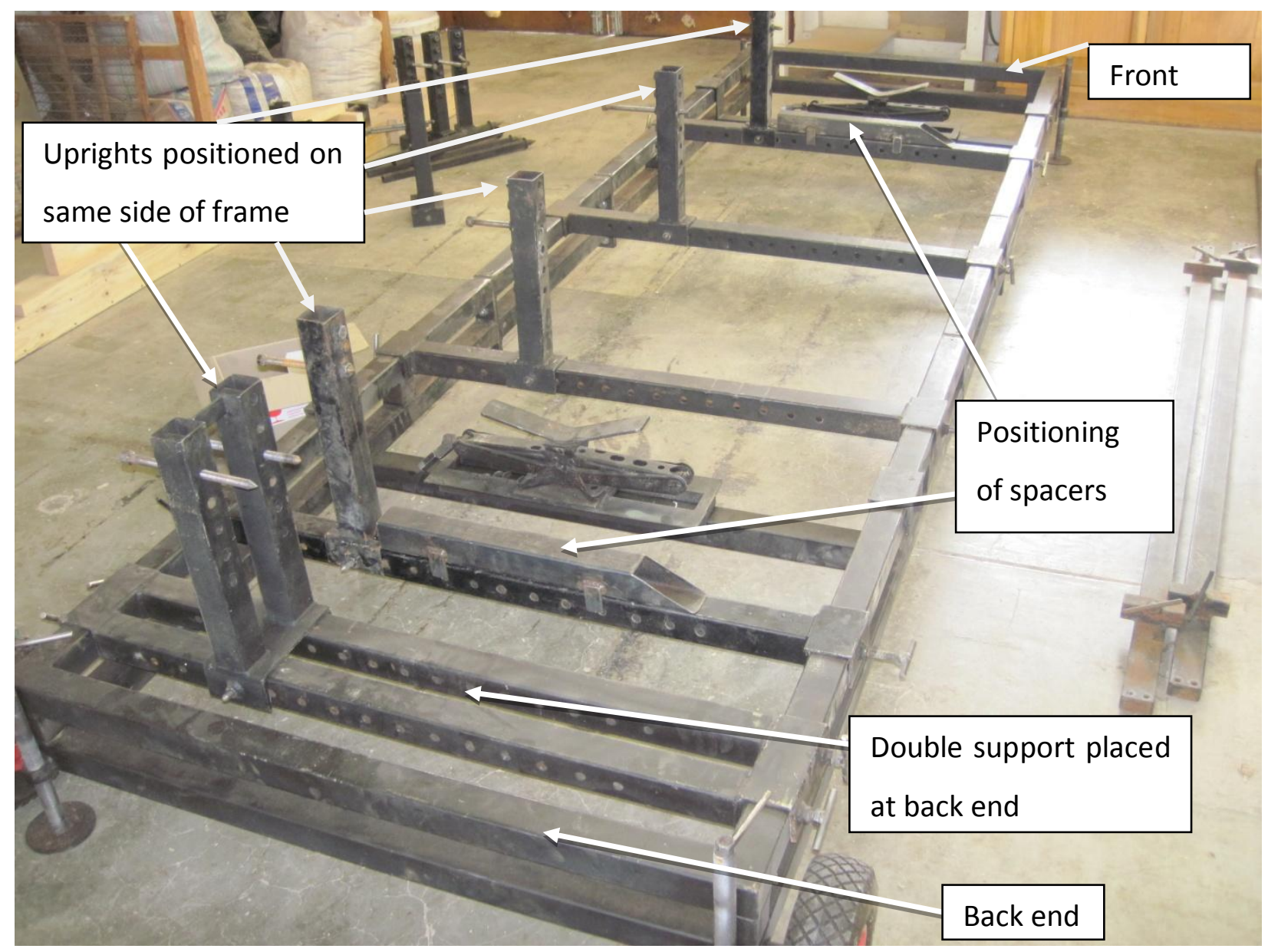

Figure 9: Figure explaining positioning of supports, uprights and spacers.

Position the ramps, which are used for the log to be rolled onto the frame, into the correct position. Positioning of the ramps is indicated in figure 10. 


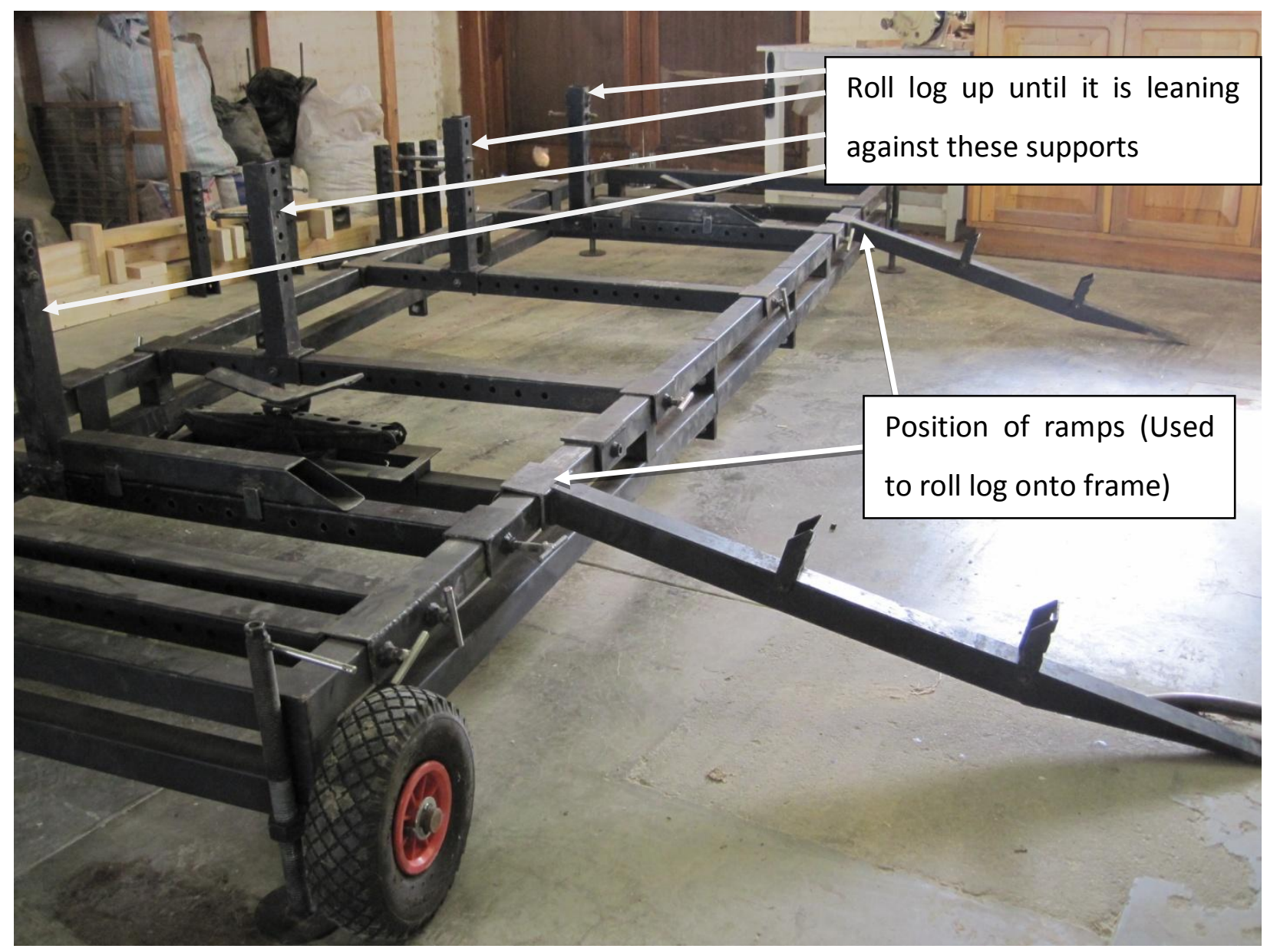

Figure 10: Figure explaining placement of ramps.

Roll the log onto the frame until it is resting against the uprights (as indicated in Figure 10). Position the log lengthwise with a felling lever. Place the uprights on the open side as close to the log as possible. Despite the fact that there is no log in Figure 11, it illustrates where supports should be inserted. Jack up the log slightly. Remove the spacers by pulling upwards and sliding them out to the side. Position the remaining uprights. Jack up the log to the required height. 


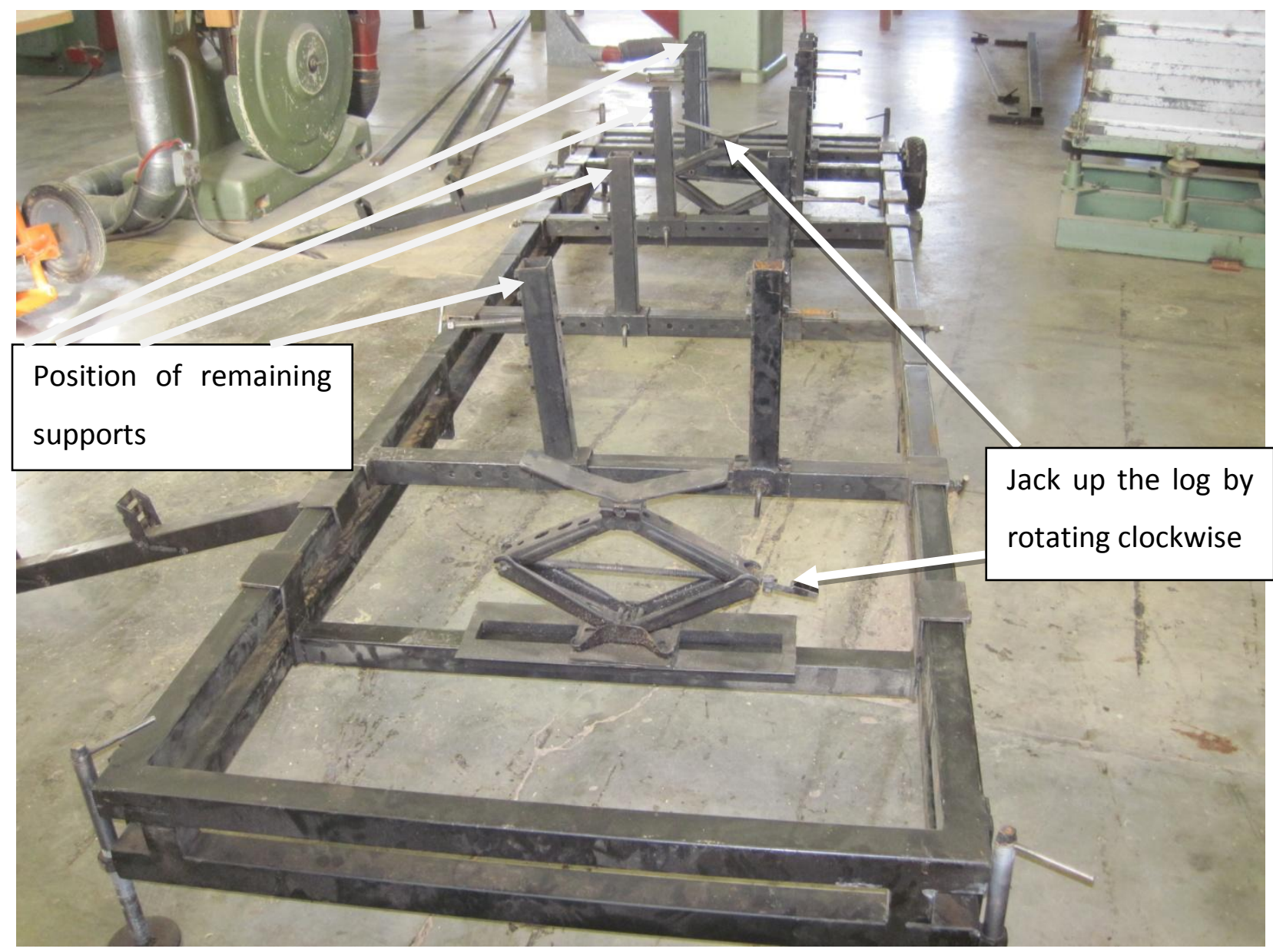

Figure 11: Figure explaining positioning of last uprights and lifting of log.

Position the sharpened bolts as indicated in Figure 12, at the side of the uprights, in the holes closest to the centre of the log. One sharpened bolt should be inserted into each upright. Turn the sharpened bolts into the side of the log with a speed wrench. Lower the jacks and remove them from the frame. Position the chainsaw at the front of the frame. It is important to ensure that the chainsaw is placed at the right side of the frame (as seen from the front) when starting. This is done so as to ensure that the last cut can be made as close to the back end of the log as possible. Positioning of the chainsaw is shown in Figure 12. 


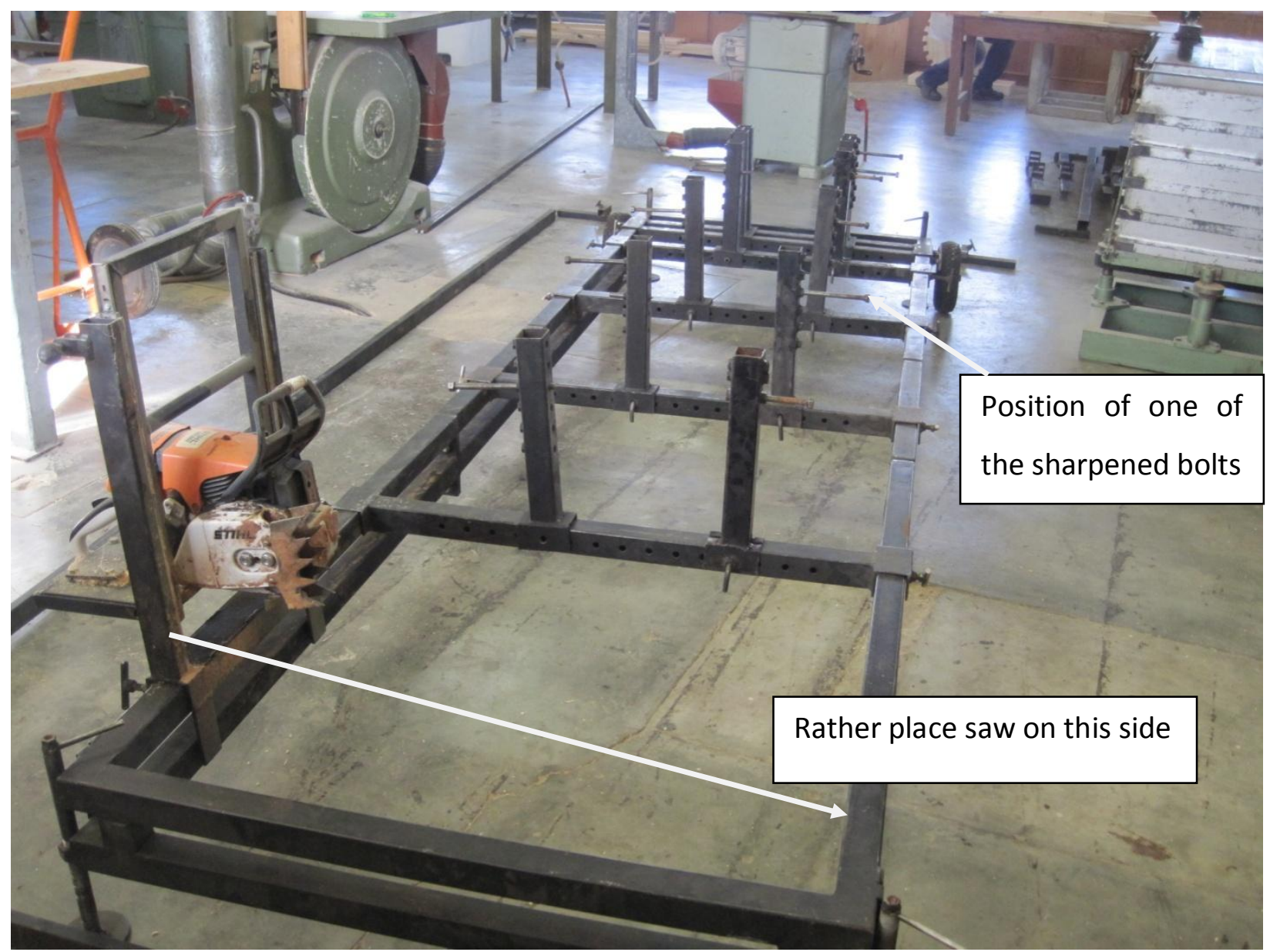

Figure 12: Figure explaining positioning of the sharpened bolt and placement of the chainsaw.

Assemble and position the camera frame. This can be done by placing the parts on the ground around the frame and assembling it there. The frame consists of eight parts: two sides, two ends and four legs. Bolt the ends onto the sides at each of the four corners as indicated in Figure 13. Then lift the frame and insert the legs through the square tubing and tighten the bolt at the required height. Take note that the camera frame is placed to one side of the frame, so as to give the chainsaw operator space to operate. Position the parts on which the camera and the laser meter are fixed, respectively, as indicated in Figure 14. 


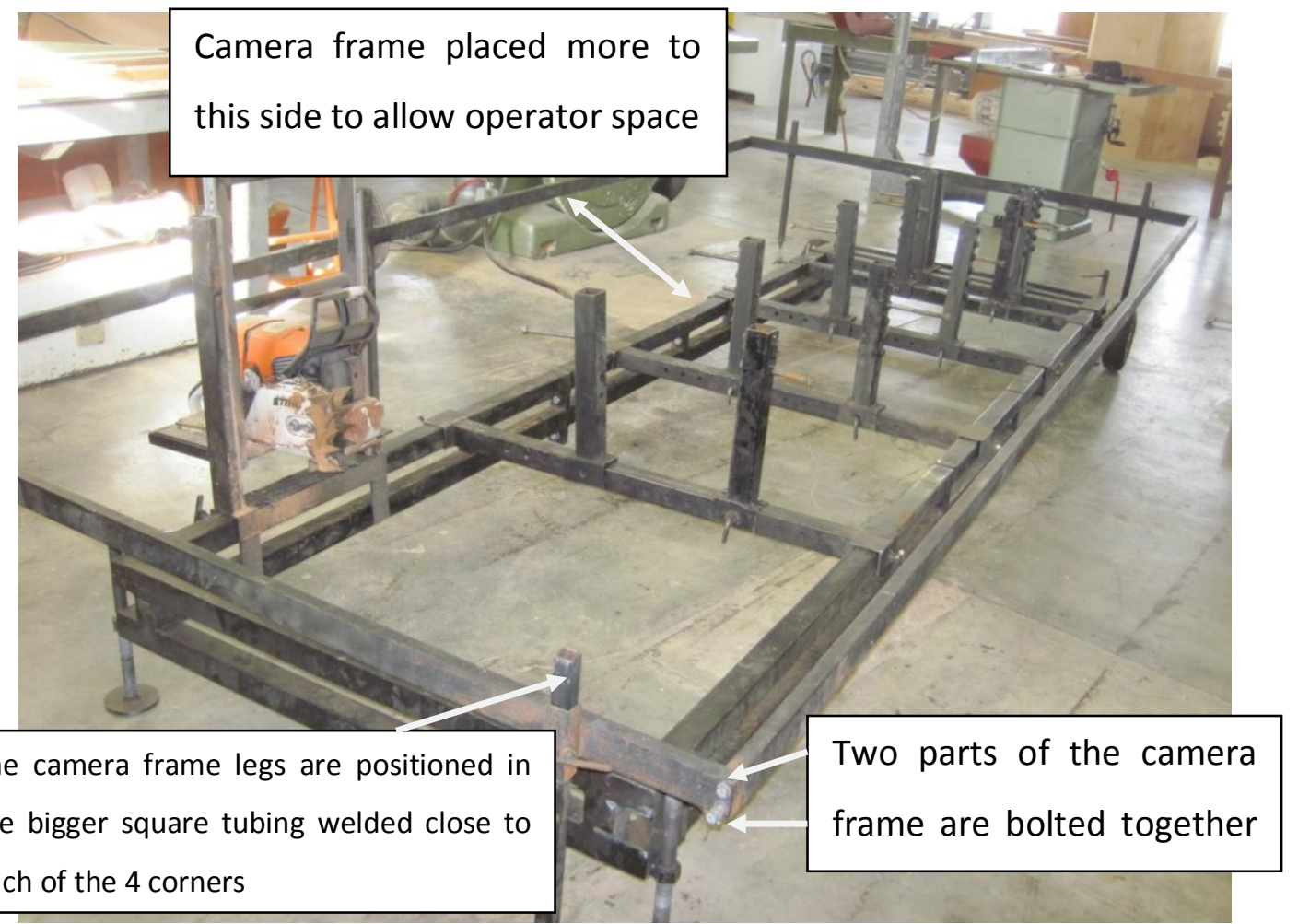

Figure 13: Figure explaining assembly and position of camera frame.

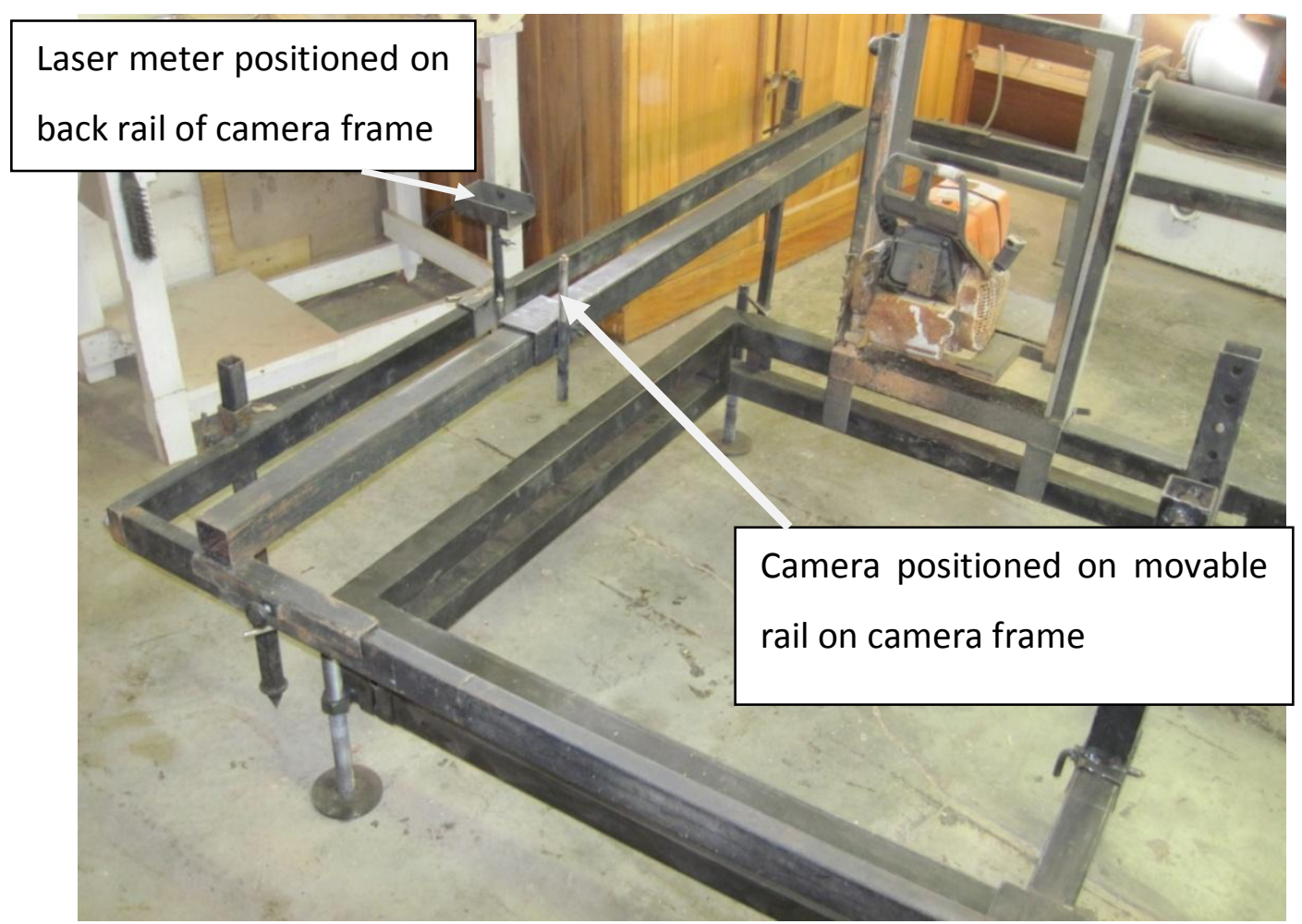

Figure 14: Position of lasermeter and camera. 


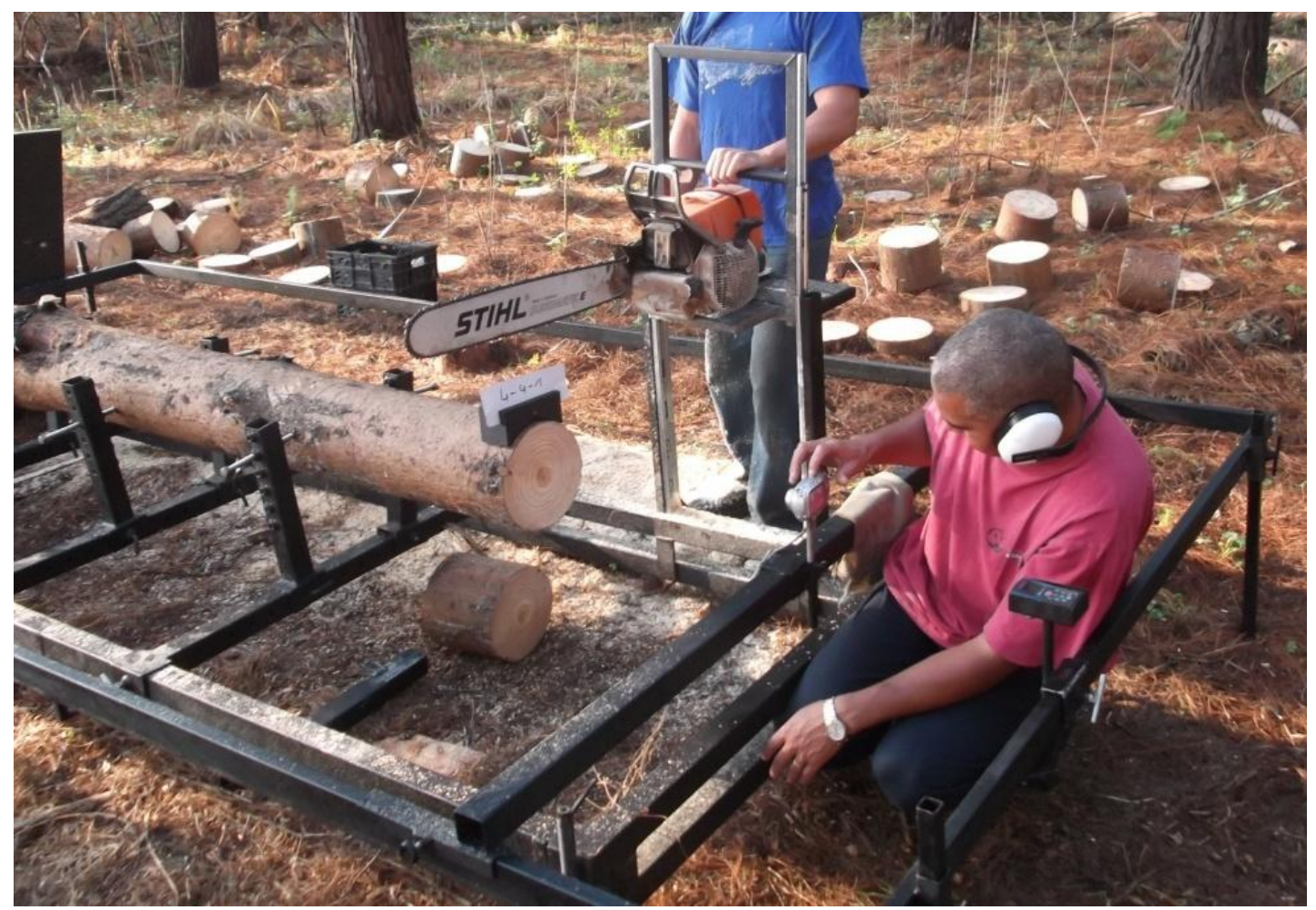

Figure 15: Image illustrating completely assembled frame infield.

For image analysis purposes the camera must be a fixed length from the log surface when taking pictures during the dissection of the log. Determine which spacer to use (3 wooden sticks were cut at $500 \mathrm{~mm}, 700 \mathrm{~mm}$ and $800 \mathrm{~mm}$ and used to space the camera from the $\mathrm{log}$ ). Selection is done simply by observing on the camera at which distance all cuts can be photographed. Position the camera in line with the log. Mark $20 \mathrm{~cm}$ increments lengthwise on the log and measure the total log length. Take a distance reading with the laser meter (from the meter to the log surface) and record it. Write the tree and log numbers on the front end of the log as indicated in Figure 16. Extend the North mark which was made before felling the tree from the bark to the front face (cross section) - this is only necessary for the first photo of a log. 


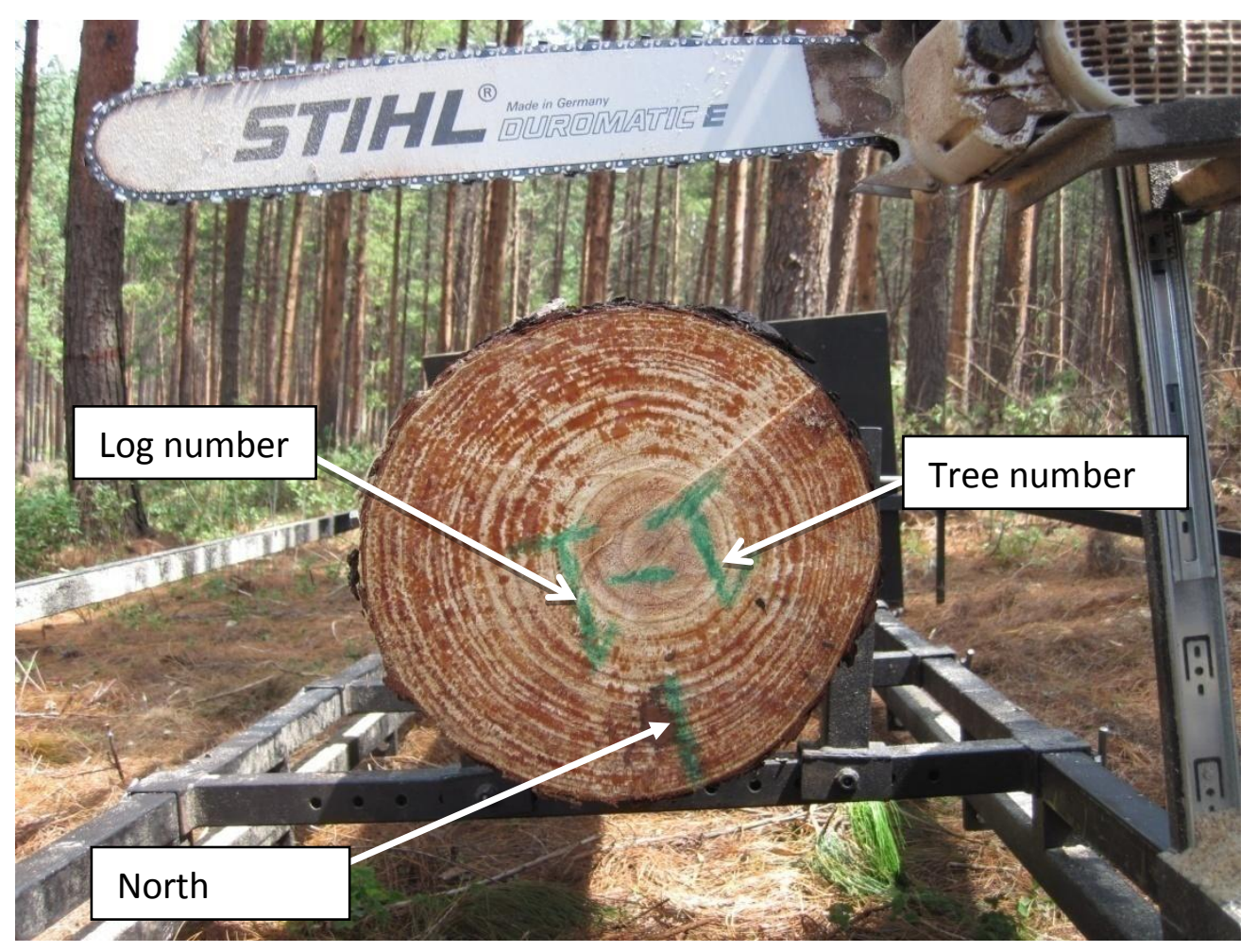

Figure 16: The log-end before cutting starts, showing the tree and log numbers and North direction. Surface quality will improve after sawing the first disc on the frame.

Make the first cut and move the camera on the camera frame to a fixed distance from the log surface. Take a photograph of the cross-cut surface. Cross cuts are made along the length of the log until a support is reached which prevents sawing from continuing. These supports are progressively removed at this stage and the dissection can continue until the full log has been processed.

\subsubsection{Digital photography}

The frame was tested under various conditions on a few different days. The circumference of the log surface could be best identified when a black background was used and two plywood sheets with total dimensions of $3 \mathrm{~m} \times 3 \mathrm{~m}$ were used as the background. The digital camera used on this frame was a Canon Power shot D10. 
The camera was used on manual settings with a manual focus of $50 \mathrm{~cm}$, flash off, light exposure of -1 , with both the ISO and AWB settings on auto.

\subsubsection{Practical considerations}

During the design and development of the frame a number of practical considerations resulted in changes to the log processing system. These changes are described below:

- A medium sized chainsaw did not give satisfactory cross cut surface quality and made identification of some properties such as year rings and knots from digital images difficult. Use of a high power chainsaw (Stihl MS 660,5.2kW) with the correct chain type helped gave vastly improved surface quality;

- Initially the normal chain type used for felling trees with a pitch of $9.32 \mathrm{~mm}$ was used. The surface quality was not good enough for image recognition. Based on advice from a Stihl representative a chain with a pitch of $6.35 \mathrm{~mm}$ was used which gave much better surface quality results;

- Initially the camera was located on a sliding rail which was fixed to the main frame on which the chainsaw was resting. Due to the vibration of the frame photos could not be taken while the chainsaw was running. Switching the chainsaw off and restarting for each cut was too time consuming. It was then decided to build a separate camera frame not attached to the main frame which solved the problem of vibration;

- There were a number of factors influencing the productivity of log dissection including the log size, increment size between cuts, the number of people available to operate the system, and the slope of the site. With three people to operate the system, one can operate the chainsaw, one can operate the camera and laser measurement, and one captures data. With a fairly steep slope, trees of mean $\mathrm{DBH}$ of roughly $35 \mathrm{~cm}$, three people, and average increments of about $10 \mathrm{~cm}$, two trees could be dissected per day. 


\subsection{Part 2: Data acquisition}

\subsubsection{Study material}

The escarpment of Mpumalanga, where the study material was obtained, is at an altitude of $1250-1750 \mathrm{~m}$. The area has an average annual temperature of about $14-19^{\circ} \mathrm{C}$ (Komatiland forestry, 2011). The mean annual precipitation, averaged from values of 17 sites, is about $1050 \mathrm{~mm}$. The mean annual temperature obtained in the same way is $16^{\circ} \mathrm{C}$ (Komatiland forestry, 2011).

\subsubsection{Site description}

The study was done in three compartments from Komatiland Forests (KLF). The sites were selected from data available on growth rates. A good, a medium and a bad site were chosen based on the site index as determined by KLF. However, due to bad roads one of the sites could not be used and had to be replaced with another with the result that the medium and bad sites were in fact not very different in terms of site productivity. The first site that was selected was Blyde C22 which can be found at coordinates $24^{\circ} 49^{\prime} 45.37^{\prime \prime} \mathrm{S} 30^{\circ} 49^{\prime} 01.38^{\prime \prime} \mathrm{E}$; the site is close to the small town of Graskop. The other two sites, Morgenzon a1A is at coordinates $24^{\circ} 52^{\prime} 01.41^{\prime \prime}$ S $30^{\circ} 43^{\prime} 02.87^{\prime \prime}$ E and Morgenzon E3 at coordinates $25^{\circ} 02^{\prime} 16.99^{\prime \prime} \mathrm{S} 30^{\circ} 45^{\prime} 49.63^{\prime \prime} \mathrm{E}$, both close to the town Pilgrimsrest. The site descriptors can be seen in Table 6 below. The geographical positions of the three sites can be seen in Figures 17 and 18

Table 6: Site descriptors.

\begin{tabular}{|l|l|l|l|}
\hline & Blyde C22 & Morgenzon a1A & Morgenzon E3 \\
\hline Age & 22 & 18 & 19 \\
\hline Tree height (Avg of 4 highest) & $29.55 \mathrm{~m}$ & $20.35 \mathrm{~m}$ & $22.05 \mathrm{~m}$ \\
\hline Mean annual precipitation (mm) & 1156 & 862 & 1015 \\
\hline Mean annual temperature & 16.1 & 15.1 & 14.3 \\
\hline
\end{tabular}




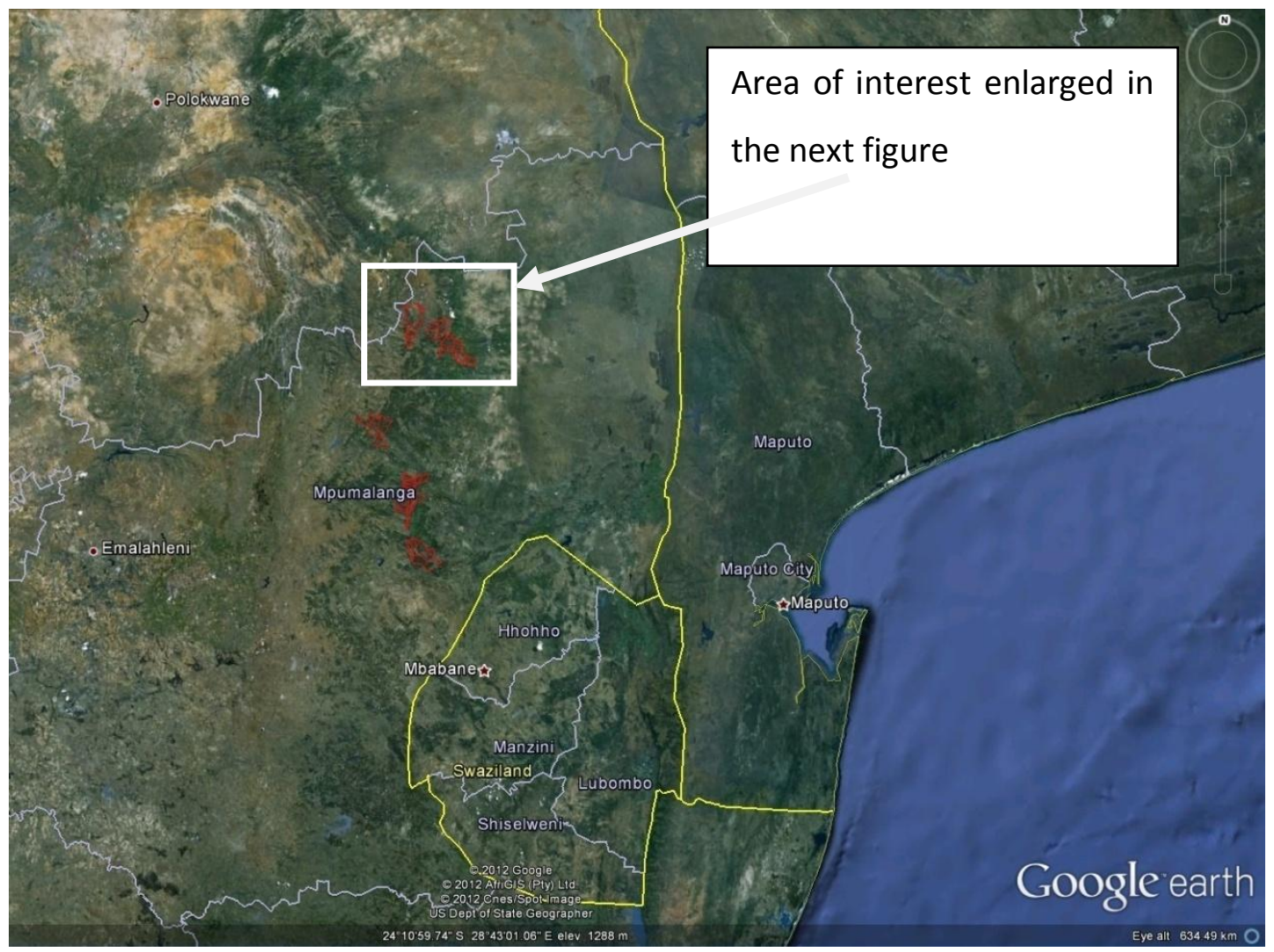

Figure 17: Area of interest in Mpumalanga.

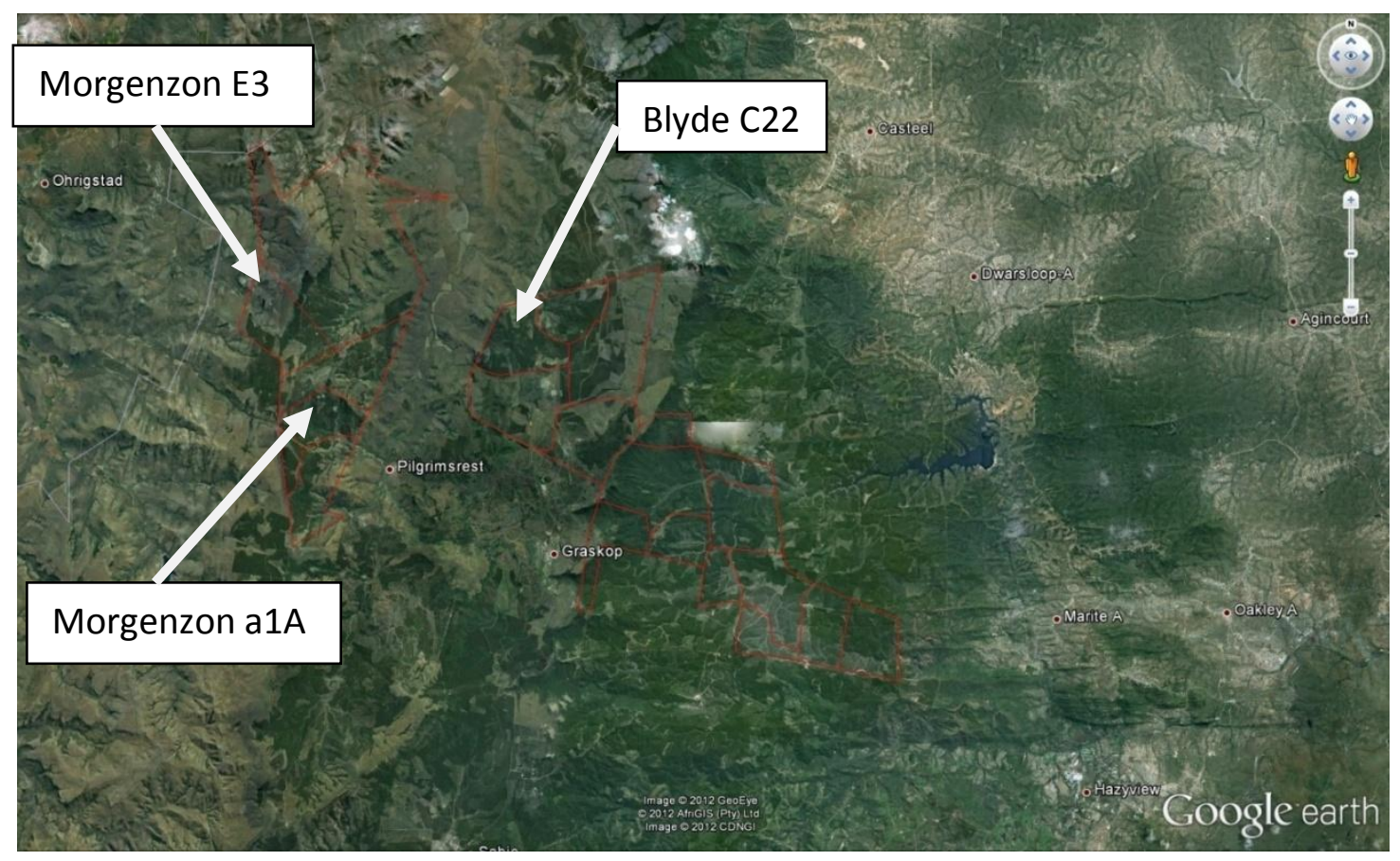

Figure 18: Enlarged image indicating locations of sites. 


\subsubsection{Data collection}

Data was obtained from eight trees from each of the three compartments for a total of 24 trees. In each compartment a centre tree was marked and the diameter at breast height (DBH) of 100 trees in a circular plot around the tree was measured. These measurements were used to determine the four DBH quartiles of the 100 trees. Two trees from each quartile were then randomly selected and marked. The DBH of each of the marked trees was also measured. The North direction was determined with a compass and marked with spray-paint on each of the marked trees.

The marked trees were felled and a measuring tape was used to measure the total length of the tree. The tree was then crosscut into four logs of three meters length each. A log was rolled onto the frame, lifted slightly with the jacks and fixed into position with the sharpened bolts. After this $20 \mathrm{~cm}$ increments were marked on each log surface indicating where crosscuts should be made. Roughly $300 \mathrm{~cm} / 20 \mathrm{~cm} \times 4$ logs $\times 8$ trees $\times 3$ compartment $=1440$ cuts made.

Additional crosscuts were made whenever a knot or set of knots was identified. These cuts were made at roughly two centimetre increments as to obtain as much information on the branch as possible (i.e. branch angle, diameter, azimuth). Unfortunately the back end of each log could not be processed, due to the method of holding the log stable for the last cut. The disks with resin pockets in them were clearly marked and taken back to Stellenbosch University for further analysis.

\subsection{Software for image analysis and log reconstruction}

ImageJ 1.45, a Java-based image processing program which is available as freeware on the web, was used for processing, analysis and identification of features. In the early phase all efforts for recognition of defects and the outline of the log were purely on a trial-and-error basis using different built-in functions in the ImageJ software. 
A macro was developed which identified the circumference, pith and the knots, outlined them and cleared the rest of the image based in a supervised process by the user. The macro which was developed worked well during initial tests in a controlled environment. However, as soon as the frame described in Section 4.1 was used to obtain photos from logs in-field it became apparent that the variability in background and light conditions made it too complicated to write a single program that could automatically obtain the results required. A manual version of the program was thus developed, where the user was able to select the features of interest and take measurements on them using an interactive process. The output of the information for each disk or image on the outline, pith and knots was then saved in jpeg format. Linking of these images into a three-dimensional model is further explained in the next section.

\subsubsection{Plug-in for identifying outline, pith and knots}

A plug-in software tool was developed in the ImageJ program which was used for identifying the outline, pith and knots. This plug-in was developed by the author and used in the study for reconstructing logs and trees.

\section{Rotating image of the log:}

Since the logs from each tree stem were cut loose from each other and processed individually, it was important that the logs all be rotated to the same compass position. This was done for reconstruction purposes, where all four logs were linked to get a model of the tree up to $12 \mathrm{~m}$. Since the northerly direction was marked on the first cut of each log, it was easy to rotate each image to an unambiguous position where North was at the top of the image.

The first step of analysis in the plug-in was to measure the deviation on the first cut from North to the vertical top-part above the pith as indicated in Figure 19. (Note: the surface quality of the first cut was fairly poor since this cut was made by the chainsaw operator felling the tree. The surface quality of cuts made on the frame was much better - see Appendix B). The process of measuring the angle was repeated only once for every log. 
After this the disk number was assigned. The program then rotated the log in such a way that the North indicator was pointing to the upper edge of the image. Figure 20 shows the image of a log after rotation.

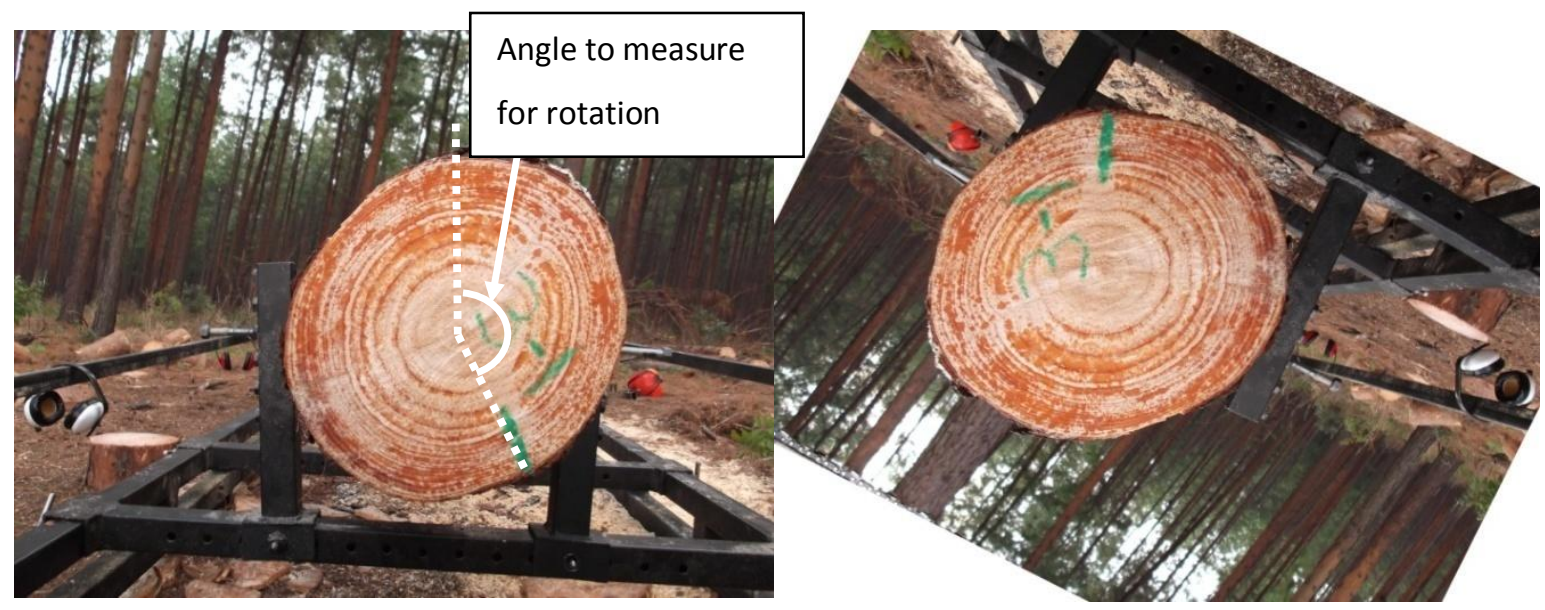

Figure 19: Image indicating angle to measure. $\quad$ Figure 20: Rotated image.

\section{Outline identification:}

After rotating the log, the polygon tool was used to indicate the circumference of the log. In Figures 21 and 22 below images prior to, and after processing are shown. The images were then saved and closed.

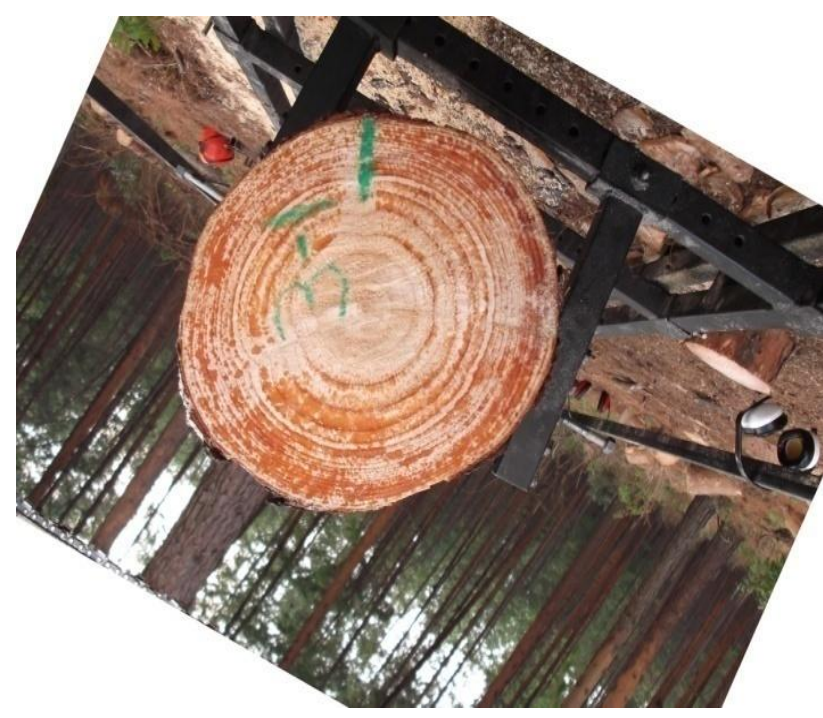

Figure 21: Rotated image.

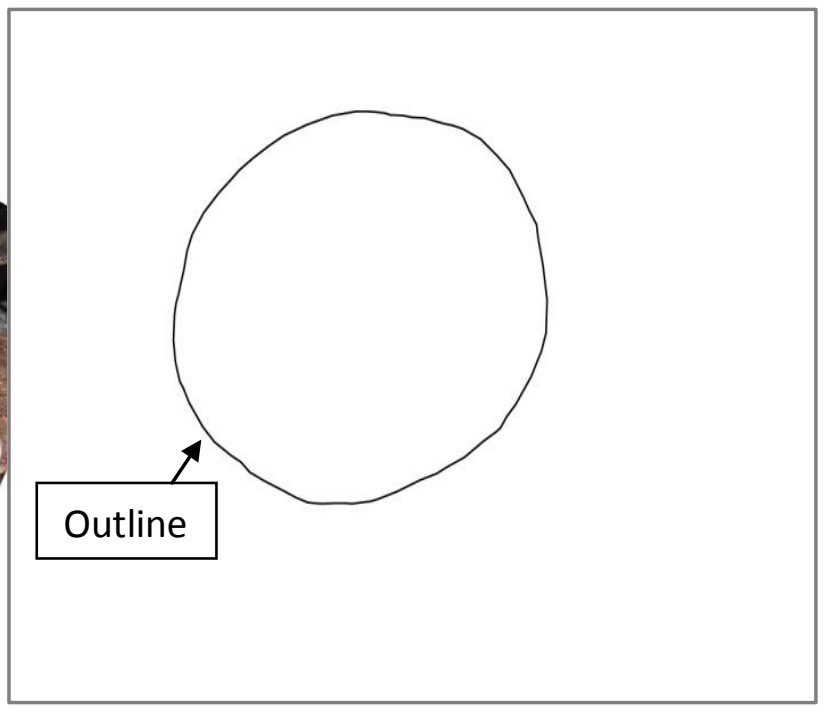

Figure 22: Identified outline. 


\section{Locating the pith:}

The position of the pith was of importance for measuring the angle from North at which knots and resin pockets were located. The user selected the oval tool and outlined the pith. The software then copied the pith onto the outline image. Figures 23 and 24 indicate an rotated image of a log and a processed log with circumference and pith identified.

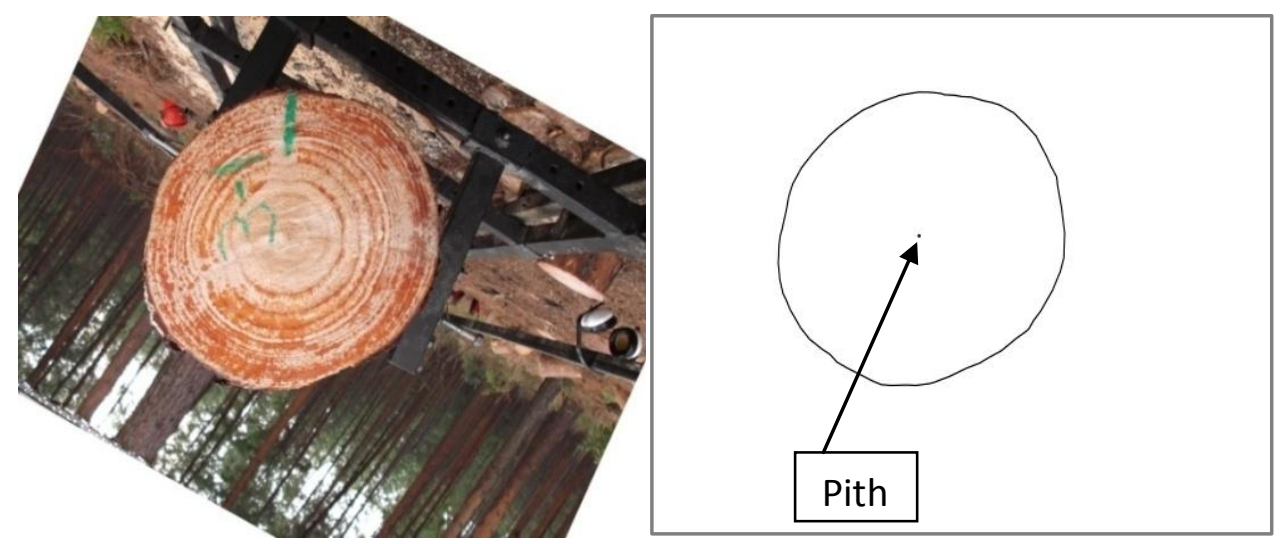

Figure 23: Rotated image.

Figure 24: Identified pith and outline.

\section{Finding knots:}

The ImageJ software provided a feature whereby the user was able to outline knots with the polygon tool. Everything except for the drawn line was cleared and the knot was saved and copied onto the outline image. Figures 25 and 26 illustrate images before and after knot identification. The plug-in was programmed to ask the user to select the angle tool and measure the angle of the knot from North. Figure 26 illustrates the angle that was measured. The next step was to select the line tool and draw a line for measuring the maximum knot diameter (Figure 26). The program then saved all the results of the measurements in a table. 


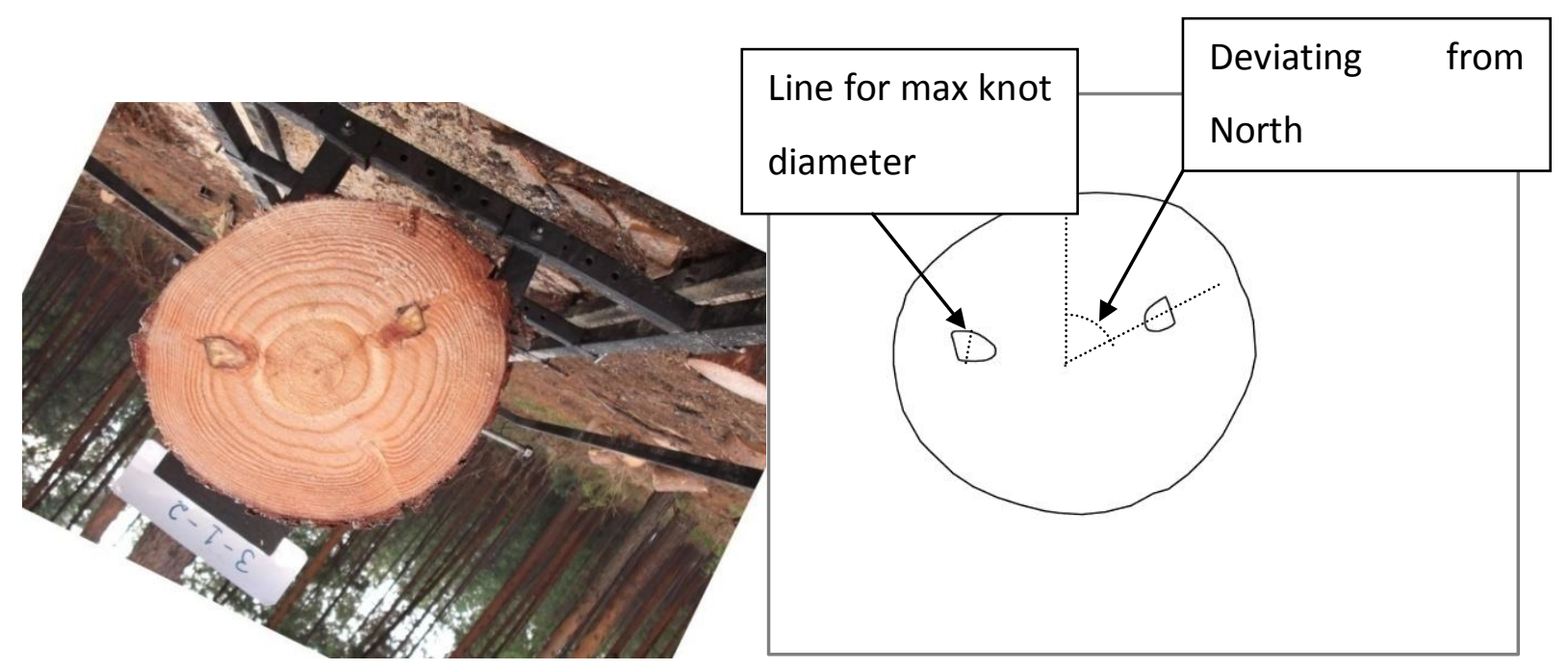

Figure 25: Rotated image.

Figure 26: Identified knots, pith and outline.

\section{Dating and measurement on resin pockets:}

An opportunity is provided for the user to observe if resin pockets are present. If the user identified any resin pockets on the cut, he then had to draw a line for measurement of the radial distance of the resin pocket from the resin pocket to the pith. The software was programmed to ask the user to select the angle tool to determine the angle from North; this measurement was done in the same way as for knots. The user then had to count in which tree ring the resin pocket was formed. This was simply done by counting the rings starting from the outside and calculating the year accordingly.

\section{3-Dimensional reconstruction of logs:}

The MATLAB R2009a software was used to write a program for reconstruction of processed images in a 3D-model

The following rules were used for linking of images:

- Outlines of consecutive disks or images were simply linked to each other to form the outline of each log. Since each log was kept stable during dissection and the camera system was moving on a stable rail in a linear path the external shape of each log would be accurate; 
- Knots from consecutive images which were from the same angle from North and from discs less than $7 \mathrm{~cm}$ from each other, were linked to each other to form an internal "branch" in the log;

- Knots or branches from the unpruned section of the tree were automatically extended to the bark of the tree;

- For the pruned section of the tree, knots or branches were terminated at the last disc where they were observed. In other words these branches "stopped" inside the log at the place of pruning;

- If a knot was observed in more than one image the branch angle could be determined. This angle was assumed for the whole branch if it extended outwards;

- The last and largest branch diameter observed was used as the maximum diameter of the branch;

- Each branch also extend inwards in a conical shape towards the pith;

- If a knot was only observed once, a default branch angle was assigned to that branch so that the branch reached the pith at a location $1.5 \mathrm{~cm}$ downwards (longitudinally) from where the cross-cut were made. This angle was selected since the discs in a knot area were cut at increments of about $2 \mathrm{~cm}$ and the fact that only one knot was observed in a series of consecutive images meant that the branch reached the pith in less than $2 \mathrm{~cm}$;

- Knots were assumed to be round and linking them resulted in a conically shaped branch.

For linking of images of logs into a model of a tree, the following rules were used:

- Since the North position of the tree was marked and all the logs rotated so that their North marks were exactly at the top of the image, all images were orientated to the same direction and could be linked. 
- Logs were processed on the frame at different angles and the axial orientation was used to link these logs.

\section{The following procedure was followed for linking of images:}

- The images were converted to binary and morphological operators were used to remove noise;

- The outline, pith as well as each knot, which were lines at this stage, were then converted to a set of coordinates by means of contour following;

- In order to link features the knots needed to have the same amount of points which were achieved by means of interpolation and equal spreading of points;

- Minimizing of distortion were used to determine which points should be linked;

- The above procedure resulted in a lot of connected quadrilaterals and; the plot function of MATLAB was used to connect these;

- For extrapolation of knots the least sum of squares lines were fitted and the points of intersection determined (also by least sum of squares).

An example of one of the 3D-models created by the software can be seen in Figure 27: 

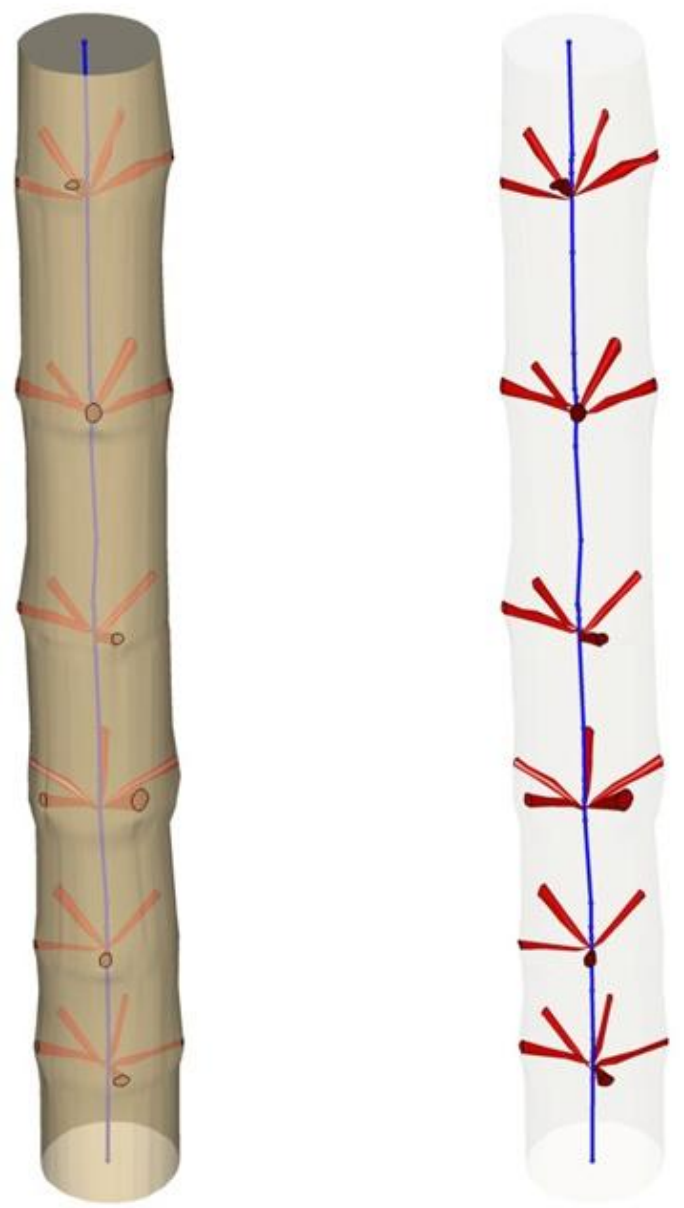

Figure 27: An example of a 3D-model of a log showing the knots and pith.

\subsection{Resin pockets}

Slices that contained resin pockets were identified during dissection, as well as during processing of the photographs in the software. These resin pockets were then dated, their height in the tree was determined, and also the angle from North determined. 
When a resin pocket was identified in field, an extra cut was made to free the disk containing the resin pocket without transporting unnecessary material. These disks were then transported to the lab for further analysis.

\subsubsection{Testing of resin pocket formation hypotheses}

\section{Storm hypothesis}

The crown size, in terms of length, was determined to see whether there was a correlation between crown size and resin pocket formation. A larger crown should result in more resin pockets being formed. An attempt was made to link resin pocket formation to extreme events such as a storms or high wind speeds. If wind was the main cause of resin pocket formation, the tree rings of years in which such extreme events occurred should contain more resin pockets.

\section{Drought hypothesis}

According to Schulze et al. (1997) the 'Mean annual precipitation characterizes the long term quantity of water available to a region for hydrological and agricultural purposes'. Reference evaporation refers to the amount of water which can evaporate into the air from a certain area. If reference evaporation values for a certain area are compared to rainfall, it can be determined whether a particular period was dry or not.

The FAO Penman-Monteith method of obtaining reference evaporation was decided upon, rather than the A-pan method, because according to Schulze et al. (1997), the A-pan method is 'intrinsically not suitable as a reference for the estimation of crop water requirements'. Reference evaporation values which had been determined by the FAO Penman-Monteith (1992) method were acquired for each of the specific sites. 
To determine whether there was enough water available for plants to grow it should be determined whether precipitation exceeds a lower limit of plant evaporative losses for growth to continue. The period where enough water was available for sustained growth to take place constituted the moisture growing season. An average moisture growing season was determined (Schulze et al, 1997) for the sample sites.

"In the FAO (1978) approach adapted for Southern Africa it is assumed that during the period when

$P \geq 0.3 * E$

sustained plant growth can take place..."(Schulze et al., 1997).

P: median monthly precipitation

E: mean monthly evaporation

'The median is the middle value when a data series is ranked from highest to lowest. It therefore designates a statistically expected value...'(Schulze et al, 1997)

Monthly rainfall data was acquired and compared to reference evaporation calculated by the FAO Penman-Monteith (1992) method. By comparing monthly rainfall with the reference evaporation, it could be determined how much water would evaporate versus how much water was available monthly.

The moisture growing season was also calculated and compared to monthly rainfall figures. From calculating this, we could analyze whether more resin pockets were formed outside of the moisture growing season or not. The annual total rainfall was also compared to a mean annual precipitation value for each site acquired from weather stations and calculated from data over many years. 
While processing the images with the software the latewood to earlywood transition was examined to identify false growth rings as proposed by Panshin and de Zeeuw (1980). False growth rings were then marked, and a visual inspection was done to see whether a correlation could be made between false growth rings and resin pocket occurrence.

\section{Damage hypothesis}

The only certain damage that was recorded and can be linked to resin pocket formation was thinning. The years of thinning were analyzed so as to determine whether there were more resin pockets in these years than in others.

\section{Other}

The year-rings at DBH for all 24 trees were measured and an average for each year per compartment was obtained. The rings containing resin pockets were compared to the average of the specific compartment it came from.

\subsubsection{Determining average resin pocket sizes}

A CT-scan was performed on the resin pockets of all the disks that were brought back from the Mpumalanga escarpment. The scan was performed with the General Electric Phoenix VTOMEX L240 CT-scanner of Stellenbosch University. The CT-scanner used for scanning can be seen in Figure 28 below. 


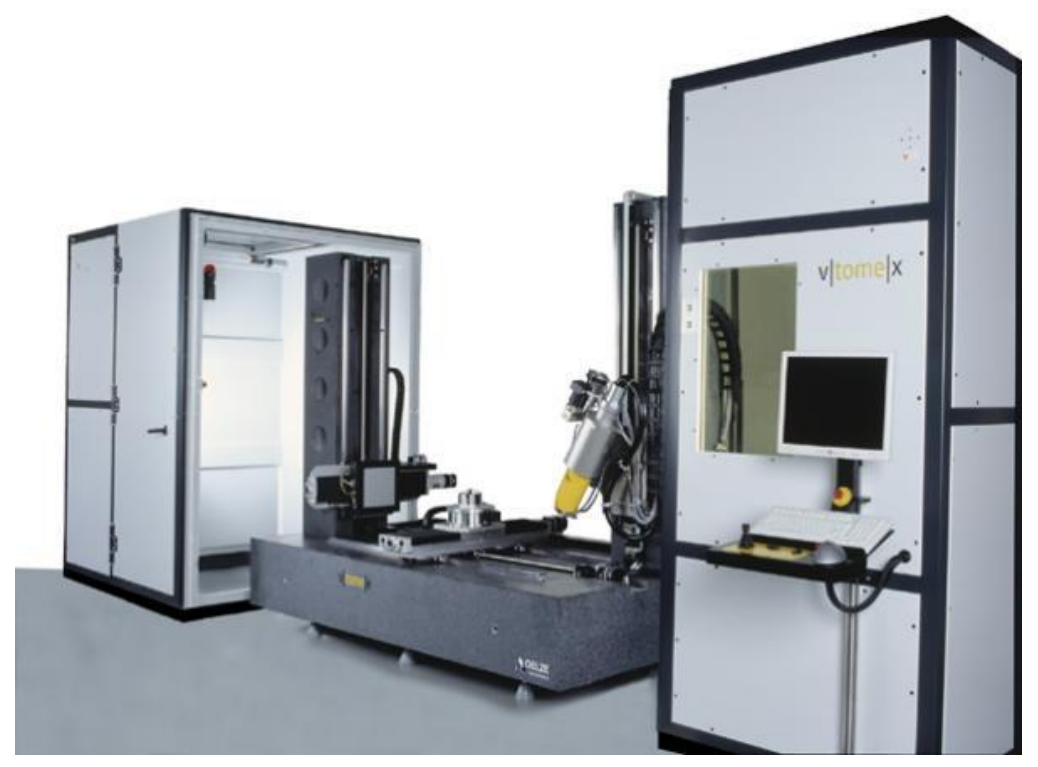

Figure 28: The CT scanner at Stellenbosch University.

During a CT scan, an object is exposed to x-rays and the absorbed radiation is measured by means of a sensor which is positioned at the opposite side of the scanner. The scanner rotates the object and several measurements are taken to enable accurate three dimensional reconstruction to be done. In this study the CT scanner was set to take 3000 photos in a single rotation. A processed image of a scanned resin pocket can be seen in Figure 29. The blue area in the top part of the figure is a resin pocket. As can be seen in the figure, the resin pocket was cut into during dissection of the log, and thus this is only a part of the resin pocket. Specialised software was used on the 3D-model after a scan for analysis to determine a threshold value that was able to differentiate between a resin pocket and the surrounding wood. A threedimensional animation of a scanned resin pocket can be viewed at the following link: http://blogs.sun.ac.za/ctscanner/2012/11/16/resin-pocket-visualization-inside-wood/ Measurements were done to determine the longitudinal, tangential and radial dimensions of each resin pocket that was scanned. 


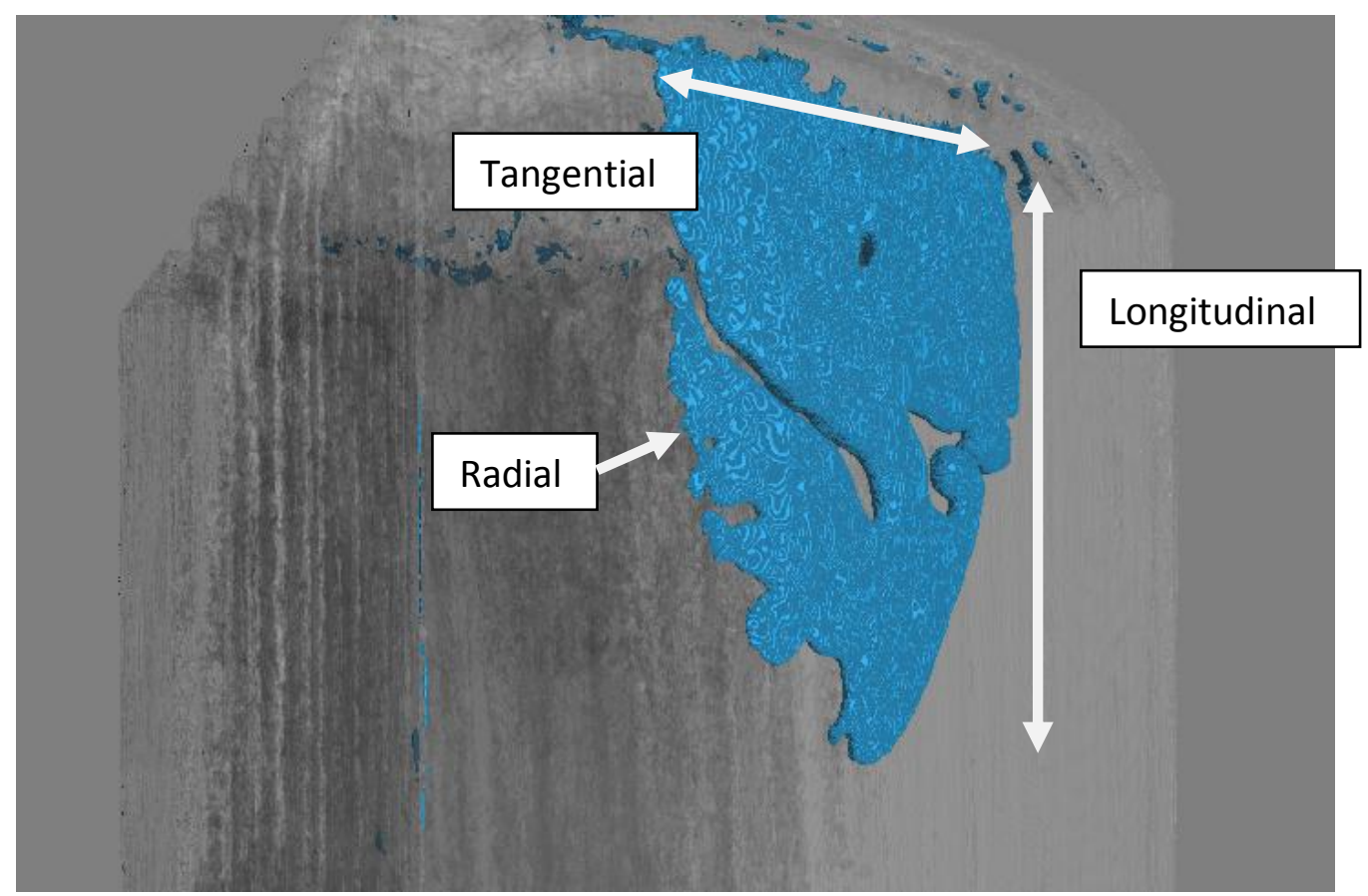

Figure 29: Scanned disk with resin pocket identified.

\subsection{Ring width measurements}

One of the possible uses of the data obtained from the stem analysis system is measurement of ring width. Three disks in total which were brought back to Stellenbosch University were used for evaluating the measurements of ring width. The disks were sanded on a belt sander to make the year rings more visible.

A straight line was then drawn from the one side of the bark, through the pith to the other side of the bark. In the first instance measurements were performed on the disks by scanning them with a normal document scanner and measuring the growth rings in ImageJ. A line of known dimensions were drawn on the disks to enable calibration of the measurements. The photographs taken infield on the log dissecting frame of the same disks were then opened in Image J 1.45, a line drawn in the same position, and measurements were done. The measurements were then compared by means of a 45 degree regression line to see whether measurements can be accurately done on data obtained from the system. 


\section{Results and discussion}

\subsection{Operation of the frame}

The frame was used in this study for 12 days. The frame generally functioned well. During this period it became apparent exactly what the shortcomings of the frame were and what improvements could still be made. The following improvements can be made:

- If a longer log can be accommodated on the frame a full tree can be processed faster as there will be fewer logs to load and fasten. The size of logs that can be accommodated can be increased by lengthening the frame. Loading and fastening logs onto the frame was one of the most time consuming tasks;

- The jacks should be better stabilized by adding a fastening device on the side to prevent lateral movement. On steep slopes the logs were sometimes unstable on the jacks during log loading;

- The height that the log can be jacked up should be increased to ensure the top part of the saw blade can cut all the way down. The log could not always be cut right through and the bottom part of a disk had to be broken off to remove it.

\subsection{Functioning of the software}

In general the manual identification of outline, pith and knots was time consuming with an average of 2.5 hours of processing per log. Problems, however, occurred with the light conditions and it was apparent that the background was too variable infield for automatic detection and manual intervention was required. The software worked after the changes, and measurements on the angle from North as well the distance to the outline could be made. The images were successfully combined into a 3D-model.

In a controlled environment such as a shed where incoming light can be controlled and additional lighting can be used, the software for automatic detection could more easily be developed. Under these controlled conditions it would be beneficial to spend additional time on software development. However, that was not possible for this study. 


\subsection{Measurement of ring width}

Measurements of ring width were done in ImageJ and compared to the measurements from the images obtained from the scanner. From Figure 30 it is clear that ring width measurements can be done accurately from the acquired data as a linear regression analysis showed a coefficient of determination of $\mathrm{R}^{2}=0.99$. The results were from 50 ring width measurements.

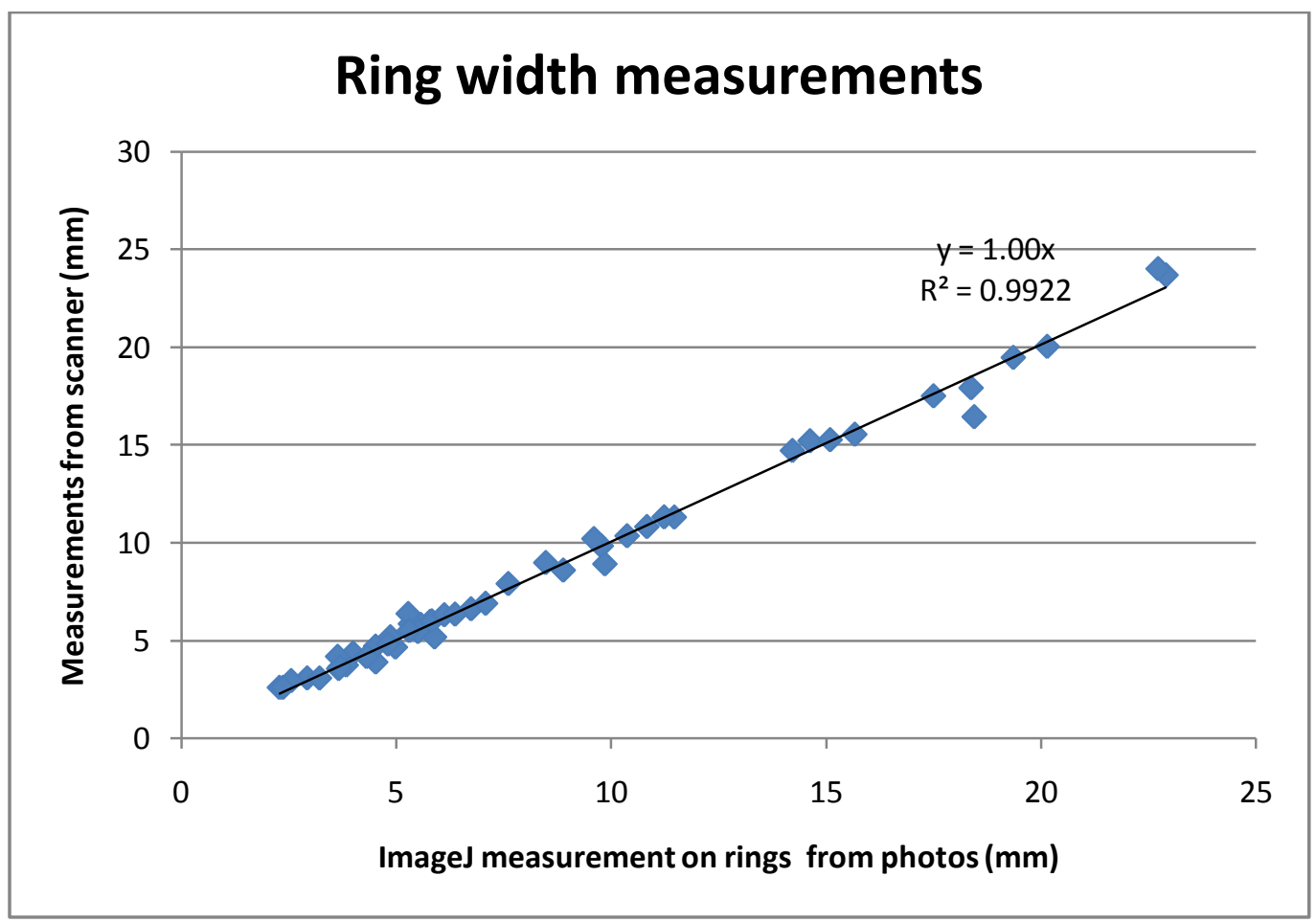

Figure 30: Comparison of ring width measurements.

\subsection{Resin pockets}

Only 61 of approximately 2750 cross-sections from 24 trees were identified as having resin pockets present. Of these 61 cuts, 42 were on the predetermined increments of $20 \mathrm{~cm}$ and the others were located in cuts to expose knots. There were $300 \mathrm{~cm}$ (log length) $/ 20 \mathrm{~cm}$ (increment) $x$ 4 (logs) $\times 8$ (trees) $\times 3$ (compartments) $=1440$ cuts made at $20 \mathrm{~cm}$ intervals. Whenever making a cut through the sample material at the $20 \mathrm{~cm}$ lengthwise increment, there was thus a 42/1440 or about $3 \%$ chance of finding a resin pocket. This, however, did not mean there were only 42 resin pockets present in the sample material. 
It can be assumed that there were resin pockets which were not situated in the cross cut area or were so small that they were overlooked on the chainsaw-cut surface.

The images of all 61 resin pockets can be viewed in Appendix B. A statistical approach to finding the number of resin pockets present in the sample material is described in Section 5.4.2.

A visual analysis of images of the resin pockets indicates that most resin pockets were formed in the centre of the earlywood-part of the growth ring (See Appendix B).

\section{Bar Chart}

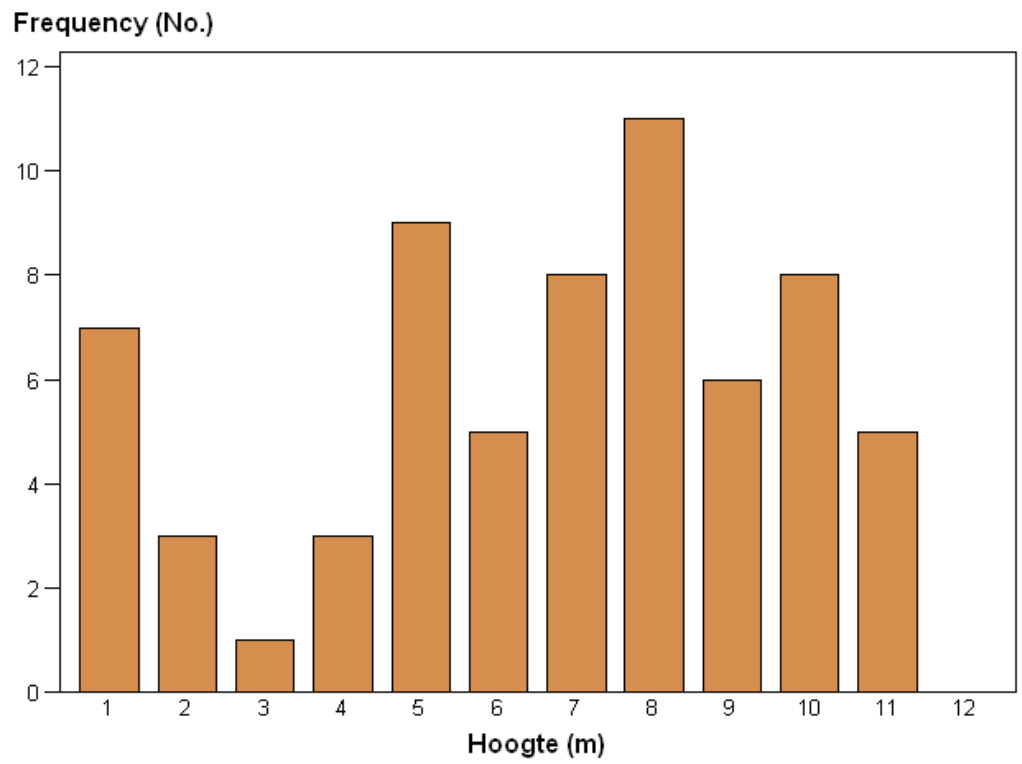

Figure 31: Height distribution of resin pockets

Figure 31 shows the height distribution of resin pockets. It can be seen that the greatest occurrence of resin pockets was at height eight to nine meters with relatively few resin pockets between two and four meters. In Figure 32 it can be observed that the year 1997 had the highest occurrence of resin pockets with ten resin pockets formed followed closely by 2004 with nine resin pockets. 
Figure 33 illustrates the occurrence of resin pockets per cambial age of the tree. The cambial age of a year ring is simply the number of year rings from the pith to that specific year ring. In this figure it can be seen that the highest frequency of resin pockets was at cambial age three.

\section{Resin pocket occurence by year}

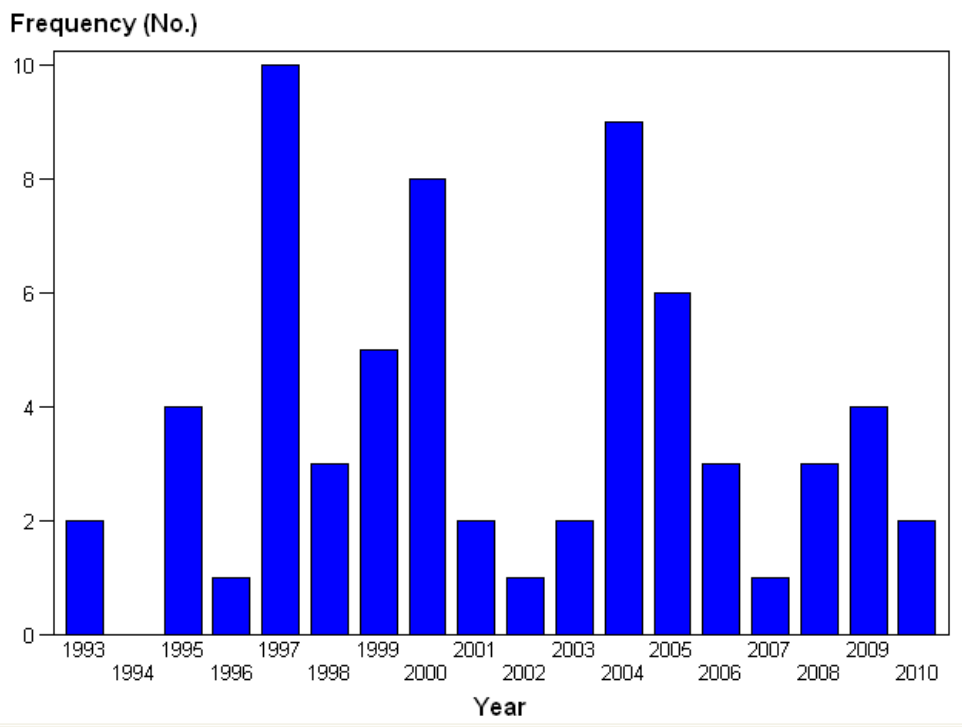

Figure 32: Frequency of resin pockets per year.

Resin pocket occurence per cambial age

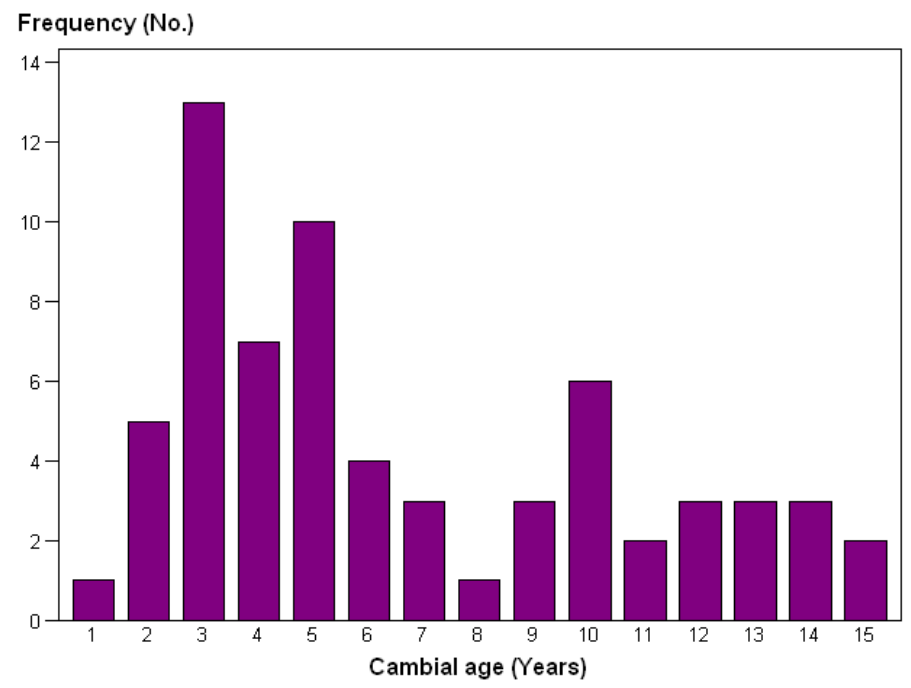

Figure 33: Frequency of resin pockets per cambial age. 
In Figure 34 the resin pocket occurrence per compartment can be seen. From the figure it is clear that by far the most resin pockets occurred in Blyde C22, with 39 out of the 61 resin pockets occurring on this site.

From Figure 35 it can clearly be seen that Tree 7 had the most resin pockets. It can also be observed that a total of 37 of the 66 resin pockets that were found occurred in just 3 trees.

\section{Resin pocket occurence per compartment}

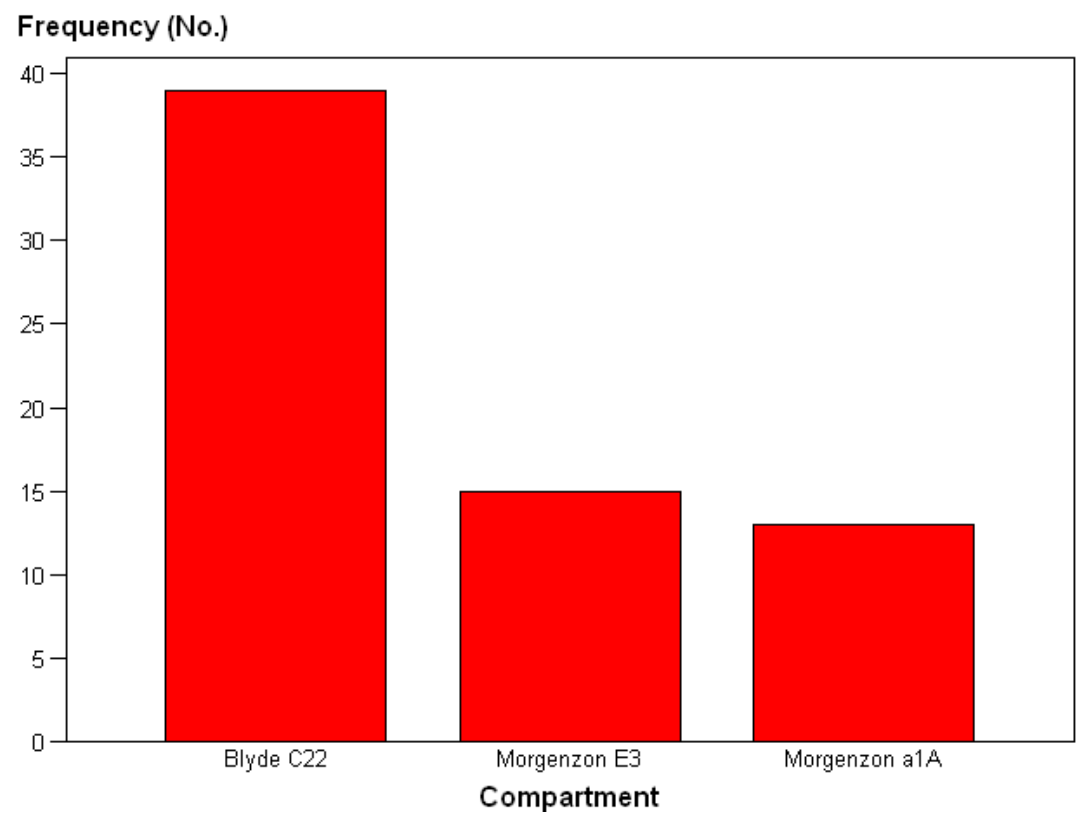

Figure 34: Resin pocket occurrence per compartment. 


\section{Resin pocket occurrence per tree}

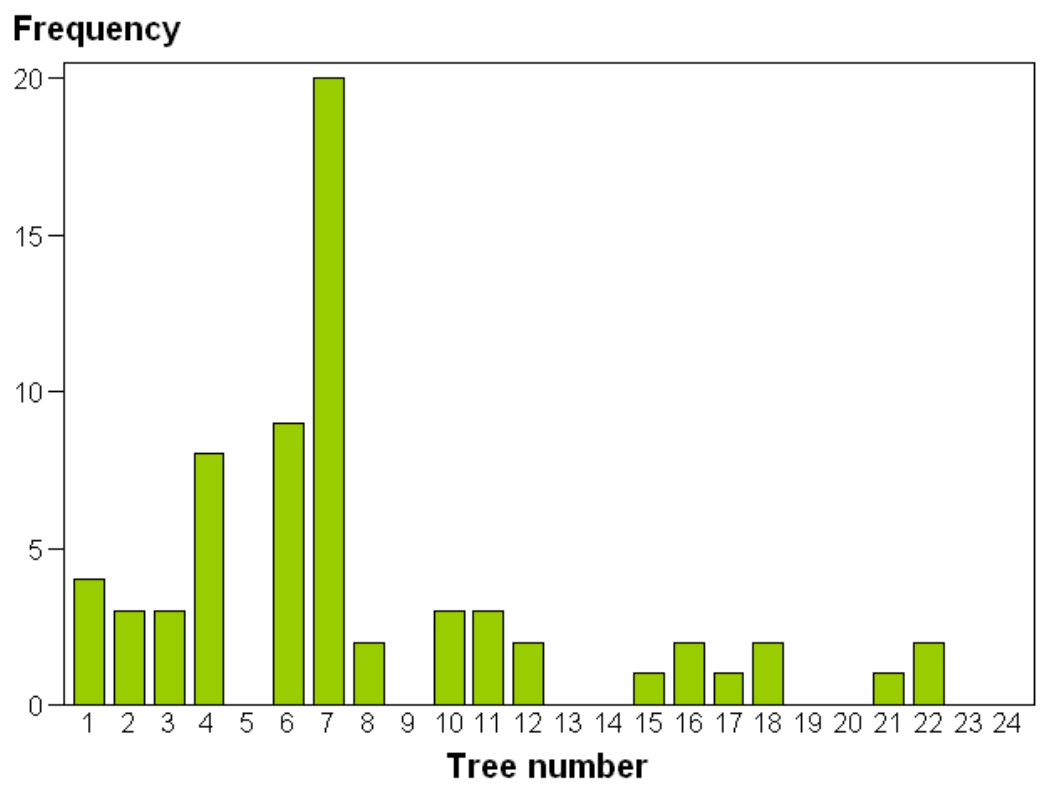

Figure 35: Resin pocket occurrence per tree.

\subsubsection{Average resin pocket size}

The average resin pocket sizes as measured on the three-dimensional model obtained from the CT-scanner are provided in Table 7 below.

Table 7: Average resin pocket dimensions

\begin{tabular}{|l|l|l|l|}
\hline Material & $\begin{array}{l}\text { Longitudinal } \\
(\mathrm{mm})\end{array}$ & $\begin{array}{l}\text { Tangential } \\
(\mathrm{mm})\end{array}$ & $\begin{array}{l}\text { Radial } \\
(\mathrm{mm})\end{array}$ \\
\hline $\begin{array}{l}\text { Pinus patula from Mpumalanga } \\
\text { escarpment }\end{array}$ & 21.79 & 22.95 & 2.09 \\
\hline
\end{tabular}

Since part of each resin pocket in the disks that were collected was cut off, none of the longitudinal measurements represents the full length of the resin pocket. 
A constant interval of $20 \mathrm{~cm}$ was used for crosscuts and no prior knowledge as to resin pocket position influenced the cutting, thus it can be assumed that the position within the resin pocket that the cut was made is normally distributed and on average represents $50 \%$ of the longitudinal dimension of the resin pocket.

Adjusting the longitudinal dimension accordingly resulted in average resin pocket dimensions as given in Table 8. The tangential as well as the radial dimensions will also represent only a proportion of the actual resin pocket size. Adjusting these measurements, however, is not that simple because of the difference in the shape of resin pockets. It should thus be noted that the radial and tangential dimensions are only a proportion of the actual size.

Table 8: Adjusted resin pocket dimensions.

\begin{tabular}{|l|l|l|l|}
\hline Material & Longitudinal $(\mathrm{mm})$ & Tangential $(\mathrm{mm})$ & Radial $(\mathrm{mm})$ \\
\hline Pinus patula from Mpumalanga escarpment & 43.58 & 22.95 & 2.09 \\
\hline Pinus radiata (Cown et al., 2011) & $40-100$ & $20-50$ & $3-6$ \\
\hline
\end{tabular}

In Table 8 it can also be seen that the dimensions of resin pockets found in this study fall in the lower part of the size range for Type 1 resin pockets in Pinus radiata as presented by Cown et al. (2011). As can also be seen in Table 8, if the sizes of resin pockets obtained in this study were compared to maximum possible dimensions as given by Oja and Temnerud (1999), these resin pockets were relatively small. 


\subsubsection{Statistical method for determining number of resin pockets in material}

Since only crosscuts containing resin pockets that were found on the $20 \mathrm{~cm}$ increments were used for statistical analysis, and the mean longitudinal dimension of resin pockets is $43.58 \mathrm{~mm}$, there was more resin pockets within the study material. From the average calculated resin pocket length and the increment at which cuts were made, the number of resin pockets actually present in the material can be calculated. The calculations were as follows:

\section{Calculations for total tree}

The probability that a resin pocket will be encountered when making an incremental crosscut $=\frac{\text { Mean resin pocket length }(\mathrm{mm})}{\text { Section length }(\mathrm{mm})} * \frac{100}{1}$

$$
\frac{43.58}{200} * \frac{100}{1}=21.79 \%
$$

Total number of resin pockets present in sample material = $\frac{\text { Number of resinpockets in section }}{\text { Probability of finding resin pocketon in section }} * 100$

$\frac{42}{21.79} * \frac{100}{1}=192.74 \approx 193$ resinpockets

Number of resin pockets per meter $=\frac{\text { Total number of resin pockets }}{\text { Number of trees } * \text { Length per tree }}$

$$
\frac{193}{24 * 12}=0.67 \text { resinpockets } / m
$$




\section{Calculations for $\log 1$ (0-3m height)}

The probability that a resin pocket will be encountered when making a incremental

crosscut $=\frac{\text { Mean } \text { resin pocket length }}{\text { Section }} * \frac{100}{1}$

$$
\frac{63.13}{200}=31.57 \%
$$

Total number of resin pockets present in sample material = Number of resinpockets in section

Probability of finding resin pocket in section

$\frac{10}{31.57} * \frac{100}{1}=31.68 \approx 32$ resinpockets

Number of resin pockets per meter $=\frac{\text { Total number of resin pockets per log }}{\text { Number of trees } * \text { Length per tree }}$

$$
\frac{32}{24 * 3}=0.44 \text { resinpockets } / m
$$

\section{Calculations for log 2 (3-6m height)}

The probability that a resin pocket will be encountered when making an incremental crosscut $=\frac{\text { Mean resin pocket length }}{\text { Section }} * \frac{100}{1}$

$$
\frac{44.48}{200}=22.24 \%
$$

Total number of resin pockets present in sample material = Number of resinpockets in section $\overline{\text { Probability of finding resin pocket in section }}$

$$
\frac{13}{22.24} * \frac{100}{1}=58.45 \approx 58 \text { resinpockets }
$$

Number of resin pockets per meter $=\frac{\text { Total number of resin pockets per log }}{\text { Number of trees } * \text { Length per tree }}$ 


$$
\frac{58}{24 * 3}=0.81 \text { resinpockets } / m
$$

\section{Calculations for $\log 3$ (6-9m height)}

The probability that a resin pocket will be encountered when making an incremental

crosscut $=\frac{\text { Mean resin pocket length }}{\text { Section }} * \frac{100}{1}$

$$
\frac{32.30}{200}=16.15 \%
$$

Total number of resin pockets present in sample material $=$ Number of resinpockets in section

$\overline{\text { Probability of finding resin pockets in section }}$

$$
\frac{24}{16.15} * \frac{100}{1}=148.61 \approx 149 \text { resinpockets }
$$

Number of resin pockets per meter $=\frac{\text { Total number of resin pockets per log }}{\text { Number of trees } * \text { Length per tree }}$

$$
\frac{149}{24 * 3}=2.07 \text { resinpockets } / m
$$

\section{Calculations for $\log 4$ (9-12m height)}

The probability that a resin pocket will be encountered when making an incremental crosscut $=\frac{\text { Mean resin pocket length }}{\text { Section }} * \frac{100}{1}$

$$
\frac{55.21}{200}=27.61 \%
$$

Total number of resin pockets present in sample material = Number of resinpockets in section

Probability of finding resin pockets in section 


$$
\frac{19}{27.61} * \frac{100}{1}=68.82 \approx 69 \text { resinpockets }
$$

$$
\begin{aligned}
& \text { Number of resin pockets per meter }=\frac{\text { Total number of resin pockets per log }}{\text { Number of trees } * \text { Length per tree }} \\
& \qquad \frac{69}{24 * 3}=0.96 \text { resinpockets } / \mathrm{m}
\end{aligned}
$$

From the calculations it can be seen that the highest occurrence of resin pockets were in log three which had 2.07 resin pockets/meter. The least resin pockets were found in the bottom three meters of the tree with only 0.44 resin pockets/meter. Veneer is mostly cut from this bottom part of the log, thus it is fortunate that the occurrence of resin pockets were lower for this part.

\subsubsection{Indications of possible reasons for resin pocket formation}

In this section the possible causes for resin pockets are discussed.

\section{Storm hypothesis}

If the following indicators were present it might suggest wind or a storm as the main cause of resin pocket formation:

- Resin pockets will be formed in the same year at the same compass angle from North since a wind or storm will probably come from one direction. The stress and ruptures causing a resin pocket will probably be in the same direction of the crown sway;

- This occurrence should be spread through the compartment as all trees will be affected by wind and a storm. Edge trees will be more severely affected;

- The incidence should increase towards the top of the tree, due to decrease in diameter and increase in sway during winds; 
- An increase in occurrence of resin pockets with an increase in crown size as wind will probably affect trees with a larger crown more than trees with a smaller crown.

In this study, we found an increasing trend of resin pockets towards the top of the tree. In the year with the highest resin pocket occurrence no clear pattern as to the direction of resin pocket occurrence could be observed, this was in line with previous studies done (Seifert et al. 2010). In the year with the second highest occurrence of resin pockets, which was 2004, most resin pockets formed more or less in the same direction in the same compartments. The pattern in 2004 suggests that in this year wind might have been the main cause of resin pocket formation. In the other years, no clear patterns could be observed. Photographs of all cuts containing resin pockets can be seen in Appendix B. No data regarding wind speed for the period was available at the compartment locations.

From the data acquired there was no conclusive evidence that wind was the main cause of resin pocket formation although anecdotal evidence suggest that it could have been a cause for resin pockets in 2004.

\section{Drought hypothesis}

If the following indicators were present it might suggest drought as the main cause of resin pocket formation:

- Resin pockets will form in the dry part of the year, which is the winter season in this area (Watt et al., 2011);

- There might be an association between false growth rings and resin pocket formation (Cown, 1973);

- The year in which there was a high occurrence of resin pockets had a rainfall below the average;

- The specific year where most resin pockets occurred had a longer dry period. 
Unlike the trees studied by Watt et al. (2011), the position of the resin pockets was mostly found to be in the centre or close to the centre of the earlywood part of year-rings.

Cown (1973) argued for water stress being the main cause of resin pocket formation in the $P$. radiata trees studied by him because it was associated with the formation of false growth rings. Only a few false growth rings were found in this material, and no association could be made between the false rings and resin pockets.

These differences from previous studies where drought was defined as the main cause of resin pocket formation indicate that drought may not have been the main cause of resin pocket formation in this case.

From the comparison of reference evaporation to monthly rainfall values obtained from weather stations, which can be seen in Figure 36 , the following was noted:

- For the high rainfall year which was 2000, only July and August were outside the moisture growing season;

- For the average rainfall year, which was 1997, (also the year that most resin pockets occurred), June, July and August fell outside of the moisture growing season;

- For the low rainfall year, which was 2002; April, May, August and September fell outside the moisture growing season.

In both the high and low rainfall years it can be observed that the longest period that fell outside the moisture growing season consisted of two consecutive months; however, for the average year, which was 1997 (which also had the highest resin pocket occurrence), 3 consecutive months were found to be outside the moisture growing season.

When the year 2004, in which the second highest number of resin pockets was found, was included a period of 5 consecutive months was shown to be outside of the moisture growing season. However, when more years were included this pattern was not observed. Most resin pockets in this study were formed in the earlywood. 


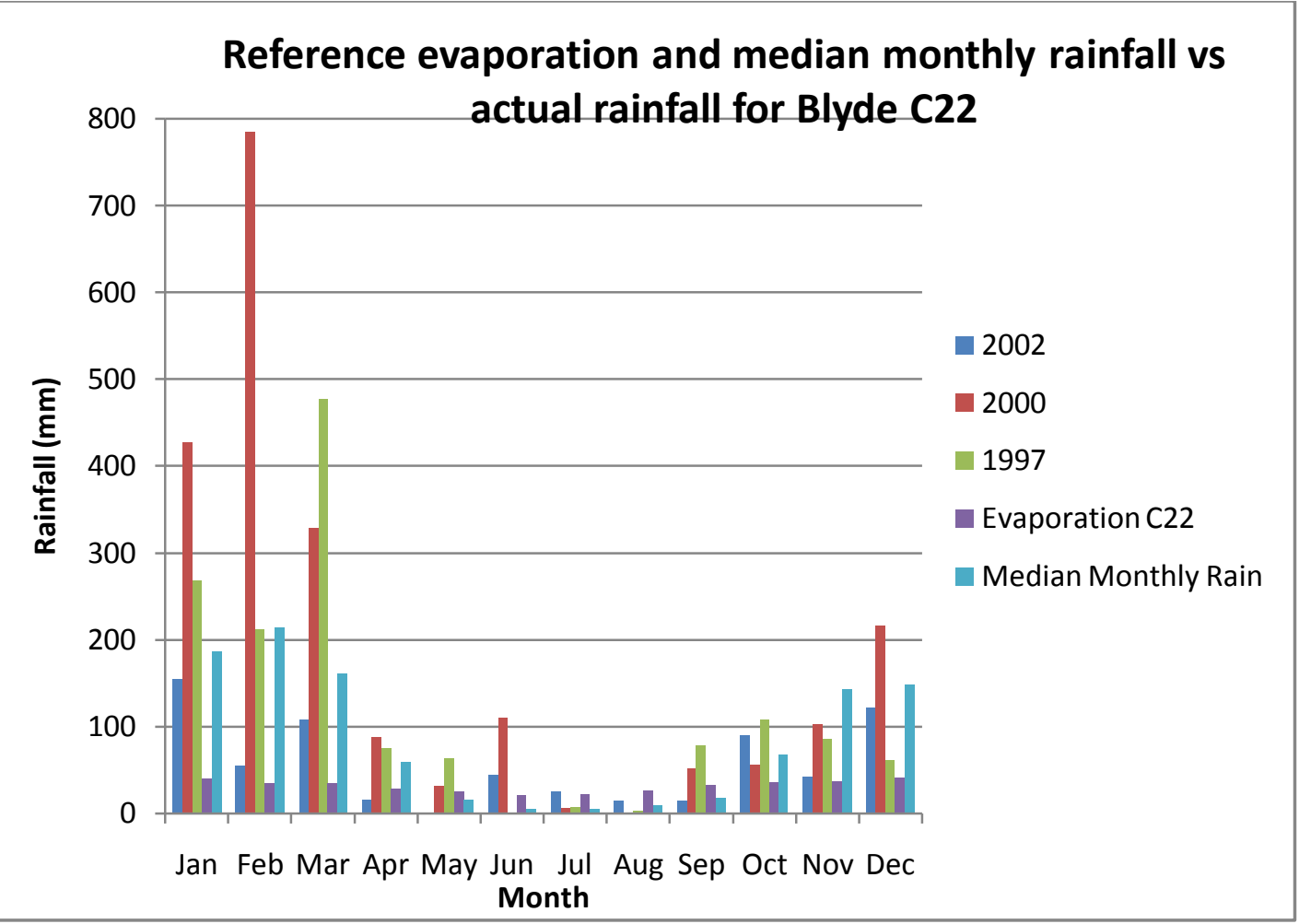

Figure 36: Reference evaporation and median rainfall compared to actual rainfall for site Blyde C22 for a high rainfall year, an average rainfall year and a low rainfall year.

The most resin pockets recorded in one year on one site were ten resin pockets formed in 1997 on Blyde C22. It can be seen in Figure 37 that $1437.5 \mathrm{~mm}$ of rain fell in 1997, which was above the mean annual precipitation of $1174 \mathrm{~mm}$ for this specific site. It can also be seen in Figure 36 that 1997 also had above the median monthly rainfall in most months. The year in which the second most total resin pockets were found was 2004, in which 7 resin pockets were found, also in Blyde C22.

The rainfall of 2004 was quite similar to that of 1997, also being a year with above the mean annual precipitation with $1201.8 \mathrm{~mm}$. Thus, for site Blyde C22, evidence suggests that the main cause of resin pockets might not be drought. 


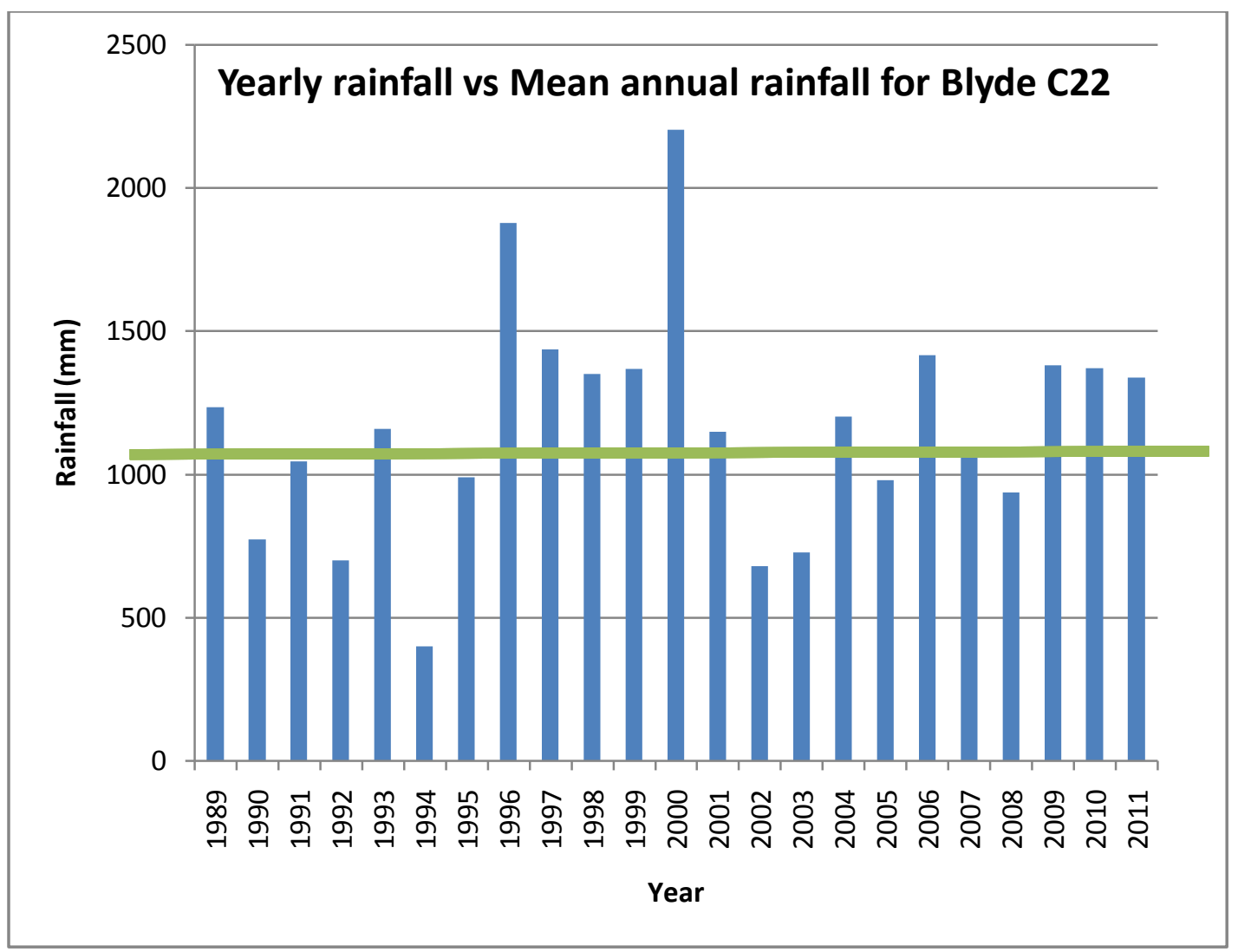

Figure 37: Annual rainfall compared to mean annual rainfall for site Blyde C22.

For the other two sites, Morgenzon a1A and MorgenzonE3, we found very few resin pockets, with the most being four resin pockets found in 2009 in Morgenzon E3. It can be seen in Figure 38 that in 2009 rainfall for this site had fallen below that of the moisture growing season already in April, which was one month earlier than with the average rainfall. The longest consecutive period in this year which was outside of the moisture growing season was also three months. Similar to Blyde C22 the period which fell outside of the moisture growing season formed part of the dry season which was not the part of the year in which the resin pockets were formed. It can also be seen that the rainfall in December was well below average. However, these lower values were similar to those for 2003, in which no resin pockets were formed. Thus drought also seems unlikely as the main cause of resin pocket formation for these sites. 


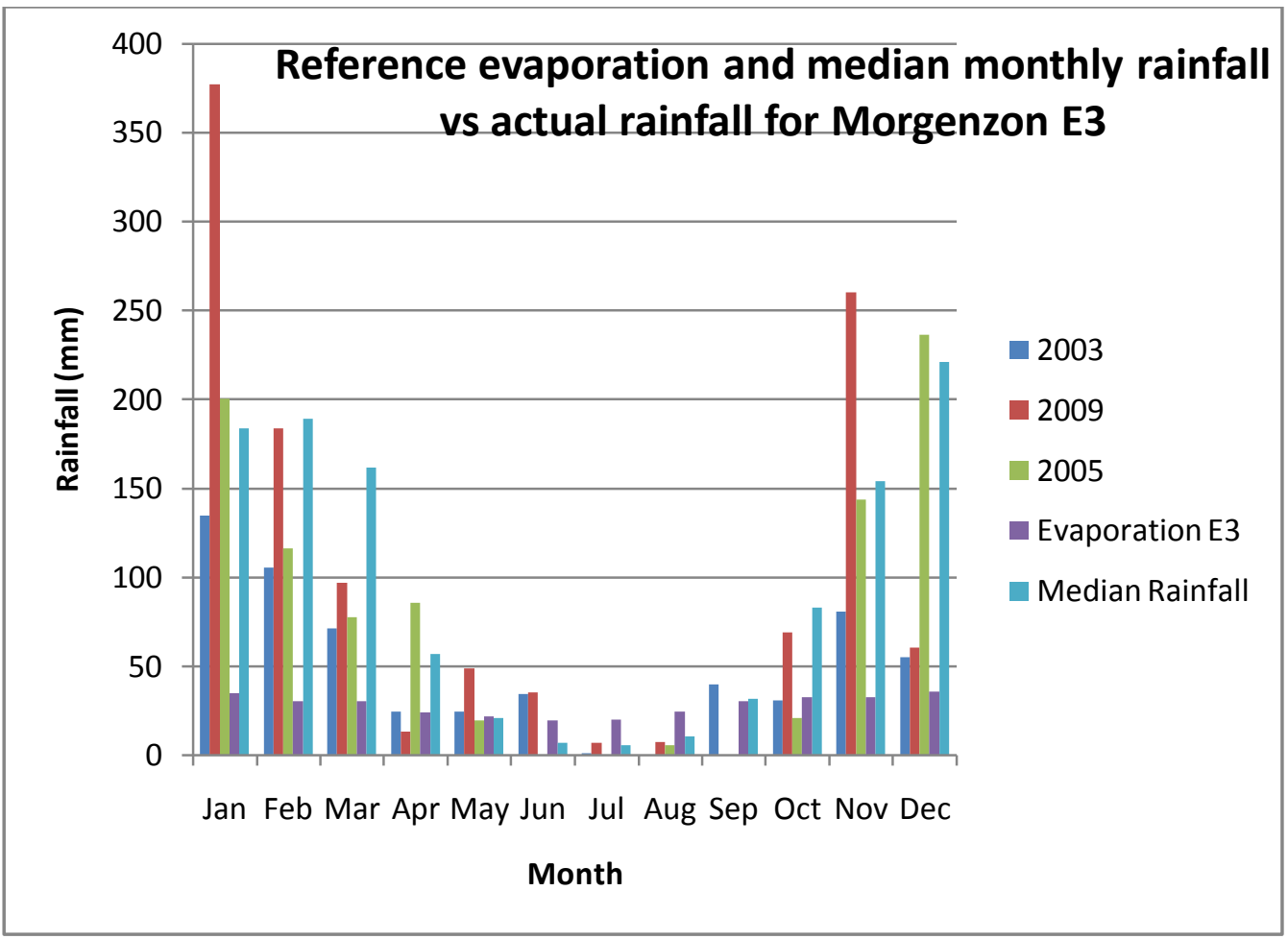

Figure 38: Reference evaporation and median rainfall compared to actual rainfall for site Morgenzon E3 for a high rainfall year, an average rainfall year and a low rainfall year.

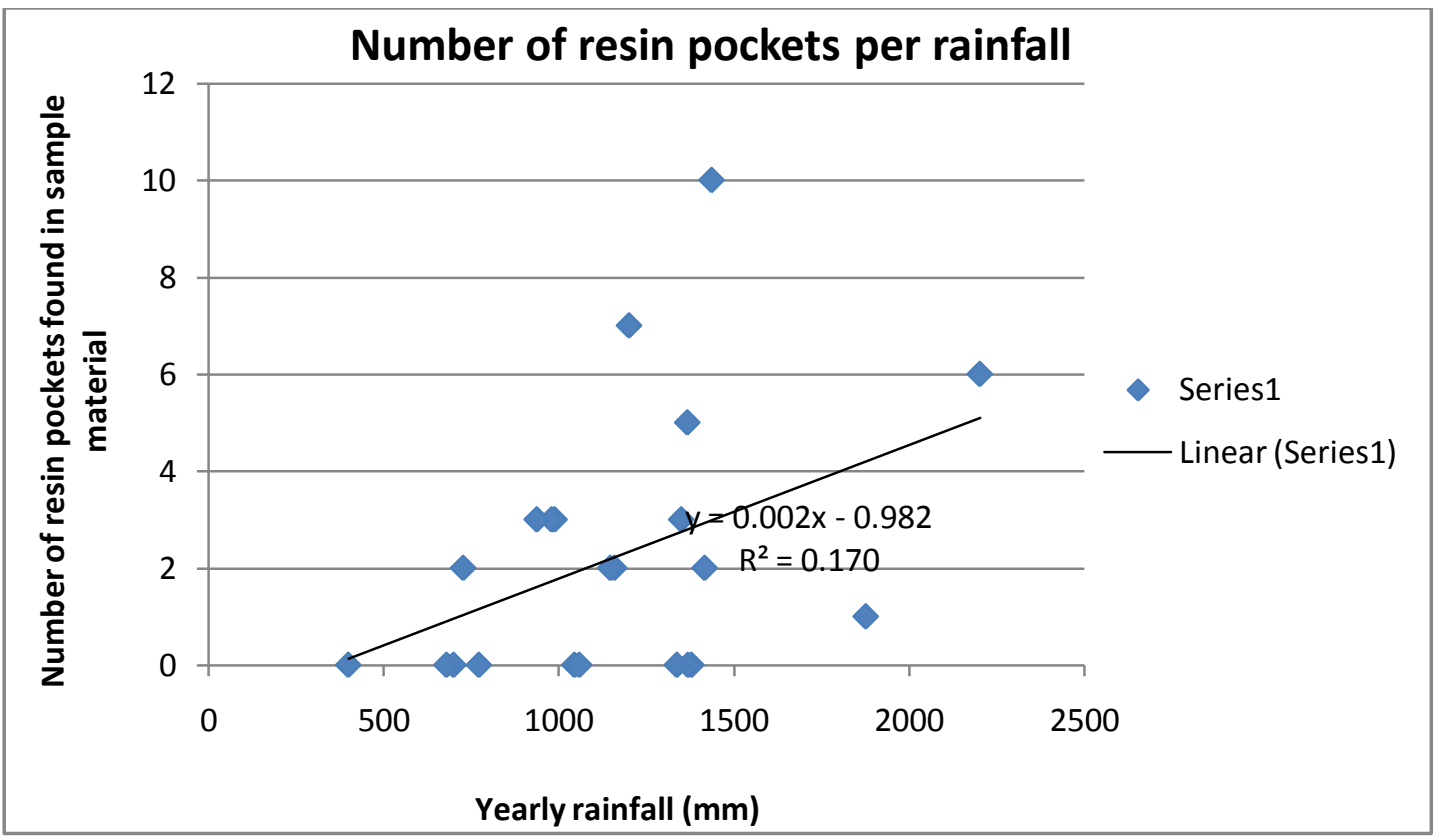

Figure 39: Annual rainfall versus number of resin pockets formed. 
The annual rainfall versus the number of resin pockets formed during the specific year was also plotted so as to establish a possible relationship. A linear trendline was fitted on the data and resulted in an $R^{2}$ value of 0.170 as can be seen in Figure 39 but it was found that the relationship was not of significance at the 0.05 level.

From the evidence obtained in this study it seems unlikely that drought was the main cause of resin pocket formation.

\section{Damage hypothesis}

This can be divided into mechanical damage due to thinning, damage caused by insects and damage caused by hail.

- If mechanical damage were to be the main cause of resin pocket formation we can expect to find some evidence in the form of wounds and resin leaking to the outside;

- If hail were to cause resin pocket formation, resin pockets would probably be limited to one direction from which the hail fell (unless no wind was present during the hail storm).

The only mechanical damage we could think of was felling damage in the course of thinning. Within the sample material, six resin pockets of Type 2 were found and all of them occurred in years when thinning was done. No other patterns around the years of thinning could be observed. According to Seifert (2010) thinning can increase wind and drought effects and thus in itself may be responsible for many more resin pockets. Evidence for this could not be found in this study. It can be concluded that thinning was most probably the main cause of type 2 resin pockets in this study.

According to Table 3, Pinus patula is 'attacked by Euproctis terminalis (Emperor moth), especially on Mpumalanga Highveld'. Insects can cause micro-wounds to the cambium and in a defence reaction the tree then might create resin pockets (Christiansen and Kucera, 1999; Hood and Gardener, 2002). 
However, Seifert et al. (2010) stated that there was no conclusive evidence of this in his study. In this study no proof was found as to exclude or support this reaction pattern for resin pocket formation.

\section{Other}

Growth was also analysed in order to determine whether faster or slower growth could result in the formation of resin pockets. The images obtained from data-gathering were used for doing the growth ring measurements in ImageJ. This method was proved to yield plausible and accurate results, as can be seen in Figure 30. From the comparison of tree-ring width containing a resin pocket to average tree-ring width for that compartment, the results were as follows:

For 31 out of the 61 images containing resin pockets, the tree-ring containing resin pockets was smaller than the specific average year-ring. Thus there was no clear pattern to link year-ring width to resin pocket formation.

\section{Conclusions and recommendations}

A frame for obtaining images from cross cut surfaces of a tree stem was successfully constructed and demonstrated in the study of Pinus patula trees in Mpumalanga, South Africa. These images were reconstructed into three-dimensional models of logs and trees including properties such as the external shape of the trees, branch structure and pith location. Properties such as ring width could be accurately measured from the images obtained.

The images obtained from the Pinus patula trees could be used in a study to establish the reason for formation of resin pockets in these trees. 
The formation of Type 2 resin pockets was most probably due to felling damage during thinning operations. It was not possible to establish a single main cause for Type 1 resin pocket formation although it seems likely that wind damage and possibly insects may have been responsible for these types of resin pockets.

Future work should focus on developing the image analysis part of the log reconstruction system further in order to automate the reconstruction process.

Future studies on resin pocket formation in Pinus patula trees should include a detailed climatic, wind and insect record of the study material in order to link any drought, storm or insect attack events to the formation of resin pockets. 


\section{Bibliography}

1. Aguilera C, Sanchez R, Baradit E. 2008. Internal wood inspection with active contour using data from ct-scanning. Wood Research, 53(4): 13-22.

2. Bhandarkar SM, Faust TD, Tang M J. 1999. CATALOG: A system for detection and rendering of internal log defects using computer tomography. Machine Vision and Applications 11(4):171-190.

3. Birkeland R. 1985. Research and practical experience of scanning techniques in Scandinavia, Int. Conf. on Scanning Technology in Sawmilling, San Francisco, CA.

4. Chang SJ, Olson JR, Wang PC. 1989. NMR imaging of internal features in wood. Forest Prod J, 39(6): 43-49.

5. Chen Z. Molloi S. 2003. Automatic 3D vascular tree construction in CT angiography. Computerized Medical Imaging and Graphics 27(6):469-479.

6. Christiansen, E., Kucera, B., 1999. Resin pockets in Norway spruce wood are not caused by the bark beetle Ipstypographus. Rapport fraskogforskningen - supplement 12, Ås, p. 9 (cited from Seifert et al. 2010).

7. Clifton N. 1969. Resin pockets in Canterbury radiate pine. New Zealand Journal of Forestry Science 14(1):38-49.

8. Cominetti R, Padilla F, Martin JS. 2002. Field methodology for reconstruction of a Pinus radiata log. New Zealand Journal of Forestry Science 32(3):309-321.

9. Cown DJ. 1973. Resin pockets: their occurrence and formation in New Zealand forests. New Zealand Journal of Forestry Science 18(1):233-251.

10. Cown DJ, Donaldson LA, Downes GM. 2010. A review of resin features in radiate pine. New Zealand Journal of Forestry Science 41:41-60.

11. Crickmay\& Associates. 2011. South African Lumber Index, June 2011. 
12. Da Silva Falcao MPP. 1998. The minimum required yield for profitable sawtimber production from Pinus patula in the escarpment area of Mpumalanga. Stellenbosch University, Stellenbosch.

13. DAFF (Department of Agriculture, Forestry and Fisheries) [Internet].2011.Report on commercial timber resources and primary roundwood processing in South Forestry South Africa 2008/2009[cited 2011, 20 October]. Available: http://forestry.co.za.

14. DAFF. 2011. Maps [accessed2011, 20 October]. Available: http://forestry.daff.gov.za/webapp/ForestsMaps.aspx.

15. Fredriksson M. 2011. A simulation tool for finger jointing of boards. 20th International Wood Machining Seminar.Lulea University of Technology.

16. Giudiceandrea F, Ursella E, Vicario E. 2011. A high speed CT scanner for the sawmill industry.

17. Gjerdrum P, Bernabei M. 2006. Three-dimensional model for size and location of resin pockets in stems of Norway spruce. European Journal of Wood and Wood Products 65(3):201-208.

18. Gumbau J, Chover M, Remolar I, Rebollo C. 2011. View-dependent pruning for real-time rendering of trees. Computers \& Graphics 35(2):364-374.

19. Habermehl A, Ridder HW. 1999. Computerized tomographic systems as tools for diagnosing urban tree health. Proc International symposium on Urban Tree Health.

20. Han W, Birkeland R. 1992. Ultrasonic scanning of logs. Industrial Metrology, 2(3):253281.

21. Haygreen JG, Bowyer JL. 1996. Forest products and wood science. 3rd ed. Ames: lowa state university press. 3-40.

22. Hodges DG, Anderson WC, McMillin CW. 1990. The economic potential of CT scanners for hardwood mills. Forest Prod J 40(3):65-69

23. Hood, I., Gardener, J., 2002. Armillaria-the cause of resin soaking degrade in Pinus radiata. Forest Health Newsletter 115. Rotorua, New Zealand Forest Research Institute (cited from Seifert et al. 2010). 
24. Hou Z J, Wei GW. 2002. A new approach to edge detection. Pattern Recognition 35(7):1559-1570.

25. Izquierdo E, Ohm J. 2000. Image-based rendering and 3D modeling: A complete framework. Signal Processing: Image Communication 15(10):817-858.

26. Komatiland Forestry. 2012. Spreadsheet with data of sites.

27. Larson RP. 1994. The vascular cambium. Springer. Berlin. 725.

28. MakelaA, Makinen H. 2002. Generating 3D sawlogs with a process-based growth model. Forest Ecology and Management 184 (2003) 337-354.

29. Malan F.2011. Personal Correspondence. October 19, 2011 Stellenbosch.

30. Microtec. 2012. [Accessed 2012, 13November]. Available:

http://www.microtec.eu/Content.aspx?Nid=10353\&Lang=en-US\&Cid=1257

31. Moberg L. 2001. Models of internal knot properties for Picea abies. Forest Ecology and Management 147(2): 123-138.

32. National Timber Research Institute (CSIR) and SA Forestry Research Institute (Department of Environment Affairs). 1986. The eight most important pine species in South Africa. X Hout 1:1-25.

33. Nikolova P, Blaschke H, Matyssek R, Pretzsch H, Seifert T. 2009. Combined application of computer tomography and light microscopy for analysis of conductive xylem area of beech and spruce coarse roots. European Journal of Forest Research. 128(2): 145 - 153.

34. Occena LG, Rayner TJ, Schmoldt DJ, Abbott AL. 2001. Precision forestry. The proceedings of the first international precision forestry cooperative symposium. 83-91

35. Oja J, Temnerub E. 1999. The appearance of resin pockets in CT-images of Norway spruce (Picea abies (L.) Karst.).European Journal of Wood and Wood Products 57(5):400406.

36. Onoe M, Tsao JW, Yamada H, Nakamura H, Kogure J, Kawamura A. 1984. Computed tomography for measuring the annual rings of a live tree. Nuclear instruments and methods in physics research 221: 213-220. 
37. Panshin AJ, De Zeeuw C. 1980. Textbook of wood technology. 4th ed. New York: McGraw-Hill. 20-22.

38. Park JC. 2004. The incidence of resin pockets. New Zealand Journal of Forestry Science 49(3): 32.

39. Park JC. 2005. Assesment of a bark scoring system for resin defects in mature radiata pine. New Zealand Journal of Forestry Science 49: 36-39.

40. Park JC, Parker CE. 1982. Predicting value losses due to resin pockets in timber from pruned radiata pine. Forest research institute bulletin 6:1-14.

41. Reinders MP, Hendriks THB. 1989. Lumber production optimization. European Journal of Operational Research 42(3):243-253.

42. Rinnhofer A, Petutschnigg A, Andreu J. 2003. Internal log scanning for optimizing breakdown. Computers and Electronics in Agriculture 41: 7-21.

43. Rosell JR, Llorens J, SanzR, Arnó J, Ribes-Dasi M, Masip, J. 2009. Obtaining the threedimensional structure of tree orchards from remote 2D terrestrial LIDAR scanning. Agricultural and Forest Meteorology 149(9):1505-1515.

44. Ross T, Du Toit B, Dovey S. 2005. Nutrient pools in slash loads in Pinus patula sawtimber and pulpwood stands in South Africa. Institute for commercial forestry research Bulletin 10: 1-24.

45. SANS 1783(3). 2004. Sawn softwood timber. Part 3: Industrial timber.

46. Schulze RE, Maharaj M, Lynch SD, Howe Bj, Melvil-Thomson B. 1997. South African atlas of Agrohydrology and -Climatology. Pietermaritzburg: University of Natal. Department of Soil Science and Agrometeorology. 31-32, 41-42, 173-180.

47. Schutz CJ. 1990. Site relationship for Pinus patula in the Eastern Transvaal escarpment. Pietermaritzburg: University of Natal. Department of Soil Science and Agrometeorology. 33,79 .

48. Seifert T.2011. Correspondence. October 6, Stellenbosch.

49. Seifert T, Breibeck J, Seifert S, Biber P. 2010. Resin pocket occurrence in Norway spruce depending on tree climate variables. Forest Ecology and Management 260(3):302-312. 
50. Seifert T, Nickel M, Pretzsch H. 2010a.Analysing the long-term effects of artificial pruning of wild cherry by computer tomography. Trees 24(5), 797-808.

51. Smith RGB, Palmer G, Davies M, Muneri A. 2003. A method enabling the reconstruction of internal features of logs from sawn lumber: The log end template. Forest Products Journal 53(11): 95-98.

52. Tait O. 2011. Personal Correspondence. June 12, Stellenbosch.

53. Tait O. 2011. Personal Correspondence. 19 October, Stellenbosch.

54. Temnerud E. 1996. Pitch pockets in Picea abies: Variation in amount, number and size within trees and within stand. Scandinavian Journal Forestry Research 11:164-173.

55. Temnerud E, ValingerE, Sundberg B. 1999. Induction of Resin Pockets in Seedlings of Pinus sylvestris L. By Mechanical bending Stress during growth. Holzforschung 53(4):386390.

56. Temnerud E. 1999. The occurrence of resin pockets in sawlog populations of Picea abies [L.] Karst. From five geographic regions in Sweden. Scandinavian Journal of Forest Research 14(2):143-155.

57. Teng C, Chen Y, Hsu W. 2007. Constructing a 3D trunk model from two images. Graphical Models 69(1):33-56.

58. Thawornwong S, Occeña LG, Schmoldt DL. 2003. Lumber value differences from reduced CT spatial resolution and simulated log sawing. Computers and Electronics in Agriculture 41(1): 23-43.

59. Thomas E, ThomasL, Shaffer C, Mili L. 2007. Using external high-resolution log scanning to determine internal defect characteristics. General Technical Report - Southern Research Station, USDA Forest Service (SRS) 101: 497-505.

60. Thomas L, Mili L, Thomas E, Shaffer CA. 2006. Defect detection on hardwood logs using laser scanning. Wood and Fiber Science 38(4):682-695.

61. Thomas RE. 2009. Modeling the relationships among internal defect features and external appalachian hardwood log defect indicators. Silva Fennica 43(3):447-456.

62. Tian X. 1997. Developments in log and lumber scanning. FRI Bulletin (202), 1-3. 
63. Vermaak J. 2007. Genetic variation for growth, wood and fibre properties of Pinus patula families grown on six sites in South Africa. MSc thesis, Stellenbosch University, Stellenbosch.

64. Watt MS, Kimberley MO, Downes GM, Bruce J, Jones T, Ottenschlaeger M, Brownlie R, Xue J, Leckie AC, Smaill SJ. 2011. Characterization of within-tree and within ring resinpocket density in Pinus radiata across an environmental range in New Zealand. New Zealand Journal of Forestry Science 41:141-150.

65. Watt MS, Downes GM, Jones T, Ottenschlaeger M, Leckie AC, Smaill SJ, Kimberley MO, Brownlie R. 2009. Effect of stem guying on the incidence of resin pockets. Forest Ecology and Management 258(9):1913-1917.

66. Wei Q, Zhang SY, Chui YH, Leblon B. 2009. Reconstruction of 3D images of internal log characteristics by means of successive 2D log computed tomography images. Holzforschung 63: 575-580.

67. Woollons R, Manley B, Park J. 2007. Factors influencing the formation of resin pockets in pruned Radiata pine butt logs from New Zealand. New Zealand Journal of Forestry Science 38(2):323-333.

68. Zhang SY, Liu CM. 2006. Predicting the lumber volume recovery of Picea mariana using parametric and non-parametric regression methods. Scandinavian Journal of Forest Research 21(2):158-166. 


\section{Appendix A:}

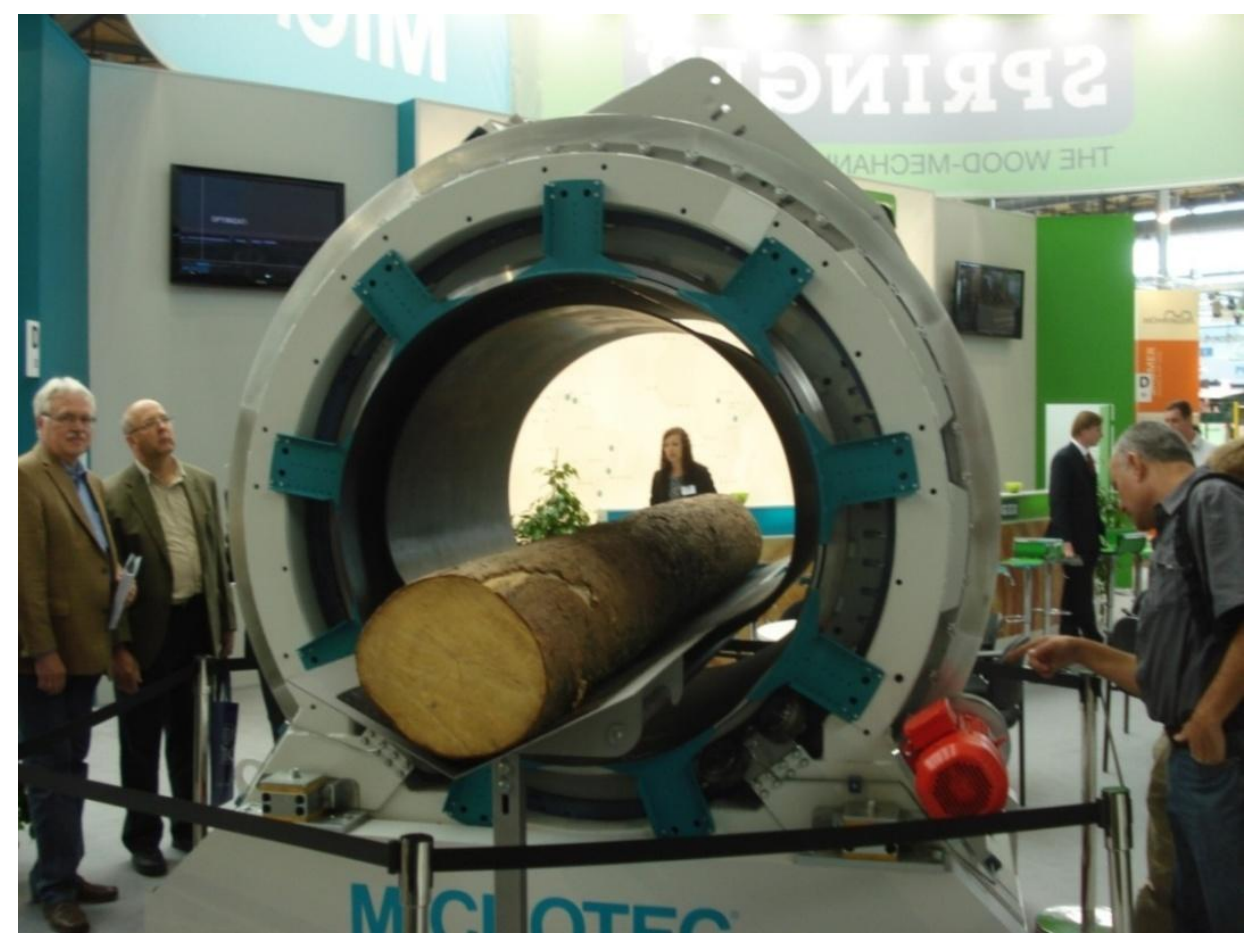

Figure 1: Microtec CT-scanner (Tait, 2011).

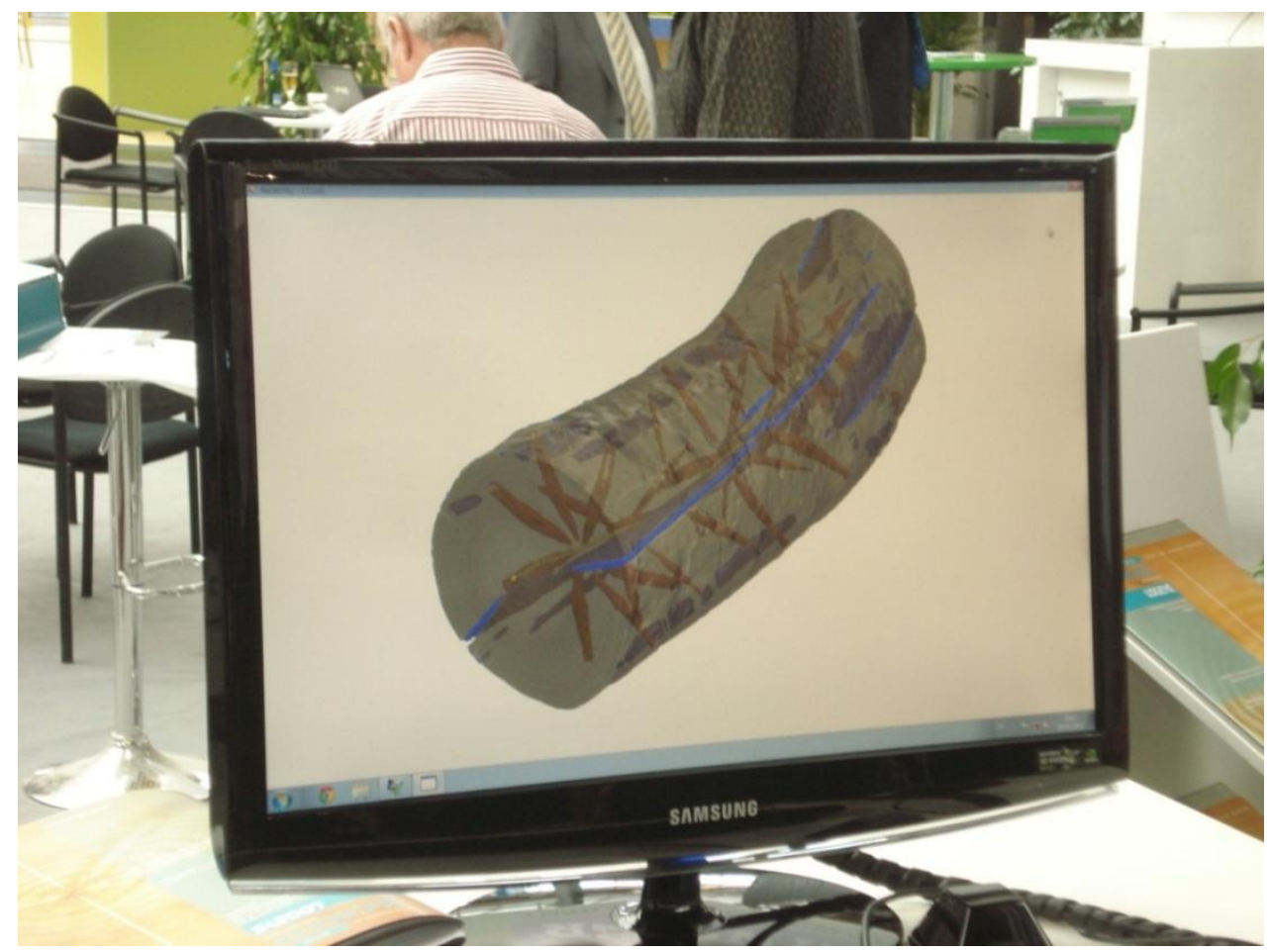

Figure 2: 3d-model of log from CT-scanner (Tait, 2011). 
Appendix B:

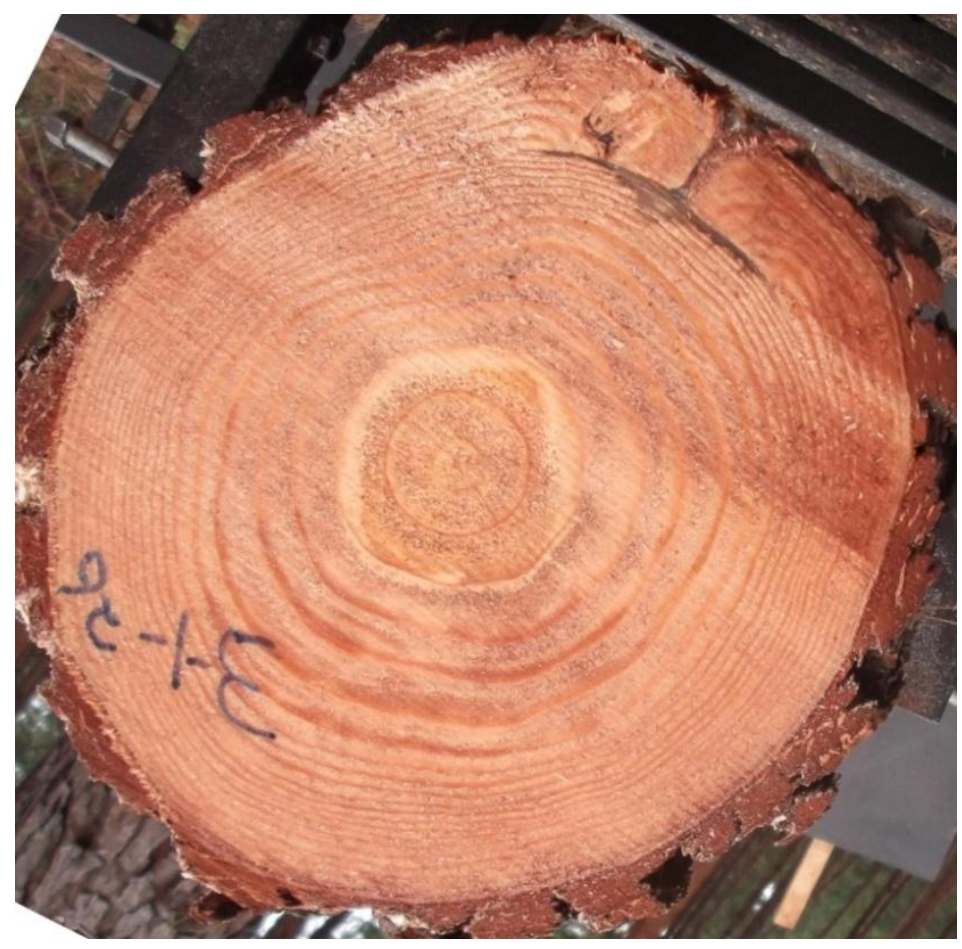

Figure information:

1. Cut number: 3-1-26

2. Year: 2005

3. Angle from North: $37.6^{\circ}$

Figure 1: Resin pocket identified infield.

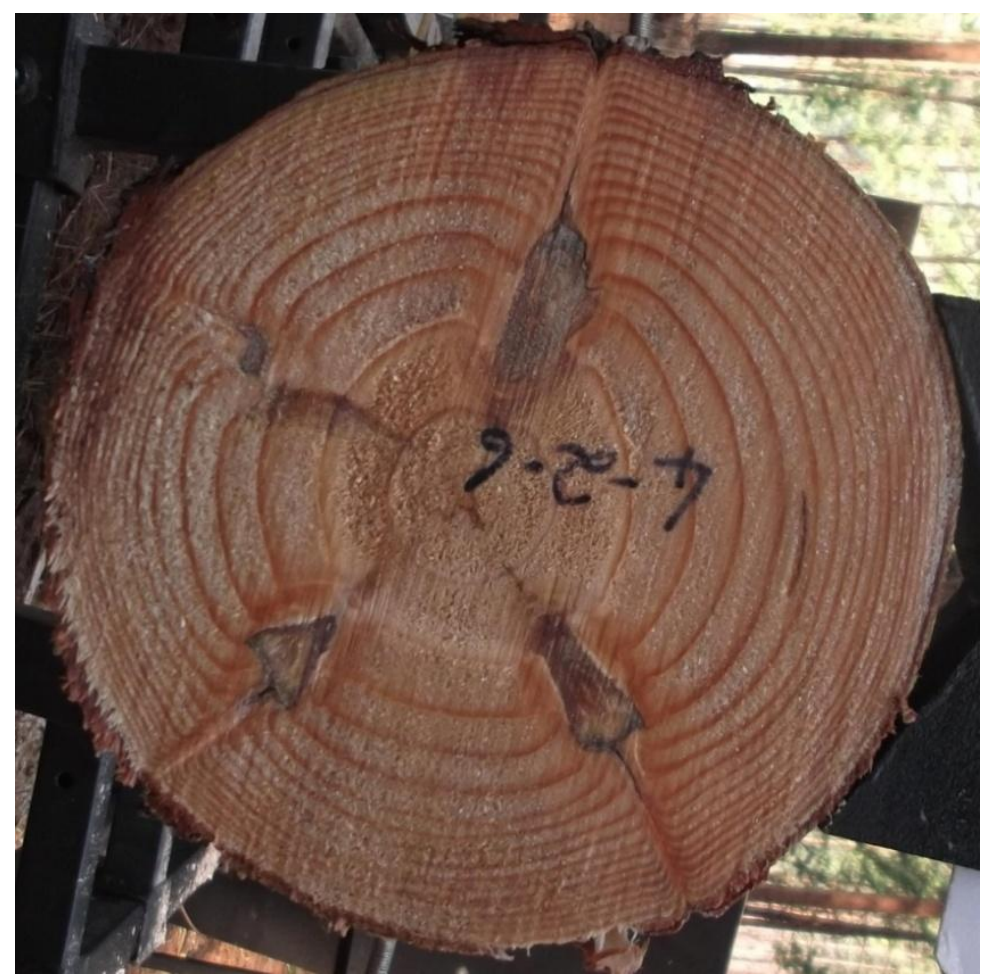

Figure information:

1. Cut number: 4-2-6

2. Year: 2000

3. Angle from North: $96.9^{\circ}$

Figure 2: Resin pocket identified infield 


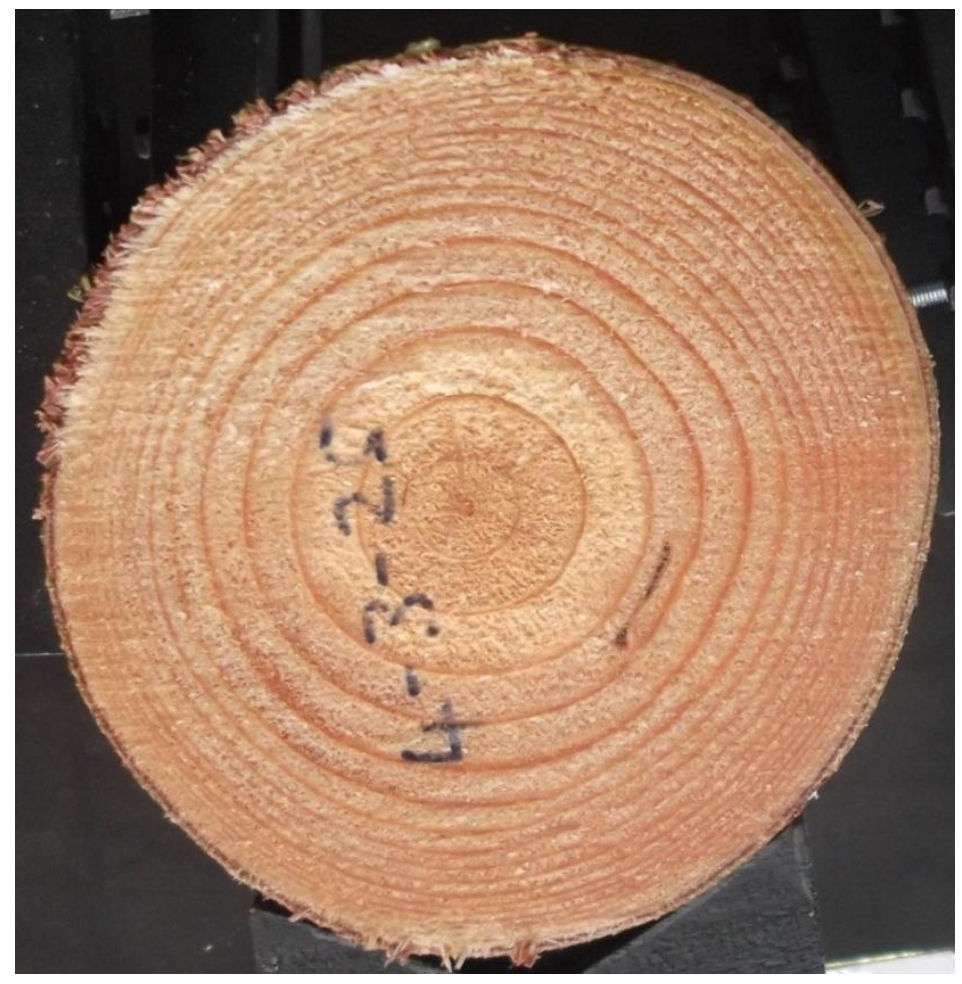

Figure information:

1. Cut number: 4-3-25

2. Year: 1998

3. Angle from North: $114.83^{\circ}$

Figure 3: Resin pocket identified infield.

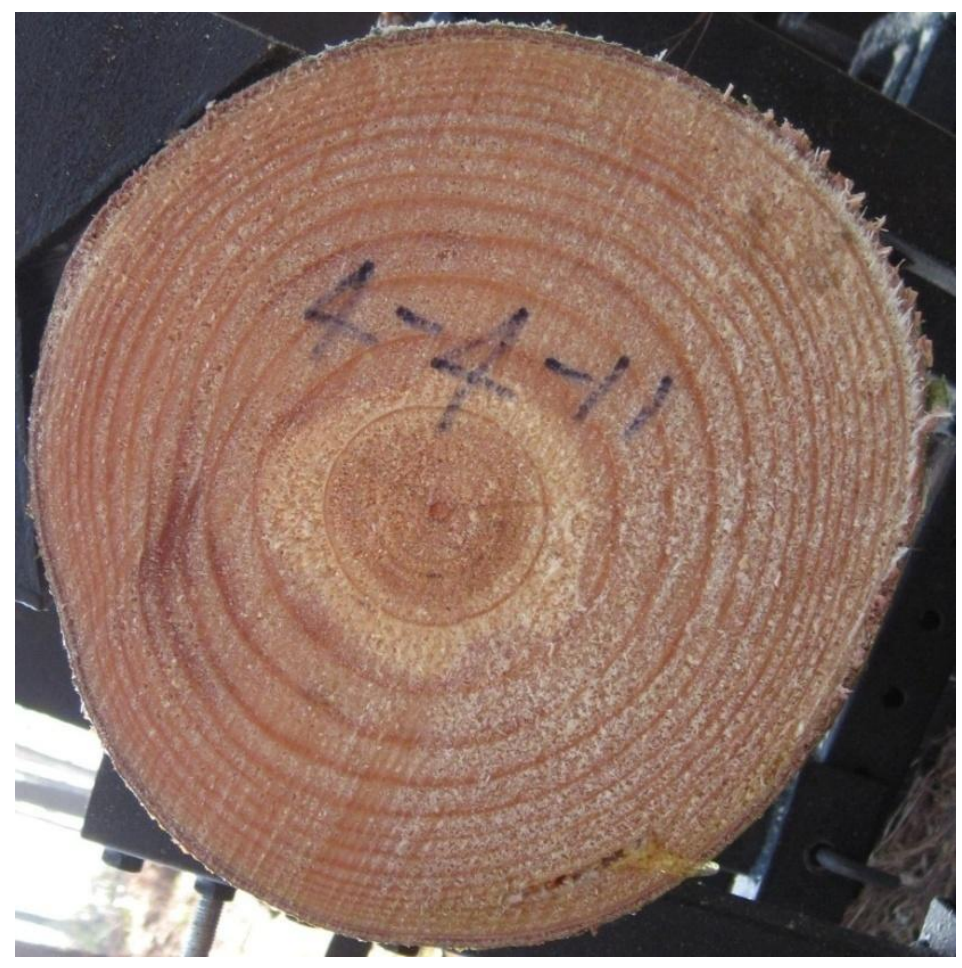

Figure information:

1. Cut number: 4-4-11

2. Year: 2008

3. Angle from North: $157.67^{\circ}$

Figure 4: Resin pocket identified infield. 


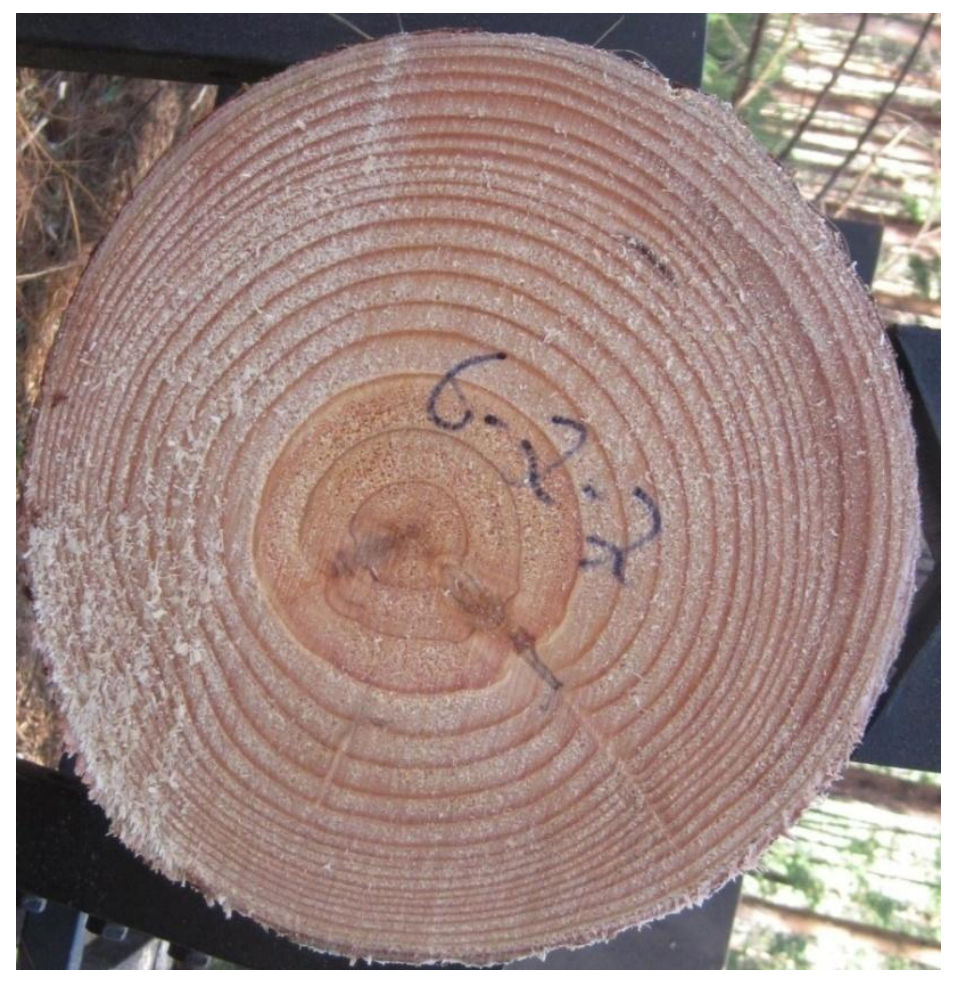

Figure information:

1. Cut number: 6-2-2

2. Year: 2004

3. Angle from North: $40.29^{\circ}$

Figure 5: Resin pocket identified infield.

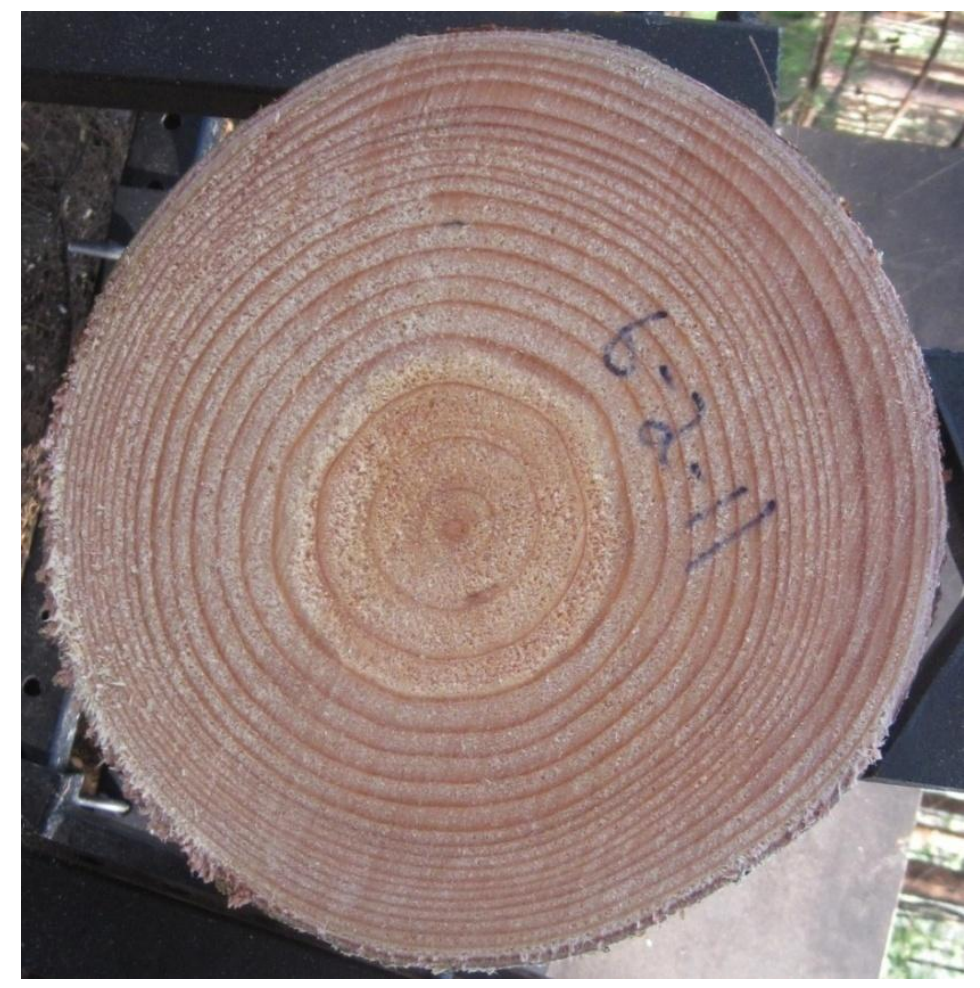

Figure information:

1. Cut number: 6-2-11

2. Year: 1999

3. Angle from North: $0.26^{\circ}$

Figure 6: Resin pocket identified infield. 


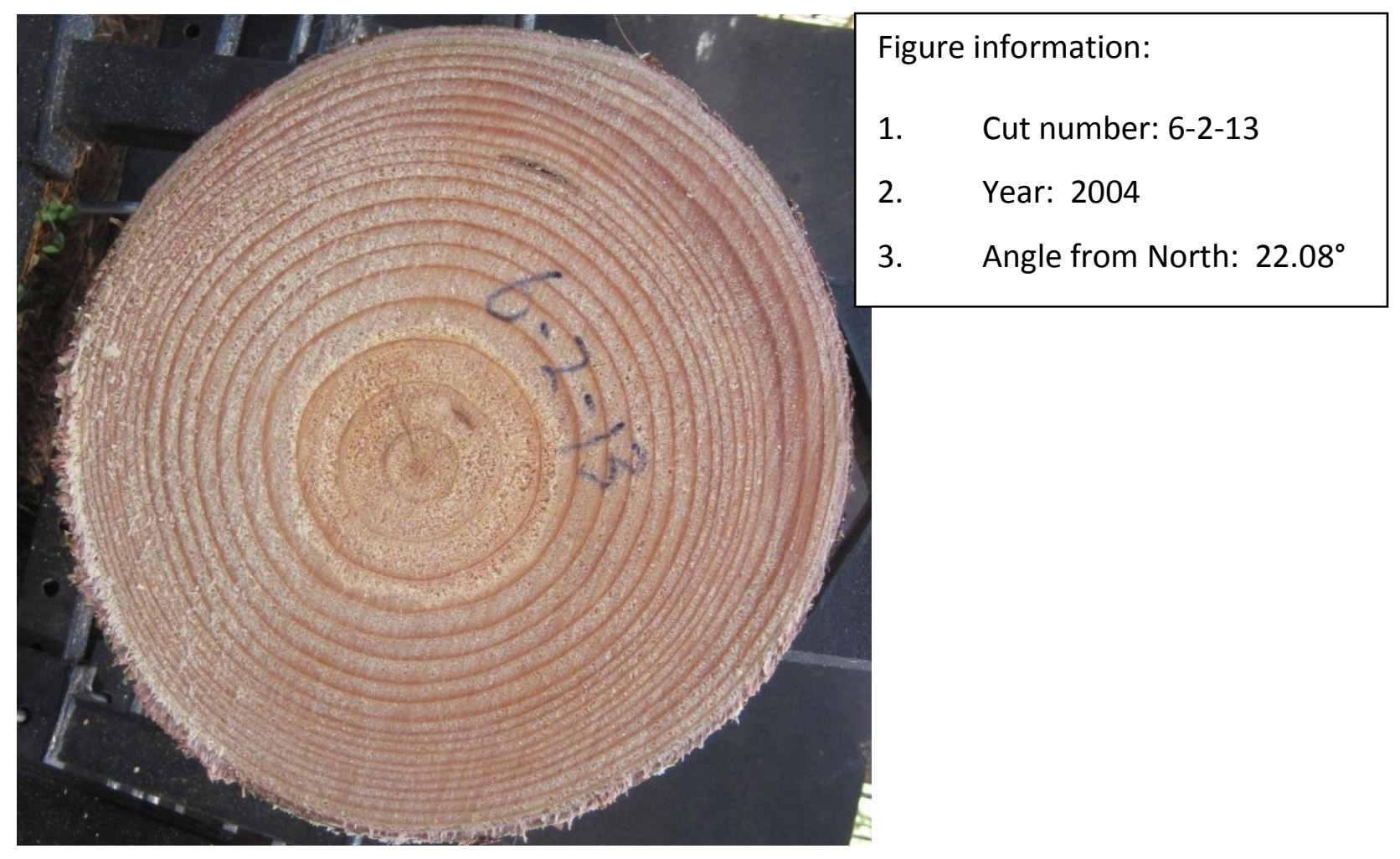

Figure 7: Resin pocket identified infield.

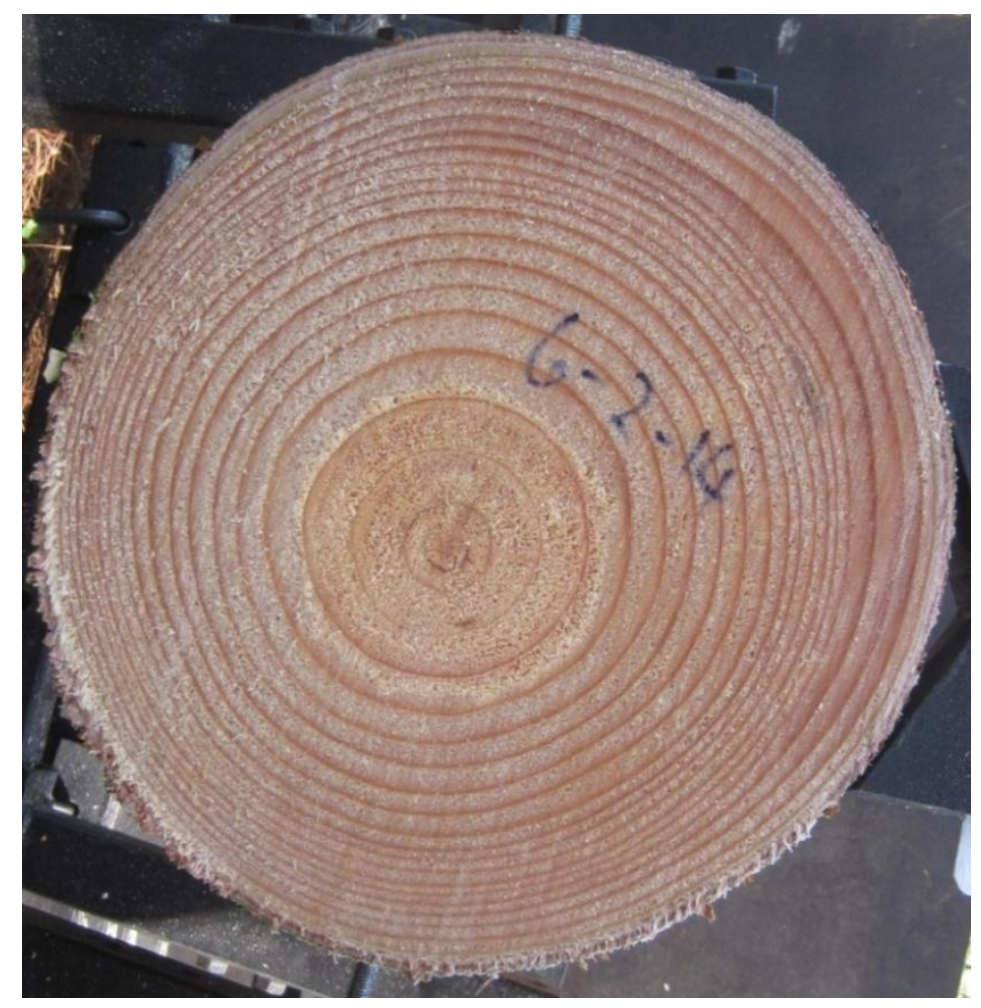

Figure information:

1. Cut number: 6-2-14

2. Year: 2006

3. Angle from North: $65.94^{\circ}$

Figure 8: Resin pocket identified infield. 


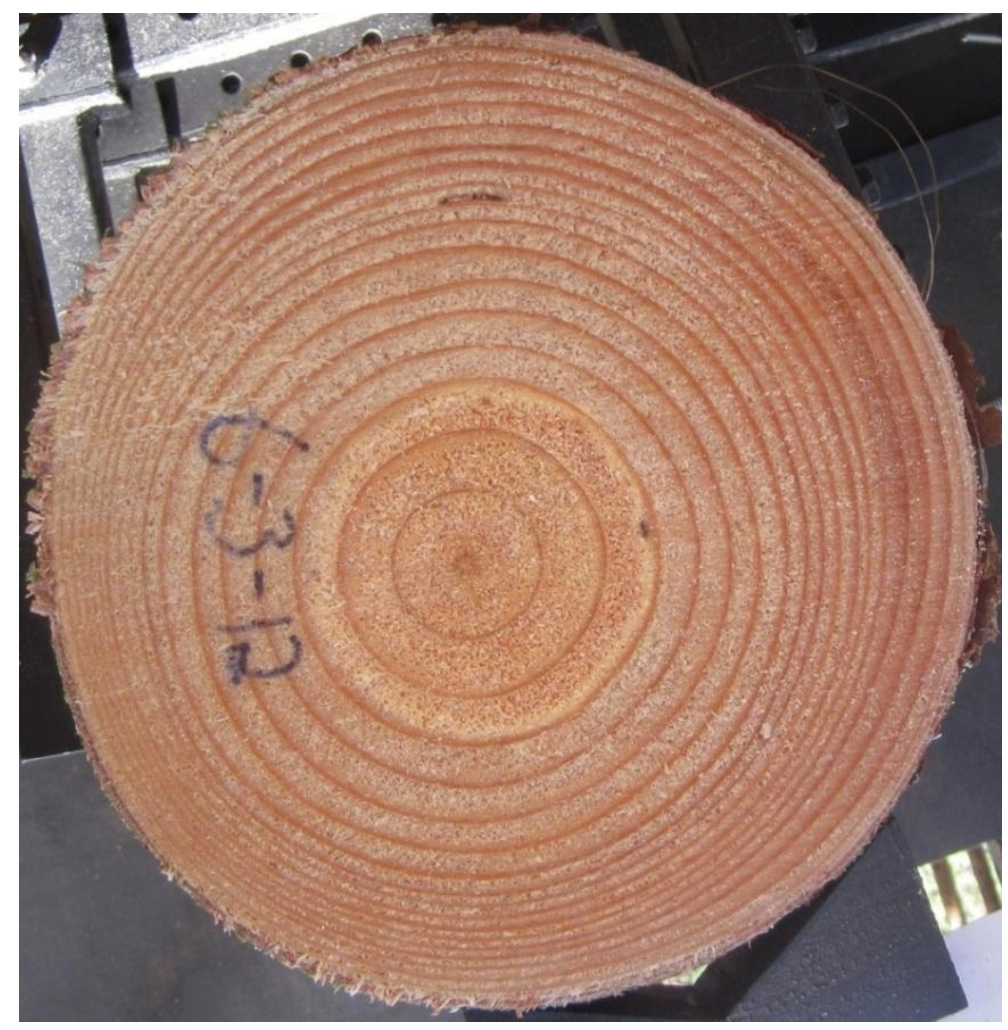

Figure information:

1. Cut number: 6-3-12

2. Year: 2004

3. Angle from North: $1.64^{\circ}$

Figure 9: Resin pocket identified infield.

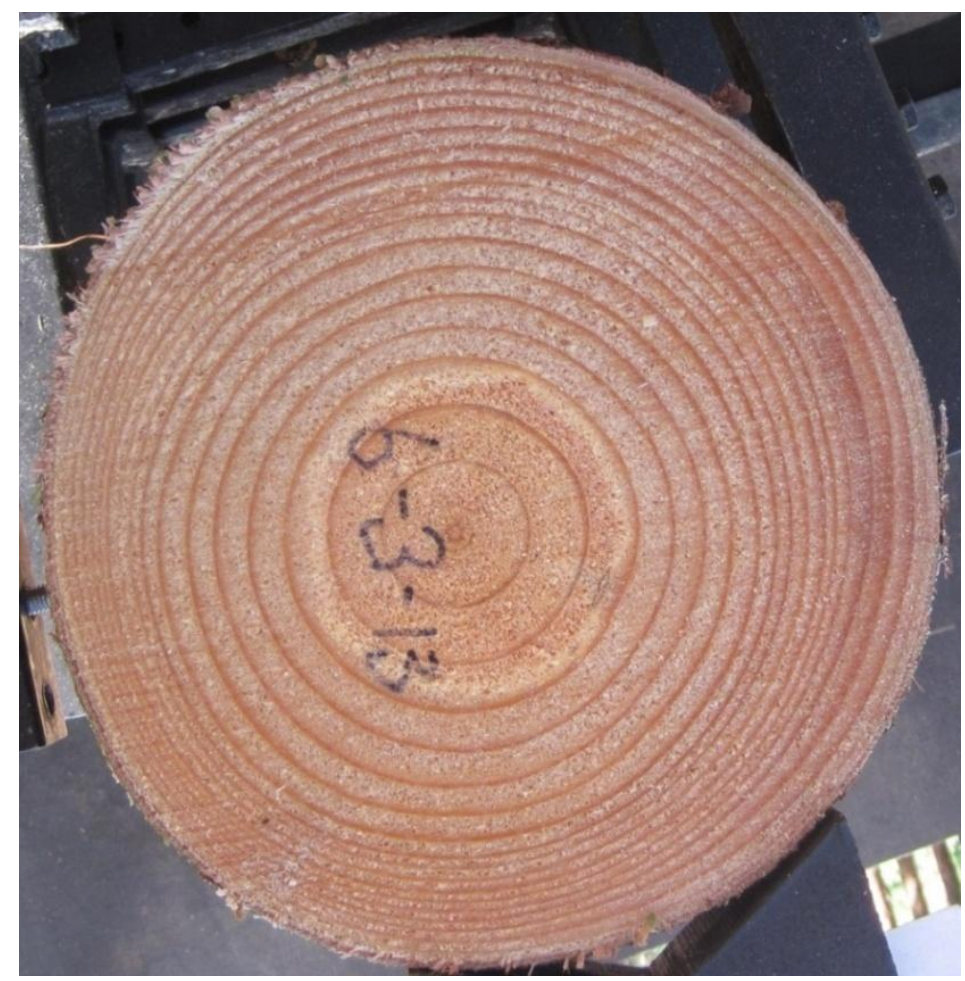

Figure information:

1. Cut number: 6-3-13

2. Year: 1997

3. Angle from North: $110.17^{\circ}$

Figure 10: Resin pocket identified infield. 


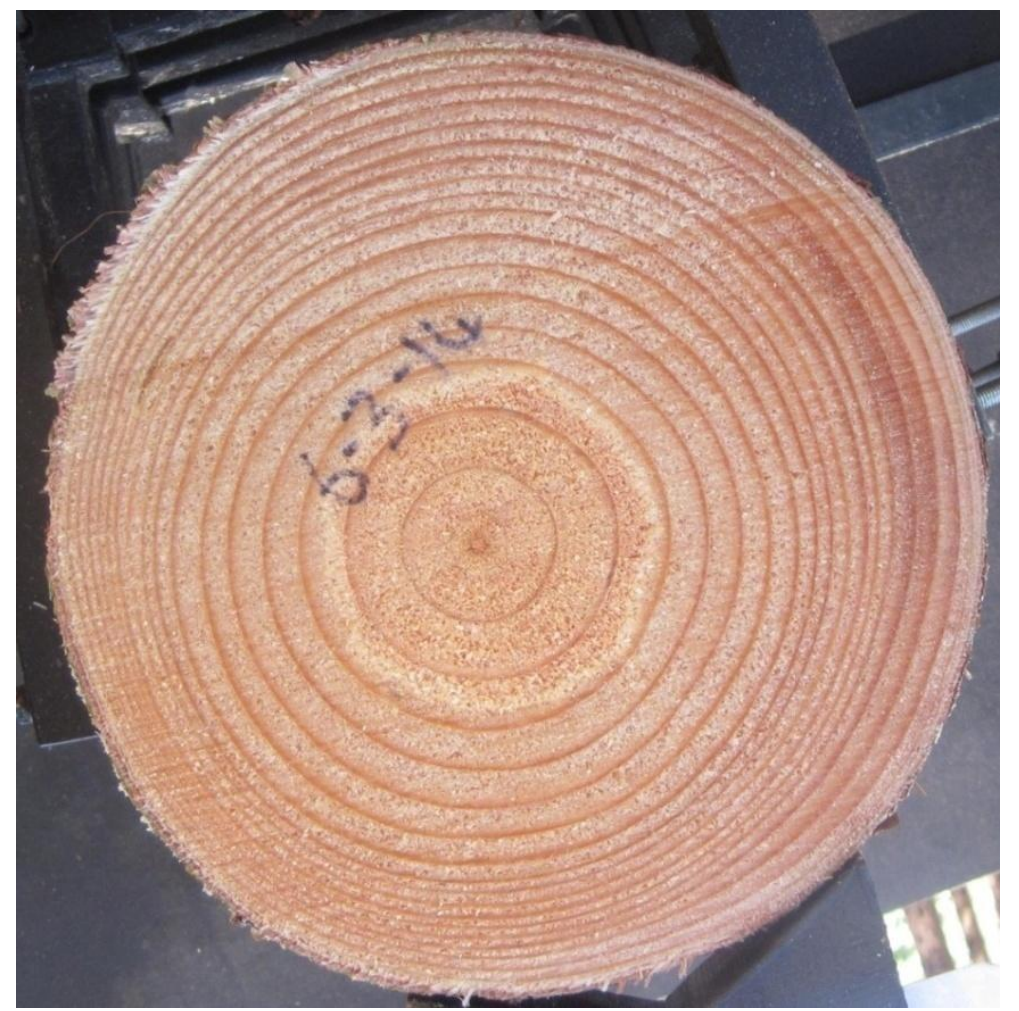

Figure information:

1. Cut number: 6-3-14

2. Year: 2006

3. Angle from North: $298.56^{\circ}$

Figure 11: Resin pocket identified infield.

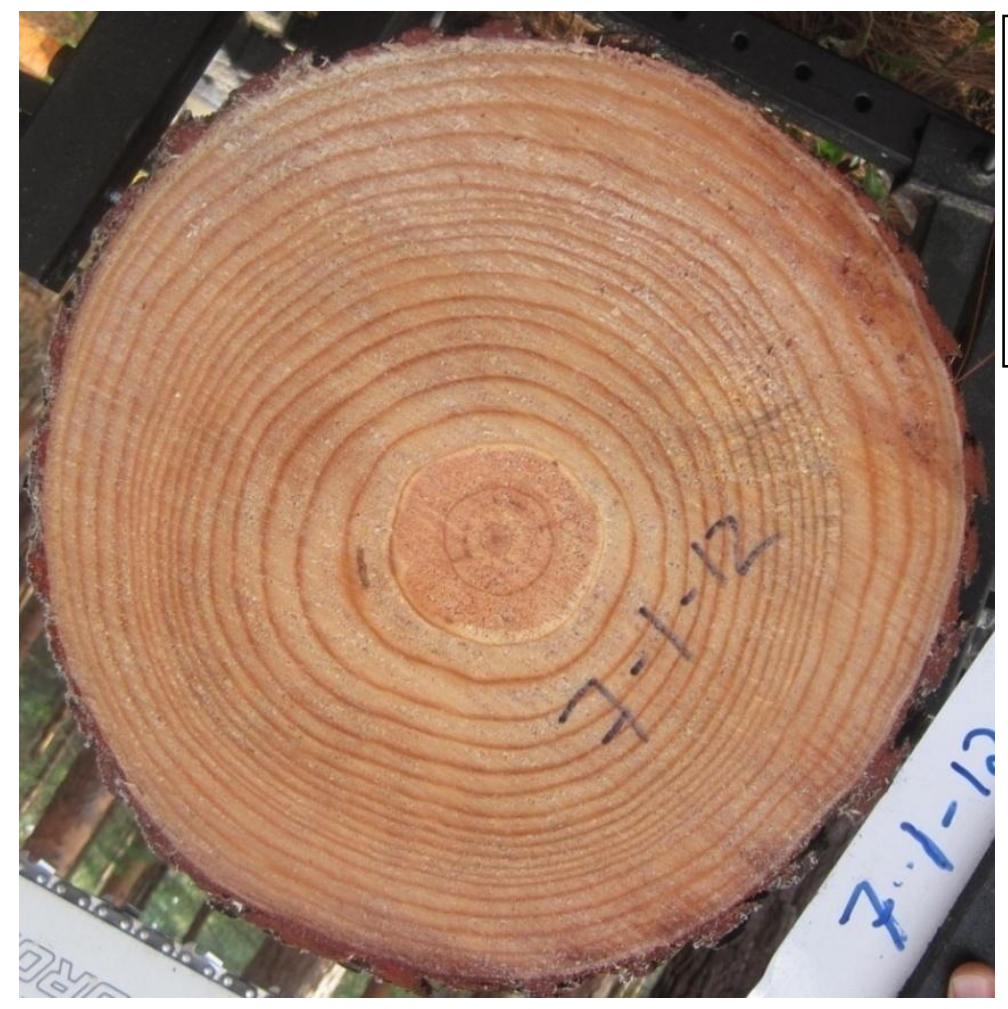

Figure information:

1. Cut number: 7-1-12

2. Year: 1995

3. Angle from North: $258.75^{\circ}$

Figure 12: Resin pocket identified infield. 


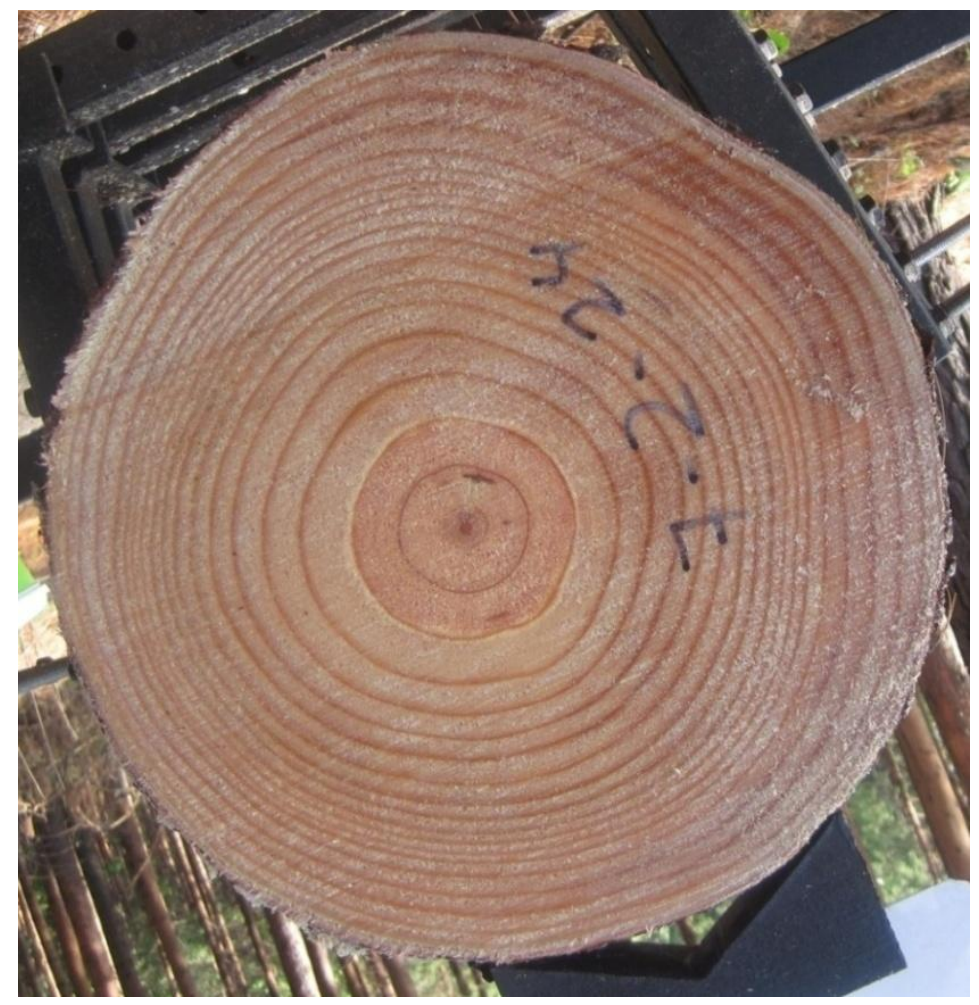

Figure information:

1. Cut number: 7-2-24

2. Year: 1995

3. Angle from North: $14.04^{\circ}$

4. Year: 2004

5. Angle from North: $40.04^{\circ}$

Figure 13: Resin pocket identified infield.

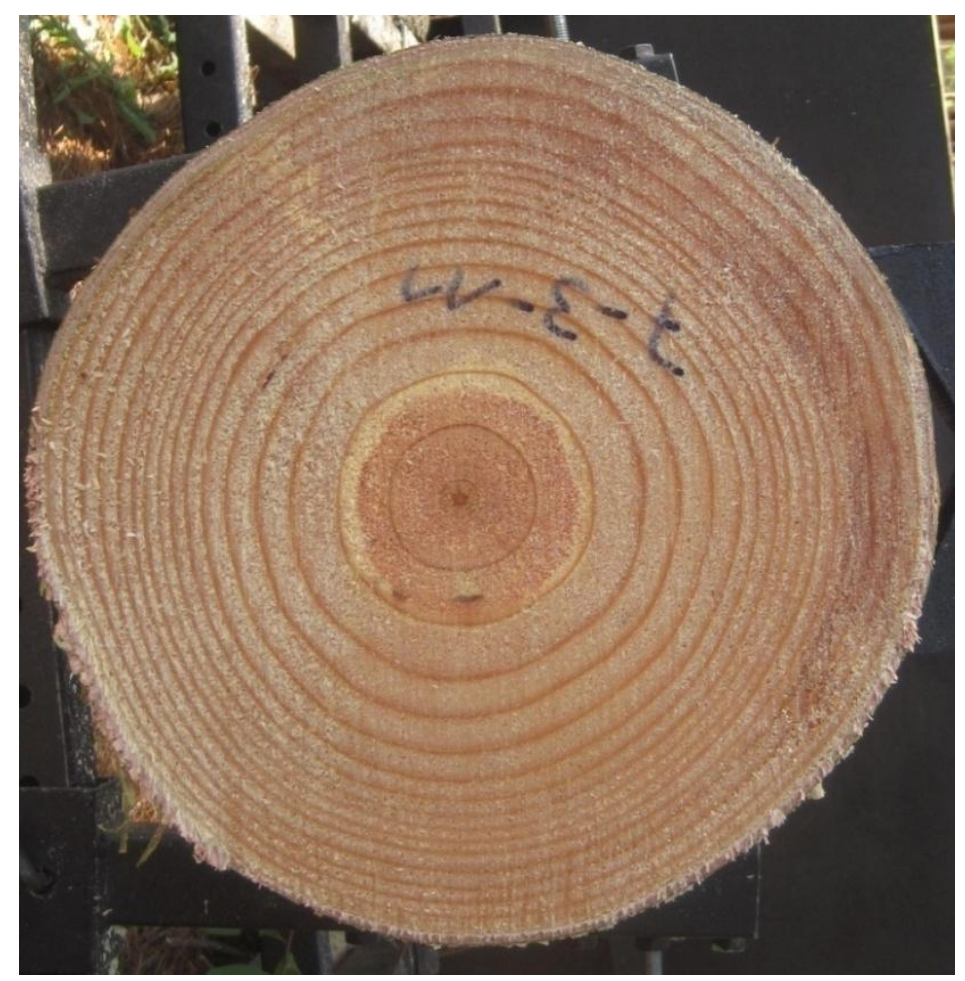

Figure information:

1. Cut number: 7-3-11

2. Year: 2000

3. Angle from North: $304.03^{\circ}$

Figure 14: Resin pocket identified infield. 


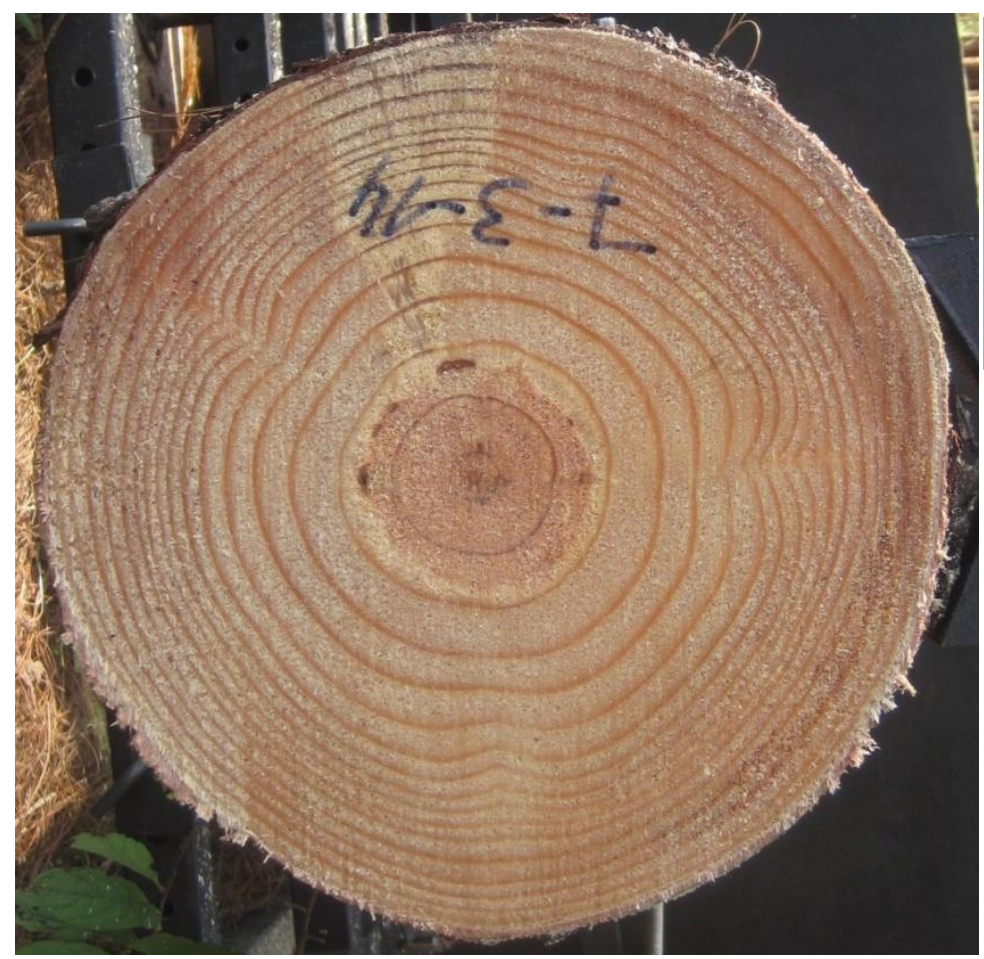

Figure information:

1. Cut number: 7-3-14

2. Year: 1997

3. Angle from North: $351.12^{\circ}$

Figure 15: Resin pocket identified infield.

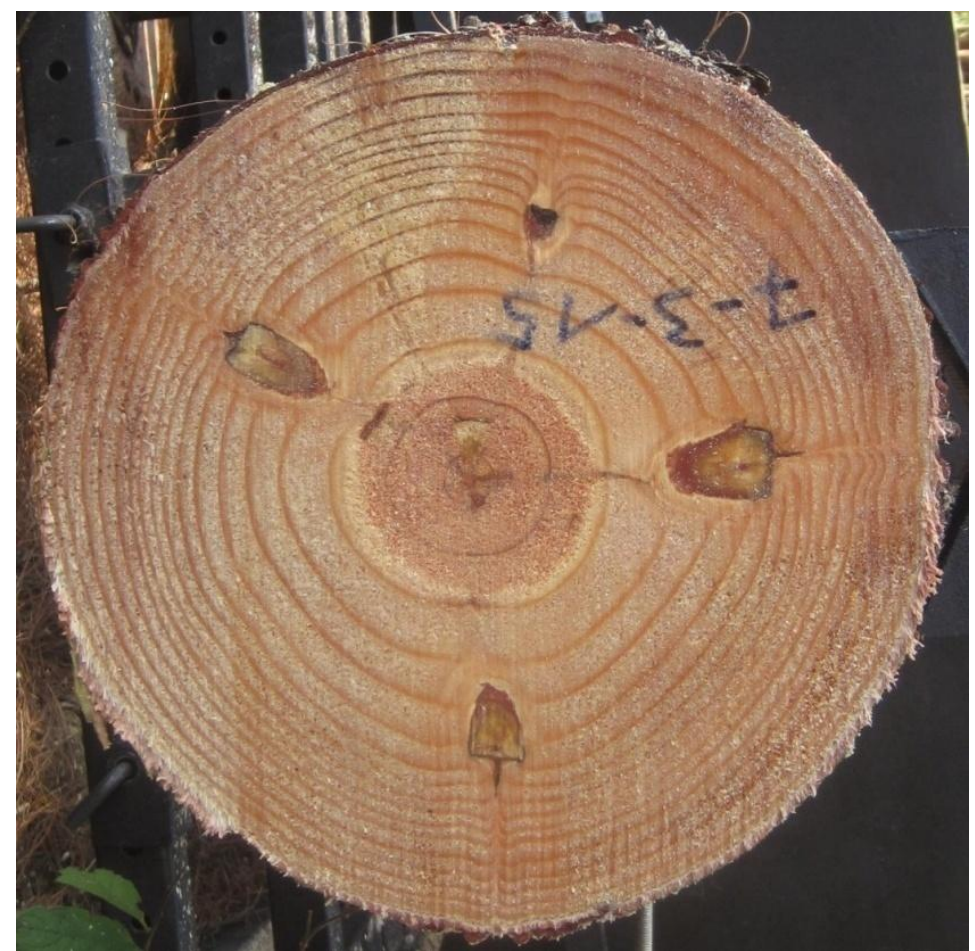

Figure information:

1. Cut number: 7-3-15

2. Year: 1997

3. Angle from North: $303.21^{\circ}$

Figure 16: Resin pocket identified infield. 


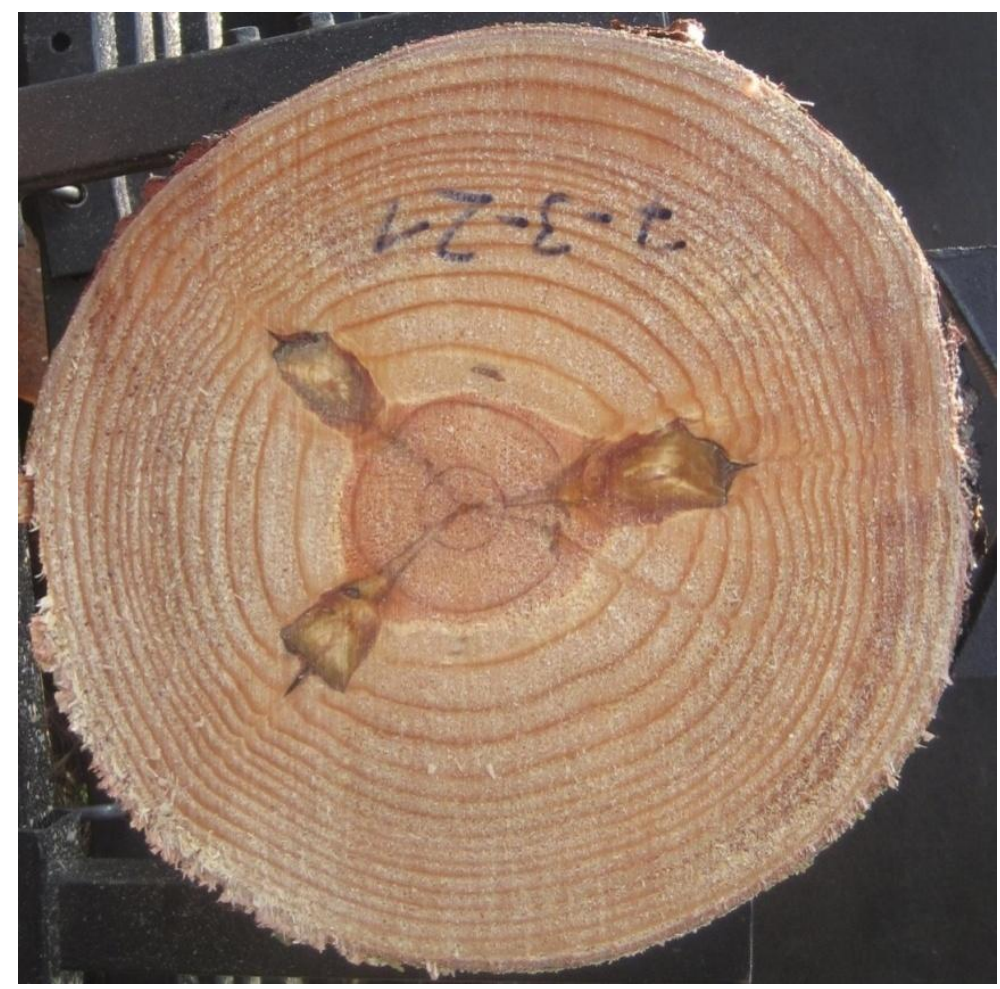

Figure information:

1. Cut number: 7-3-21

2. Year: 1997

3. Angle from North: $10.47^{\circ}$

Figure 17: Resin pocket identified infield.

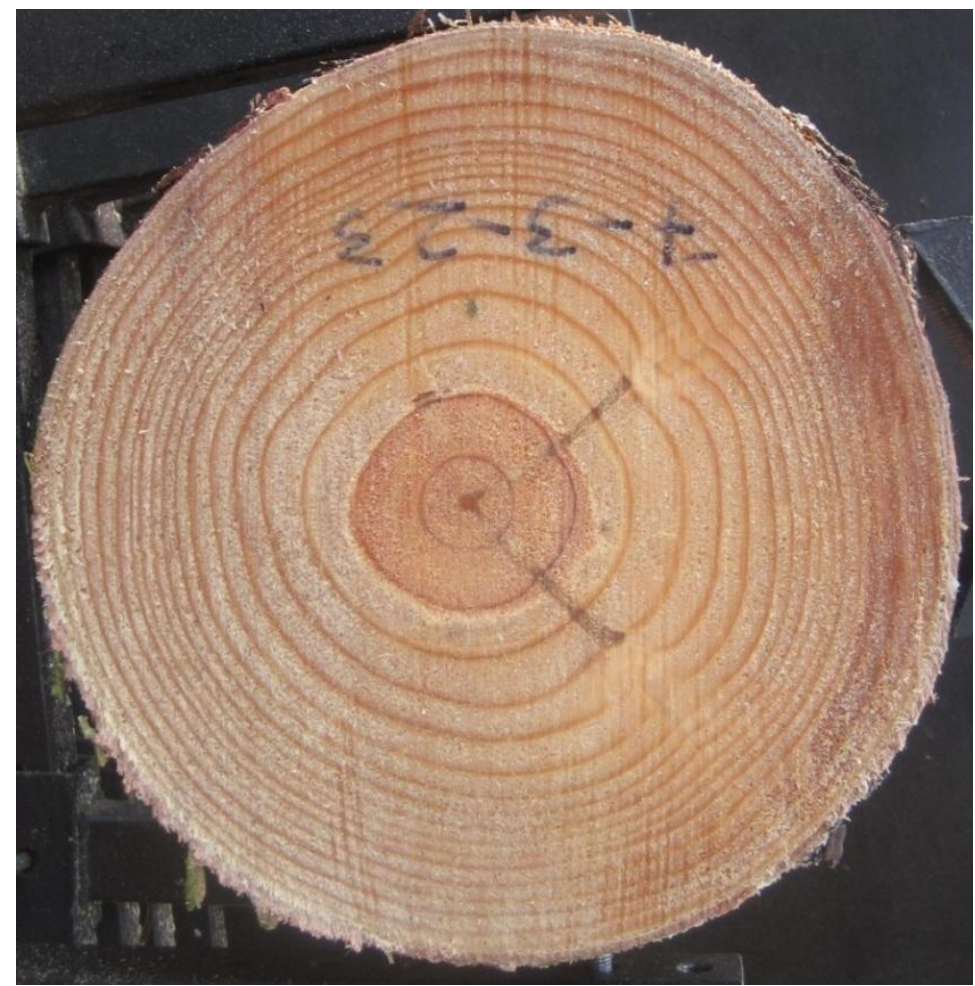

Figure information:

1. Cut number: 7-3-23

2. Year: 1997

3. Angle from North: $338.42^{\circ}$

Figure 18: Resin pocket identified infield. 


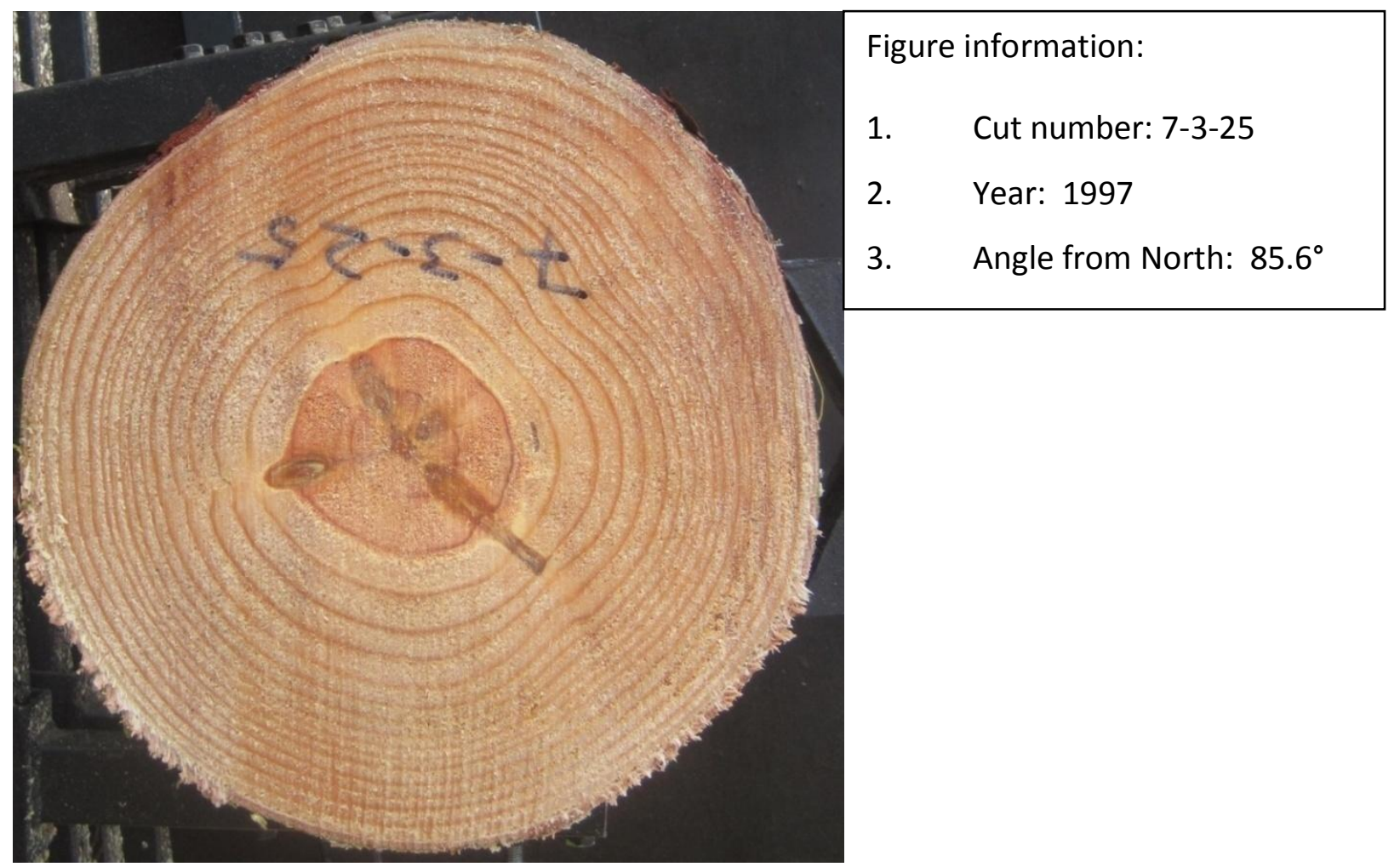

Figure 19: Resin pocket identified infield.

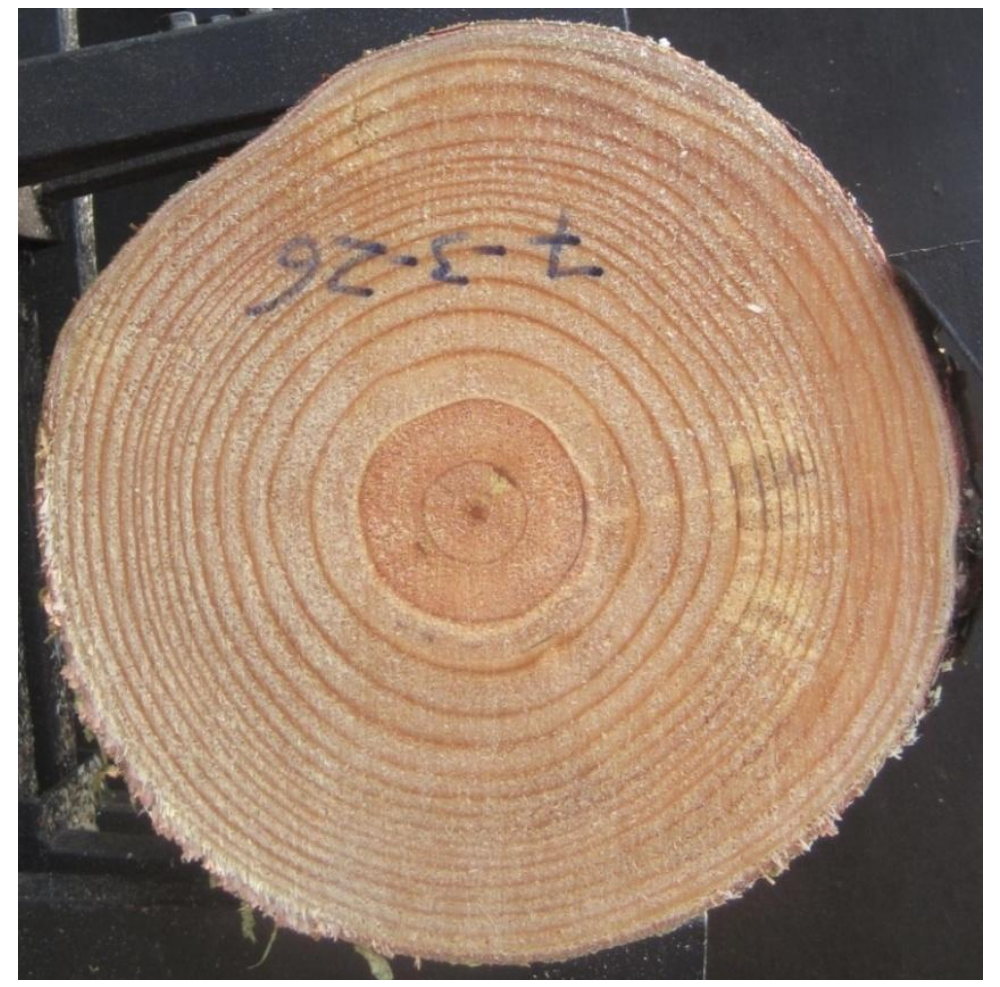

Figure information:

1. Cut number: 7-3-26

2. Year: 1997

3. Angle from North: $152.22^{\circ}$

4. Year: 1995

5. Angle from North: $37.1^{\circ}$

6. Height in tree: $8.337 \mathrm{~m}$

Figure 20: Resin pocket identified infield. 


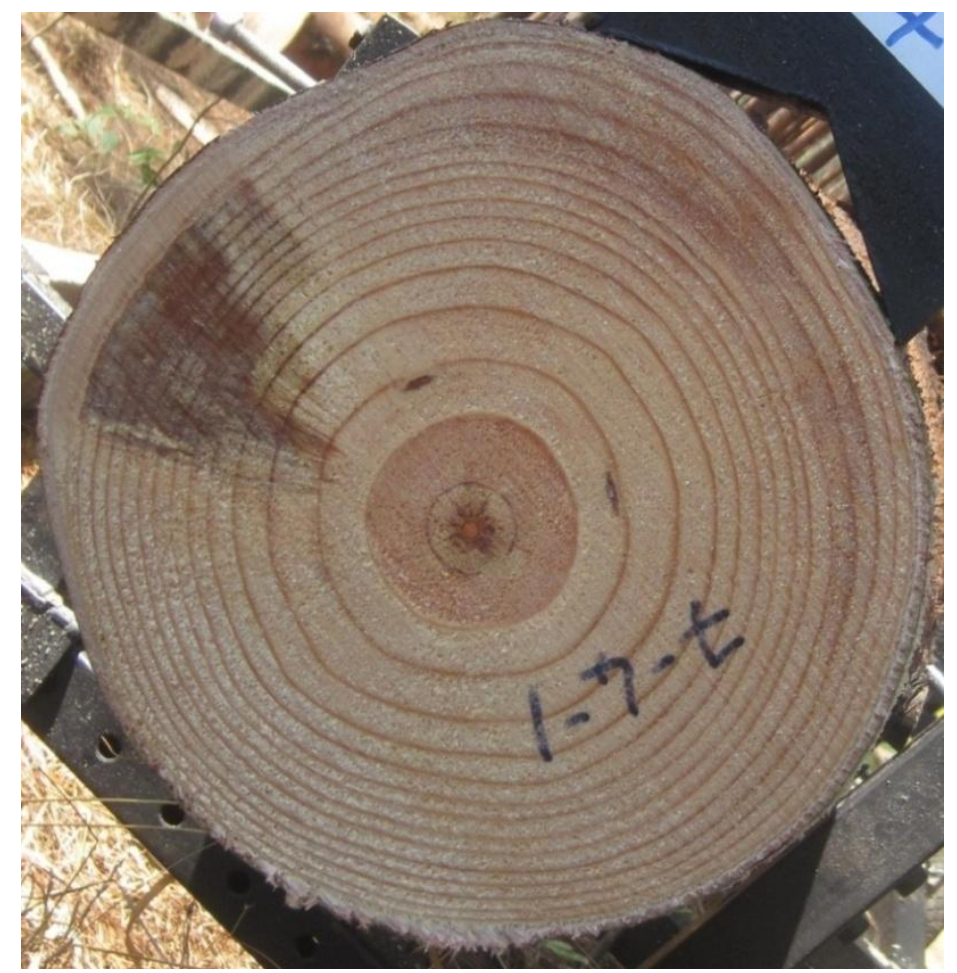

Figure 21: Resin pocket identified infield.

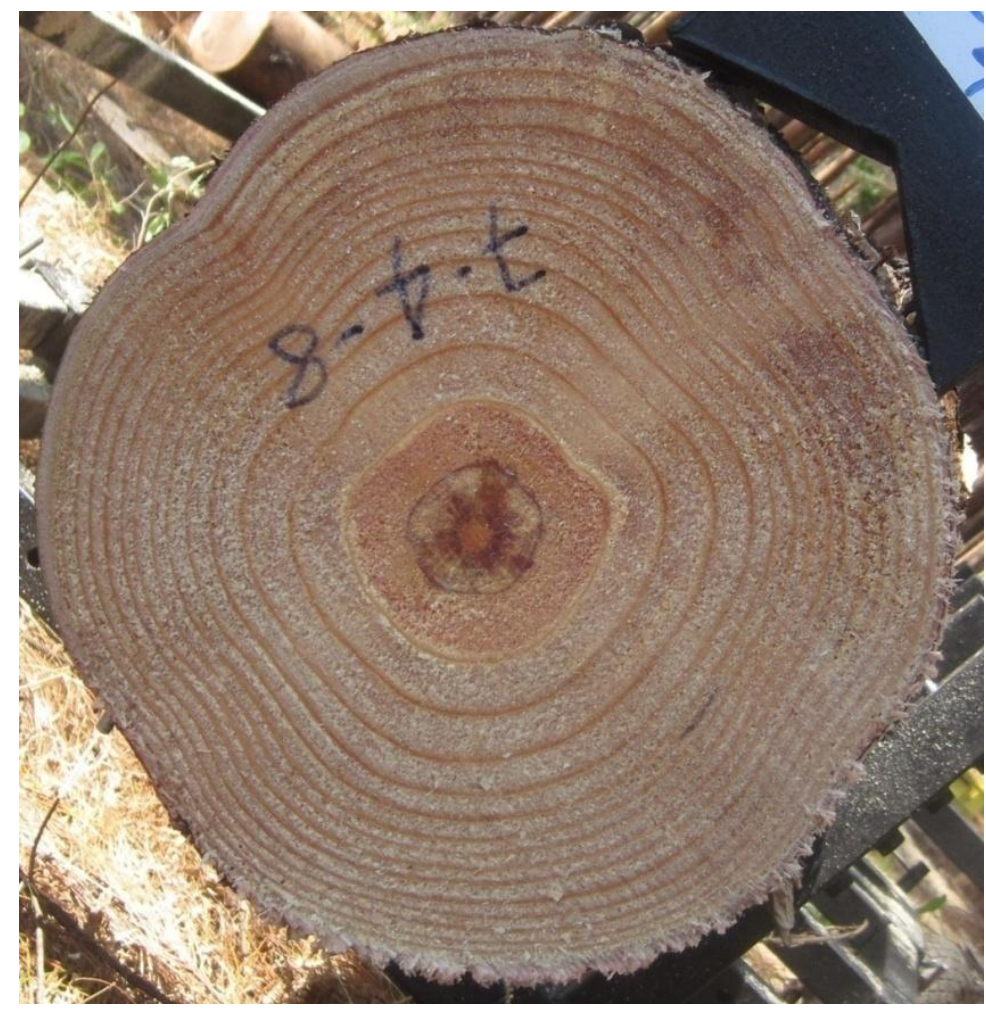

Figure 22: Resin pocket identified infield.
Figure information:

1. Cut number: 7-4-1

2. Year: 1999

3. Angle from North: $75.75^{\circ}$

4. Year: 1999

5. Angle from North: $340.44^{\circ}$
Figure information:

1. Cut number: $7-4-8$

2. Year: 2003

3. Angle from North: $127.9^{\circ}$ 


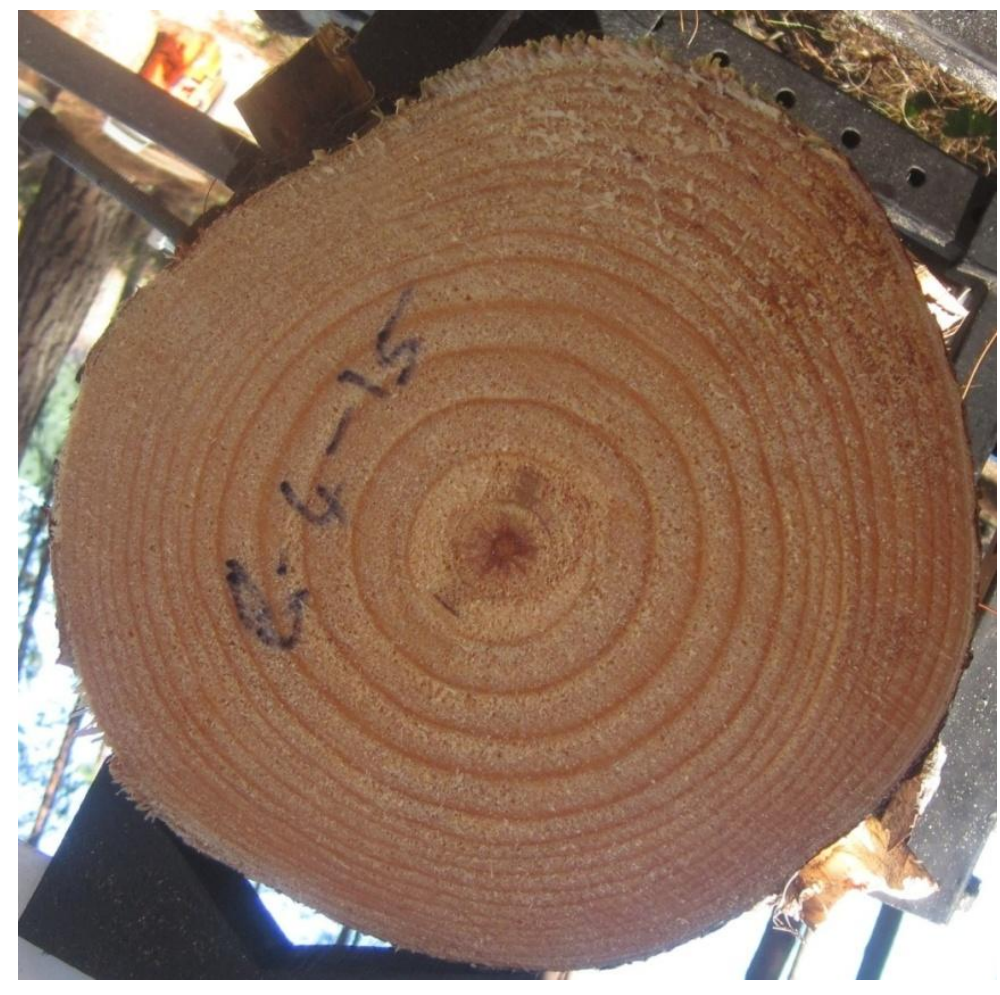

Figure information:

1. Cut number: 8-4-15

2. Year: 1997

3. Angle from North: $225^{\circ}$

Figure 23: Resin pocket identified infield.

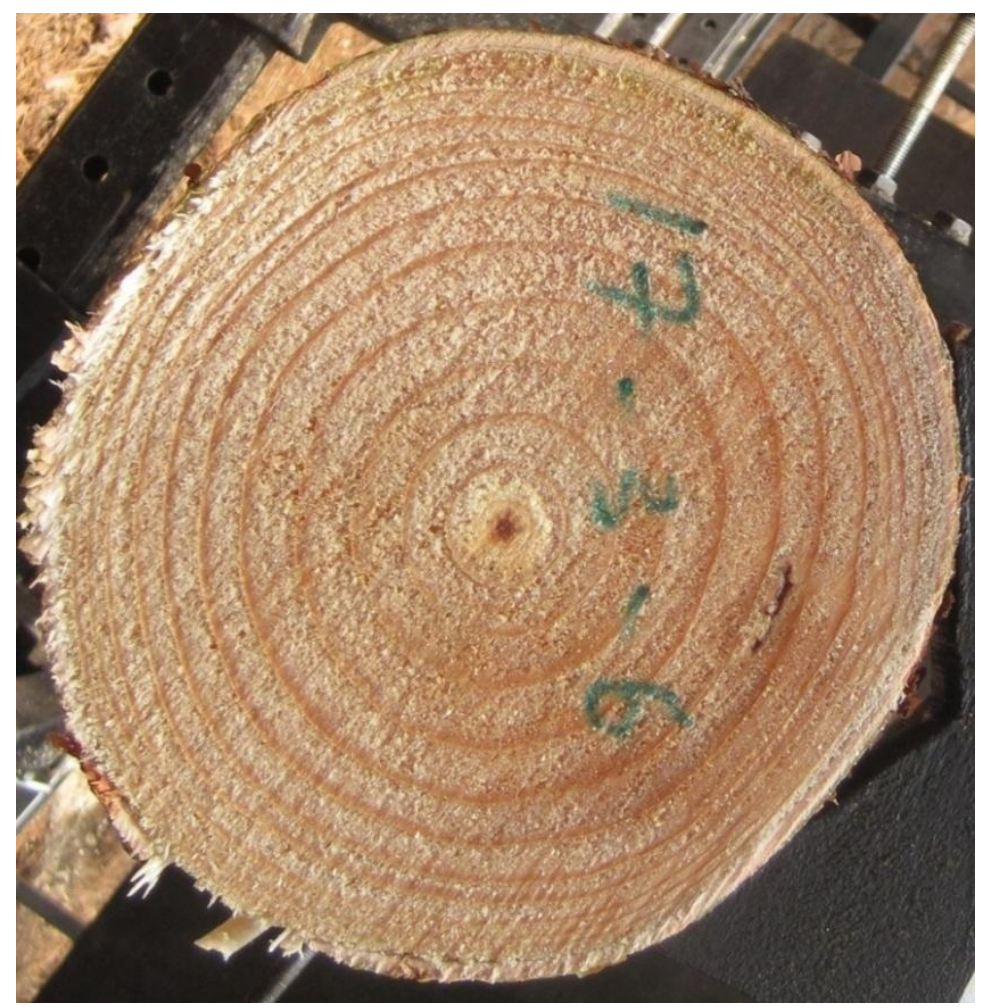

Figure information:

1. Cut number: $17-3-6$

2. Year: 2005

3. Angle from North: $106.71^{\circ}$

Figure 24: Resin pocket identified infield. 


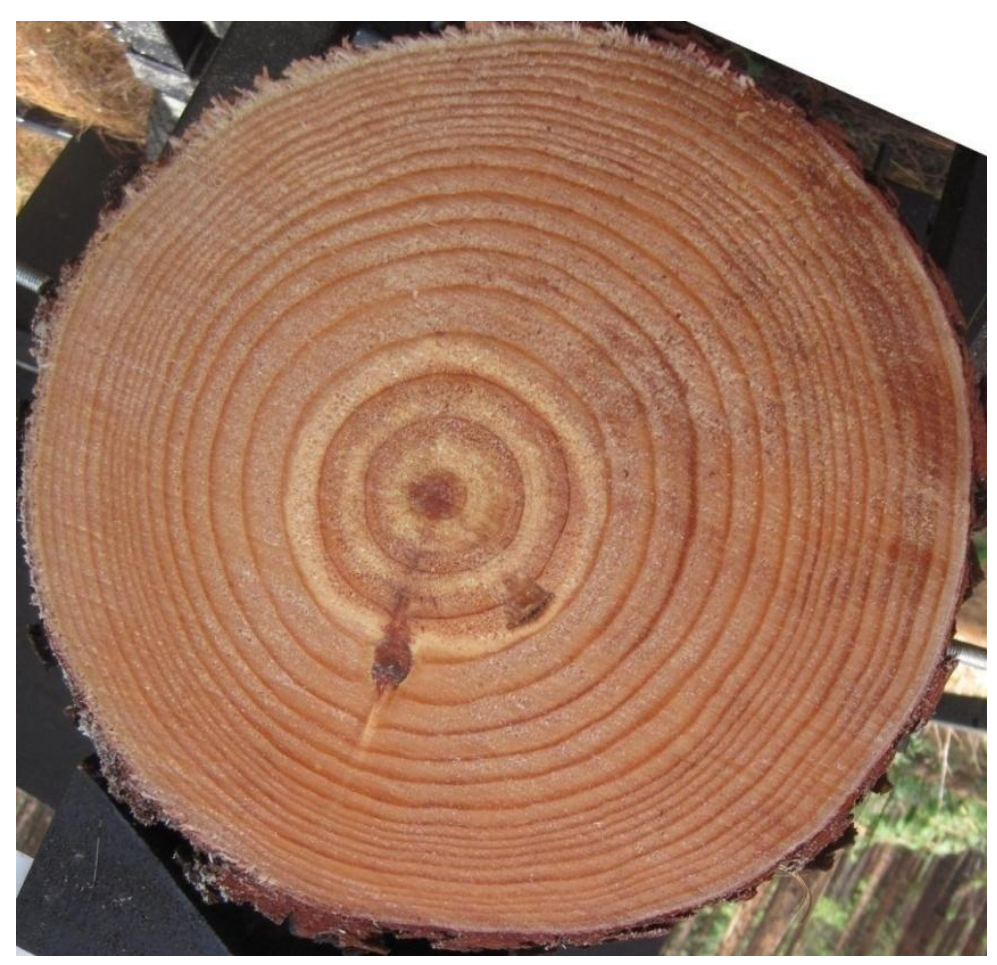

Figure information:

1. Cut number: 1-2-14

2. Year: 1996

3. Angle from North: $142.85^{\circ}$

Figure 25: Resin pocket identified from photos.

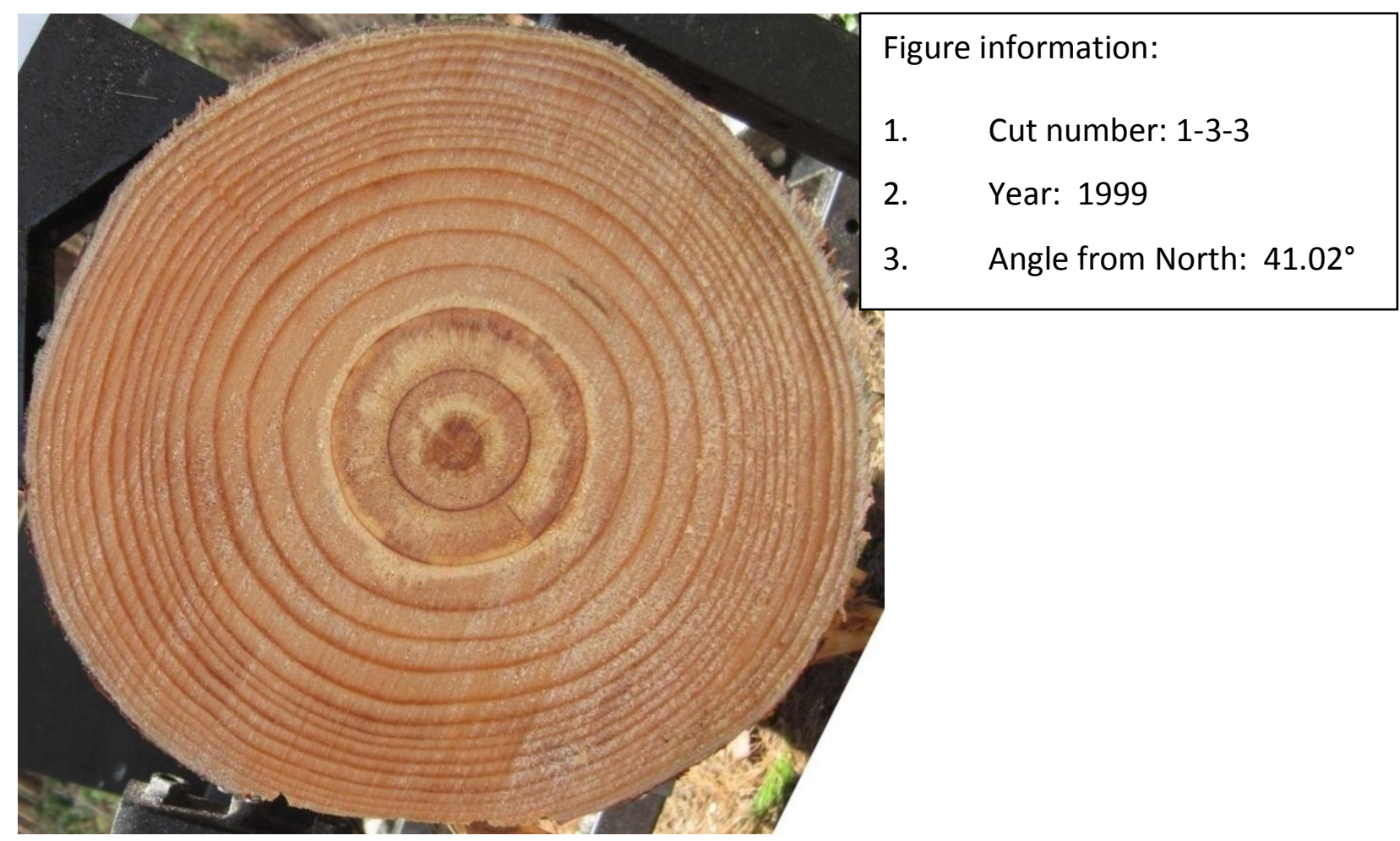

Figure 26: Resin pocket identified infield. 


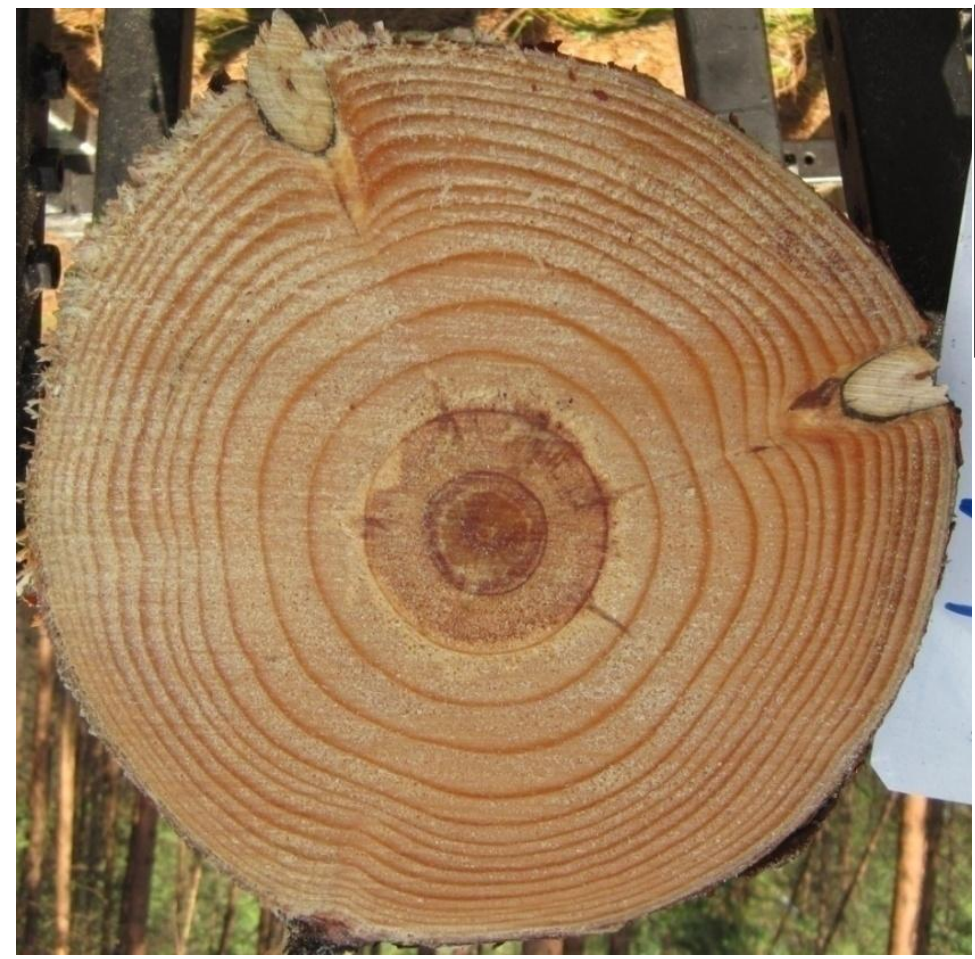

Figure information:

1. Cut number: 1-4-1

2. Year: 2005

3. Angle from North: $298.92^{\circ}$

Figure 27: Resin pocket identified from photos.

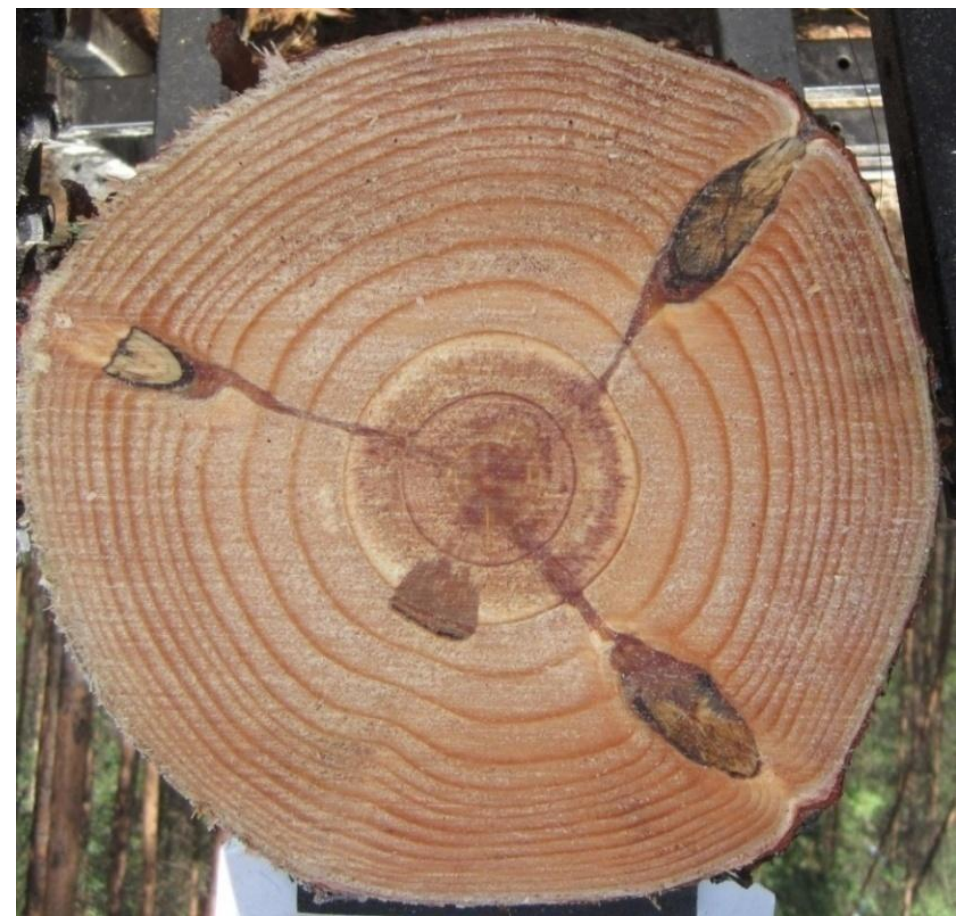

Figure information:

1. Cut number: 1-4-13

2. Year: 1999

3. Angle from North: $206.11^{\circ}$

Figure 28: Resin pocket identified from photos. 


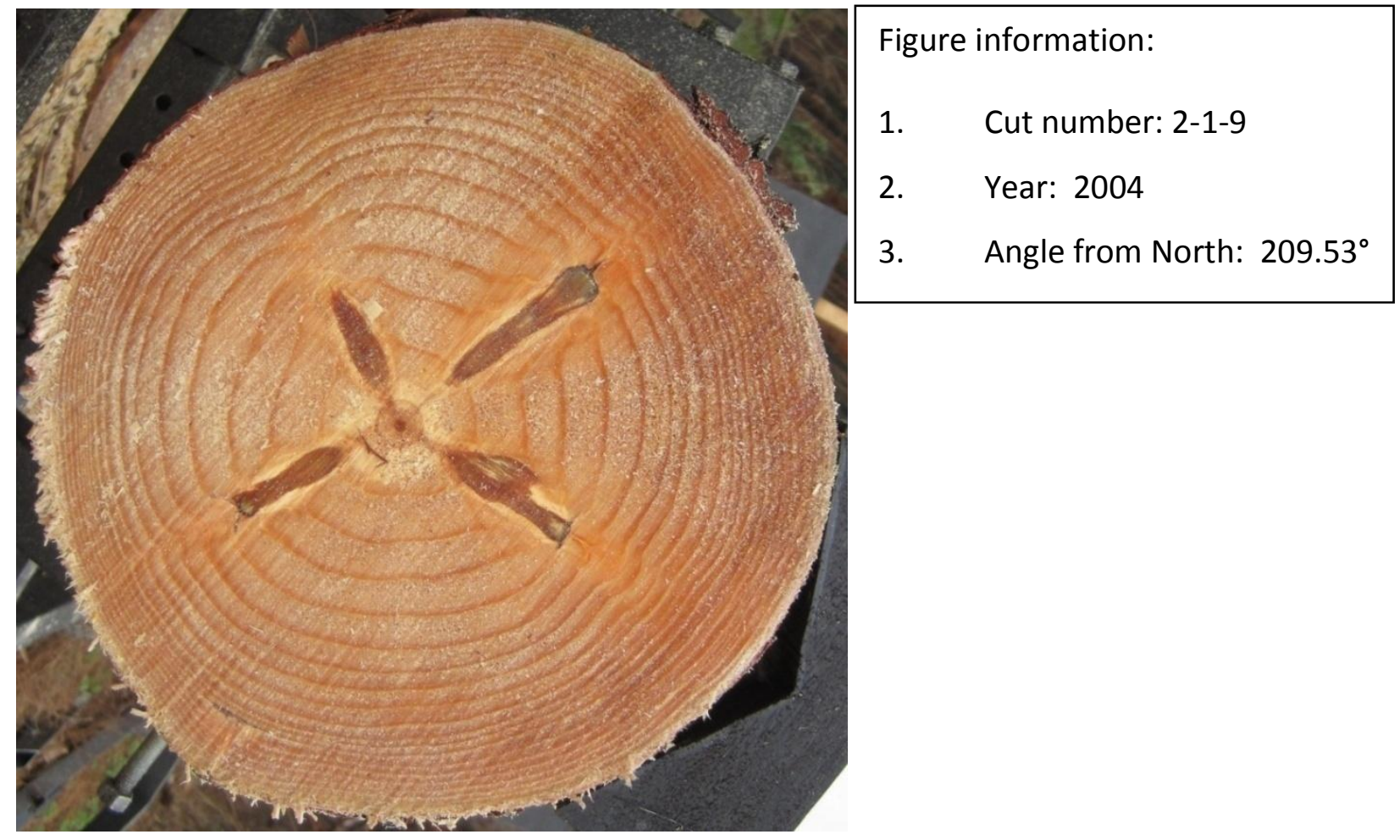

Figure 29: Resin pocket identified from photos.

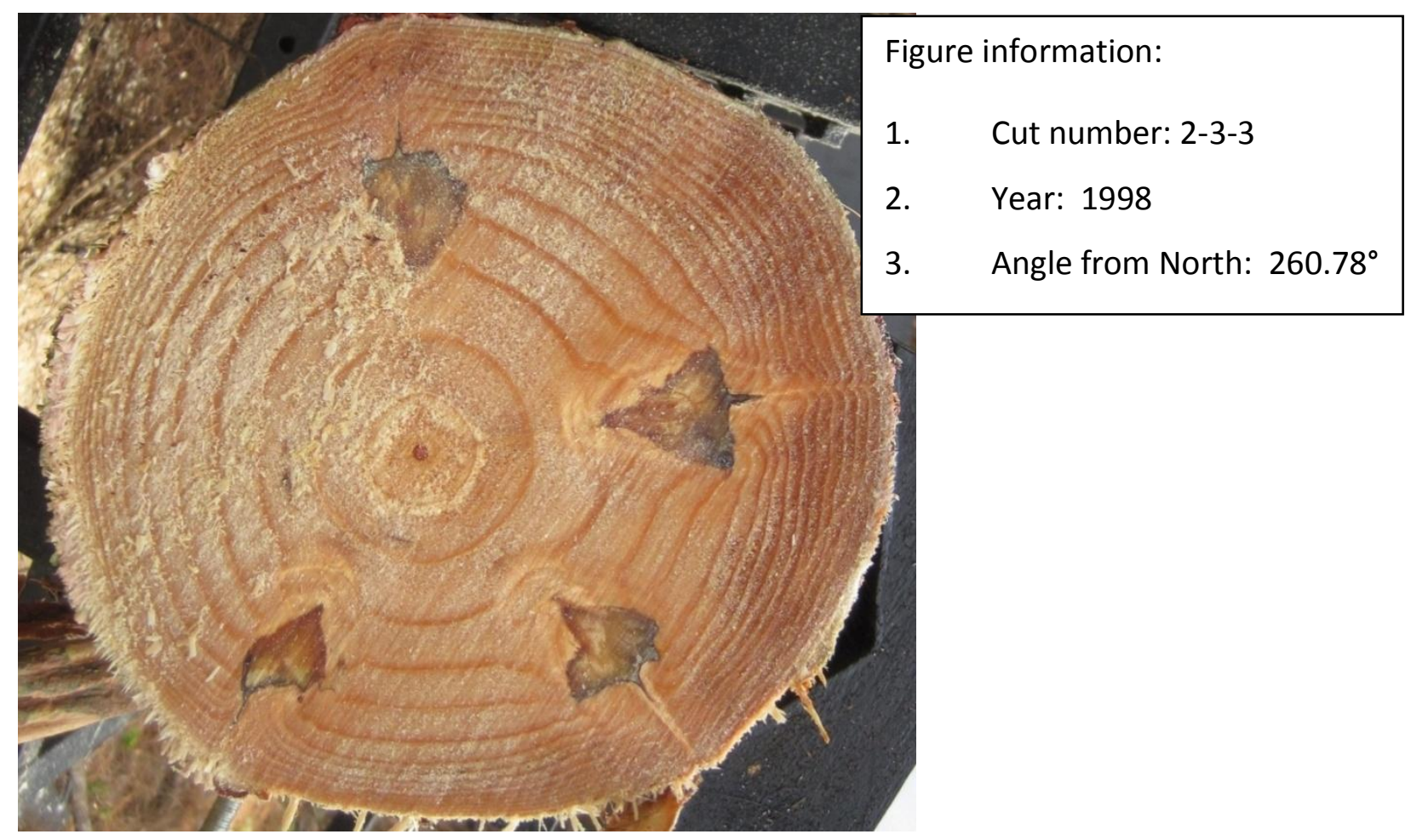

Figure 30: Resin pocket identified from photos. 


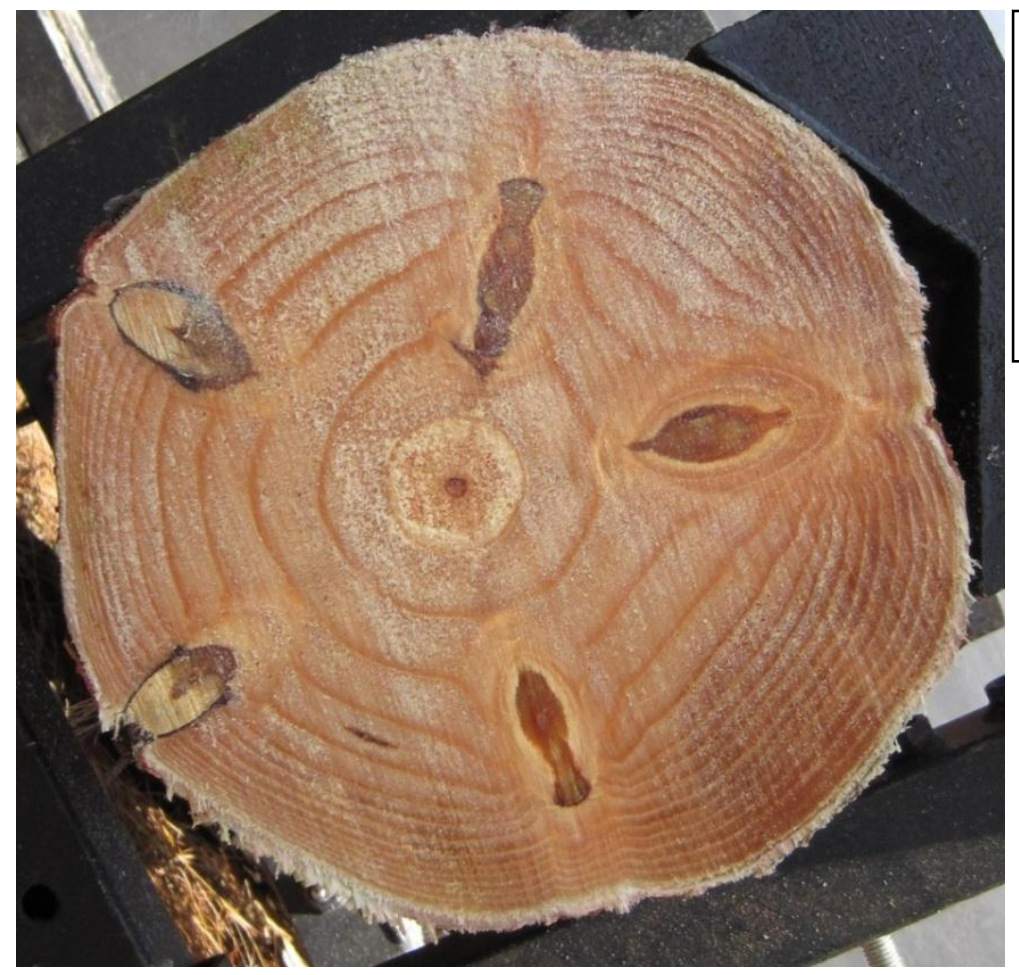

Figure information:

1. Cut number: 2-4-32

2. Year: 2001

3. Angle from North: $200.57^{\circ}$

Figure 31: Resin pocket identified from photos.

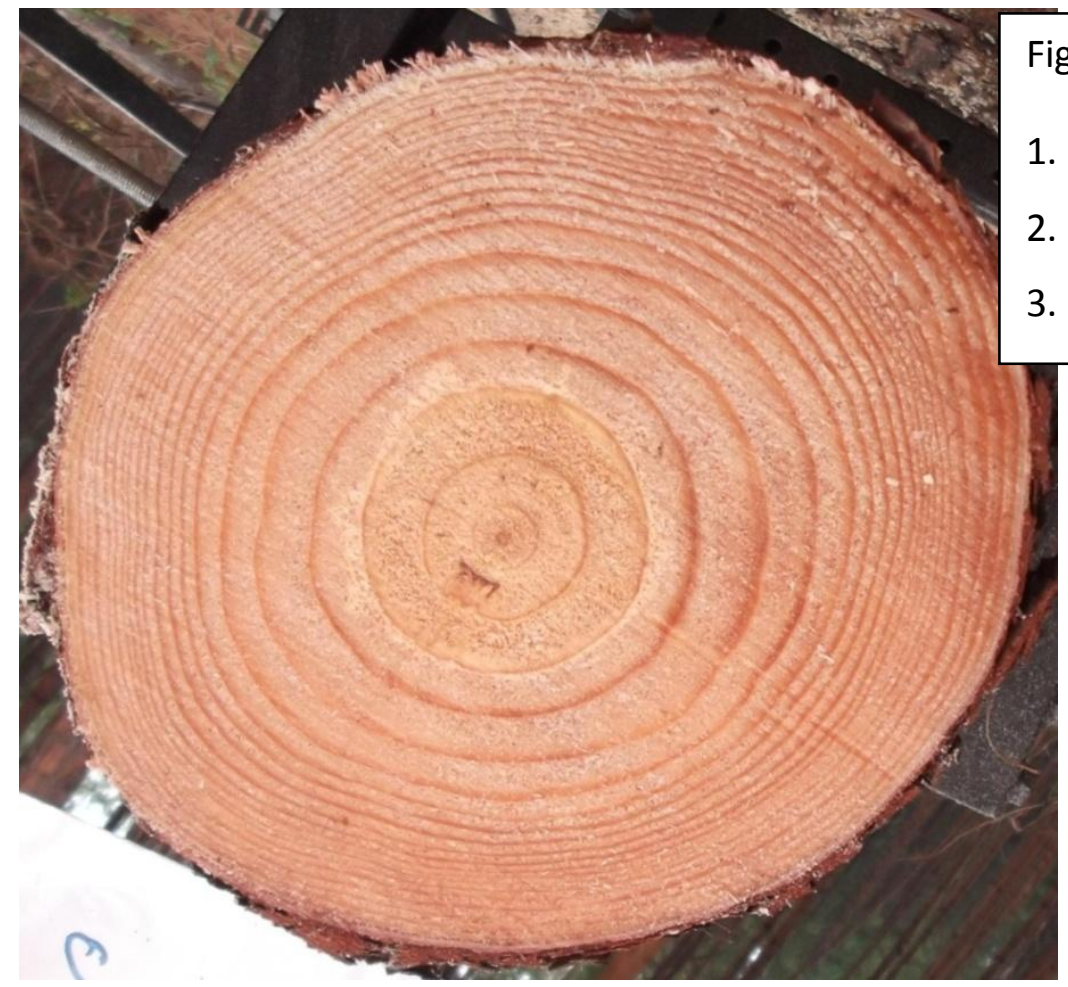

Figure information:

1. Cut number: $3-1-5$

2. Year: 1993

3. Angle from North: $212.63^{\circ}$

Figure 32: Resin pocket identified from photos. 


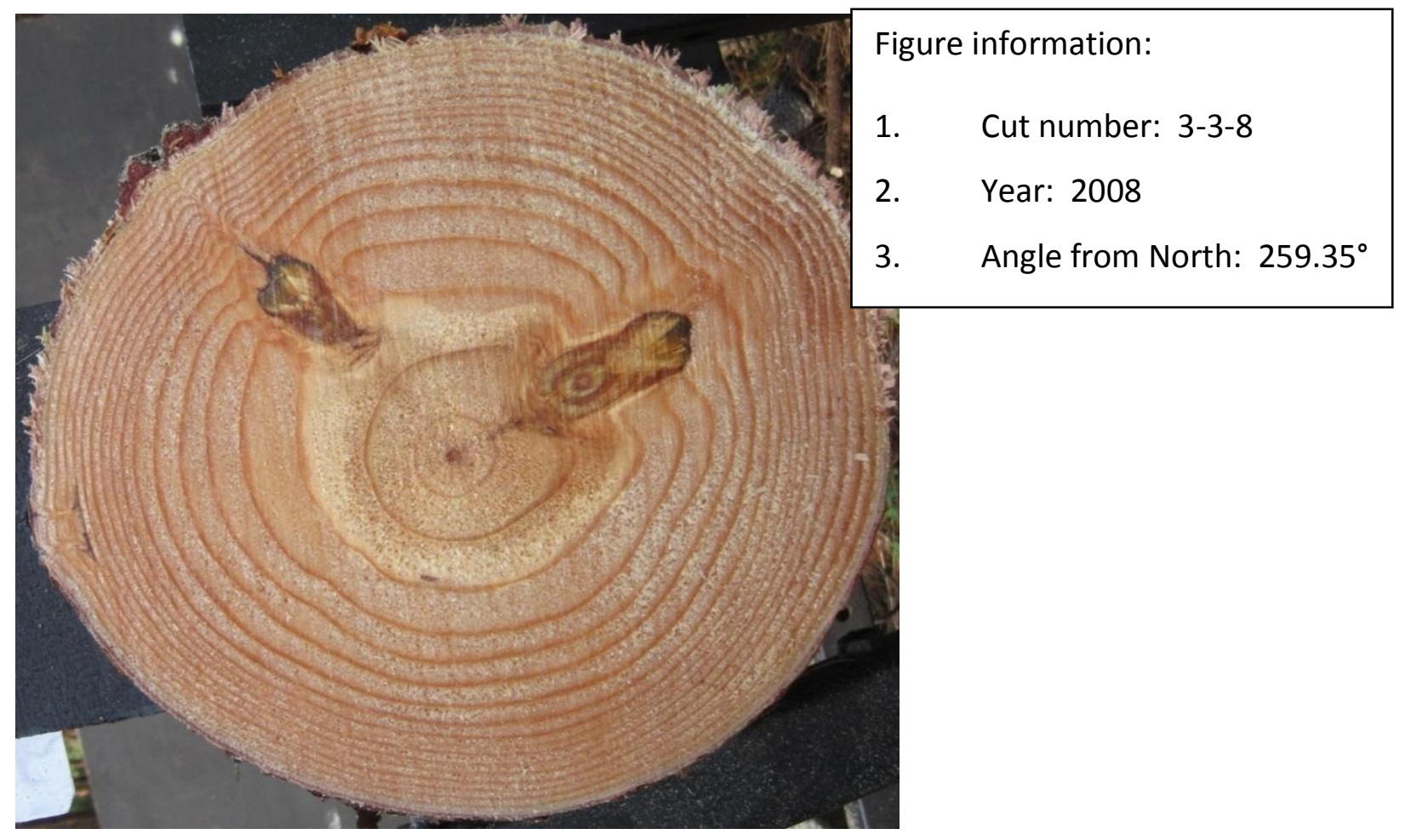

Figure 33: Resin pocket identified from photos.

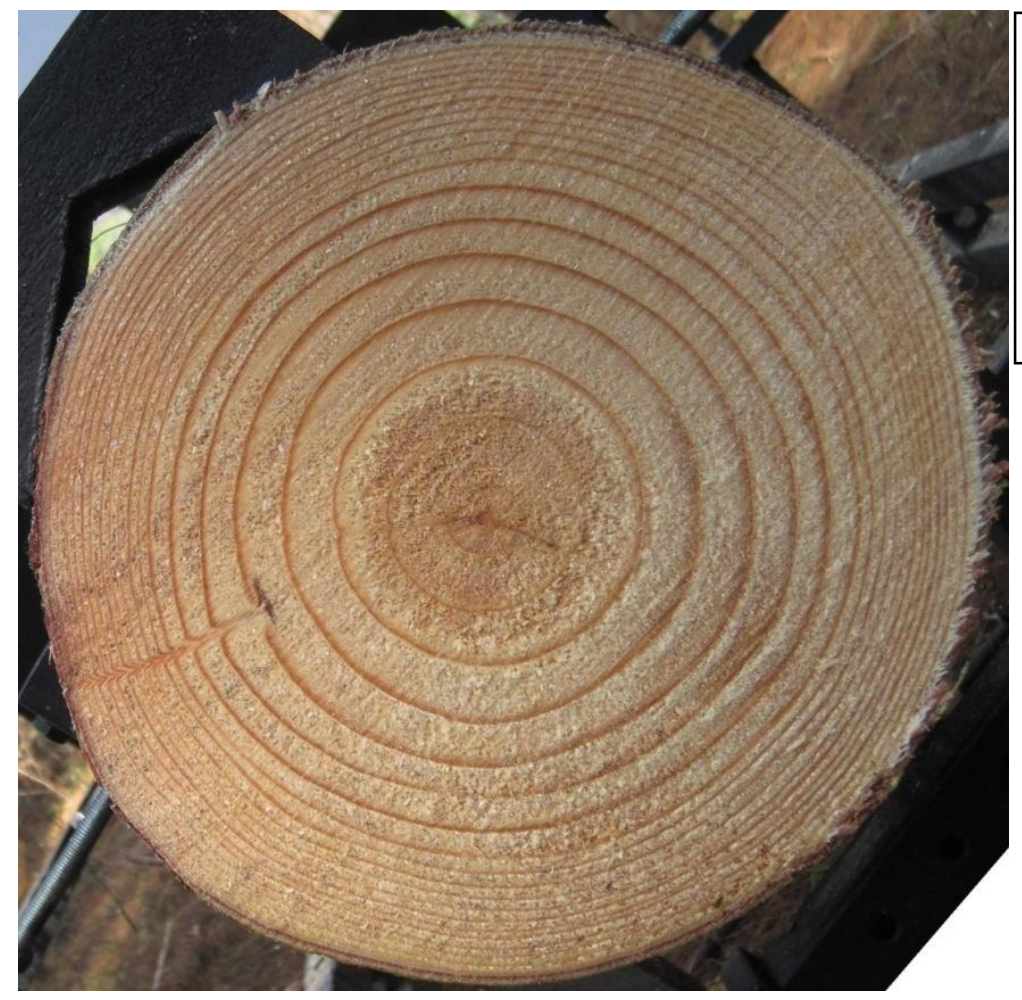

Figure information:

1. Cut number: 4-1-1

2. Year: 1997

3. Angle from North: $249.27^{\circ}$

Figure 34: Resin pocket identified from photos. 


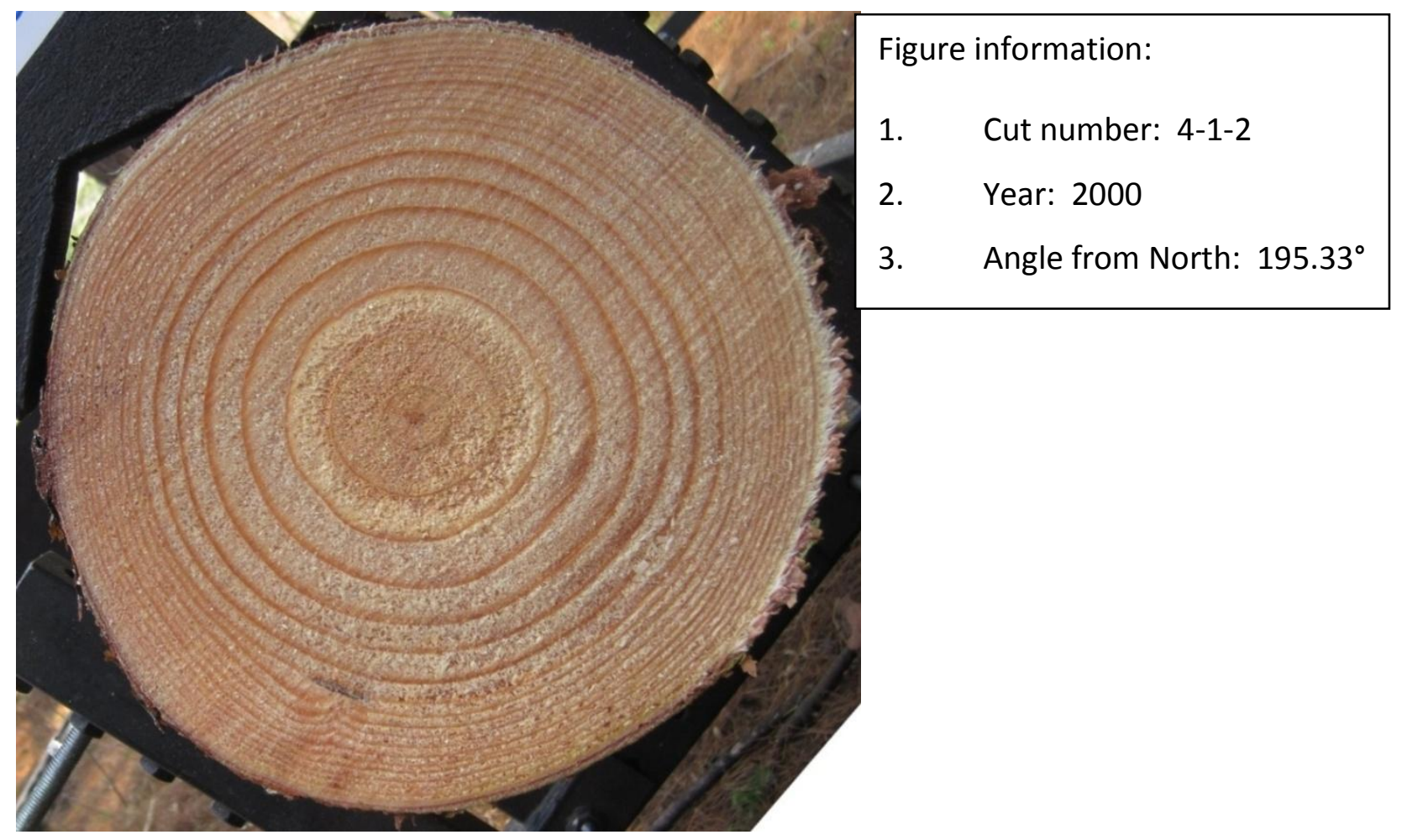

Figure 35: Resin pocket identified from photos.

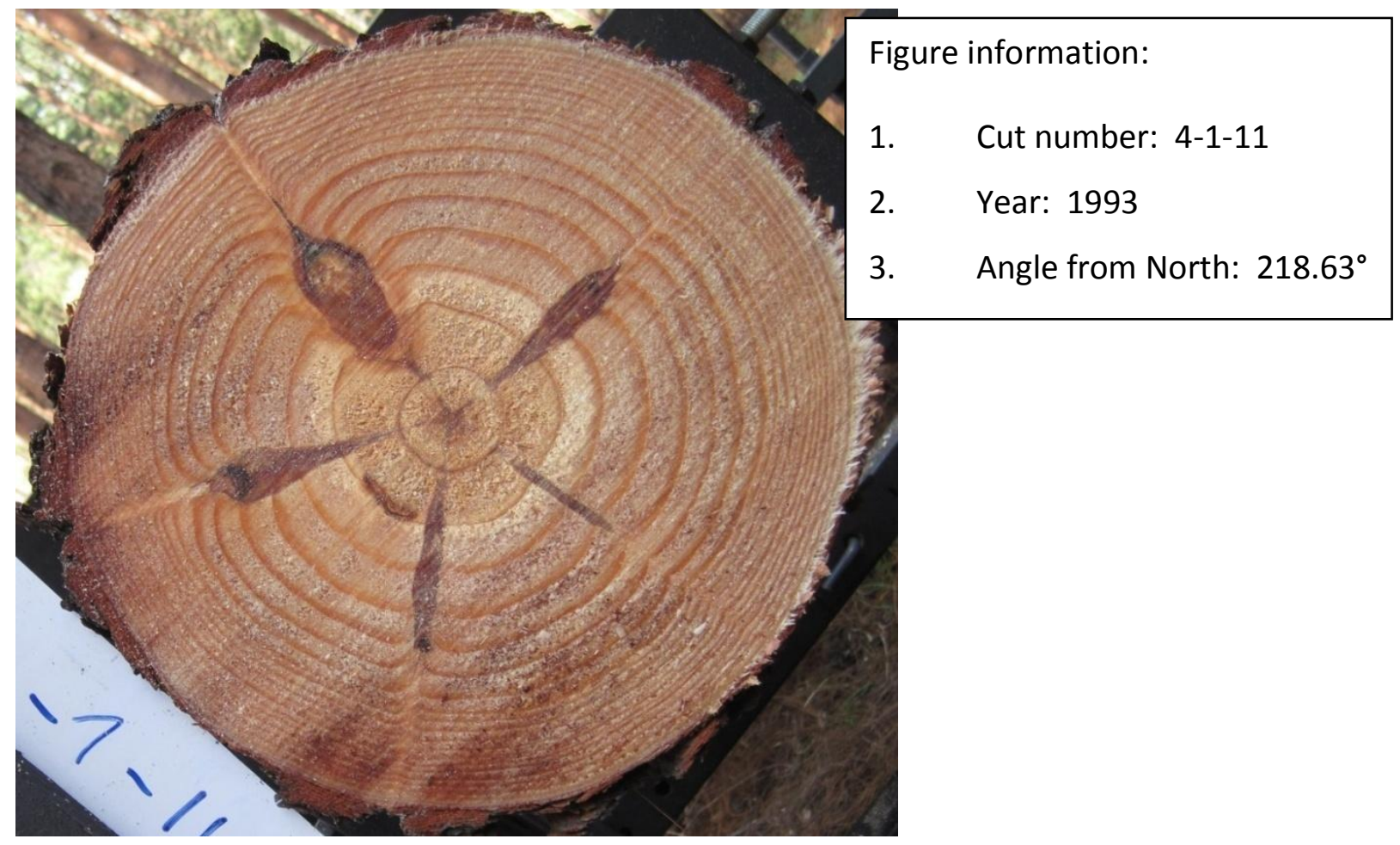

Figure 36: Resin pocket identified from photos. 


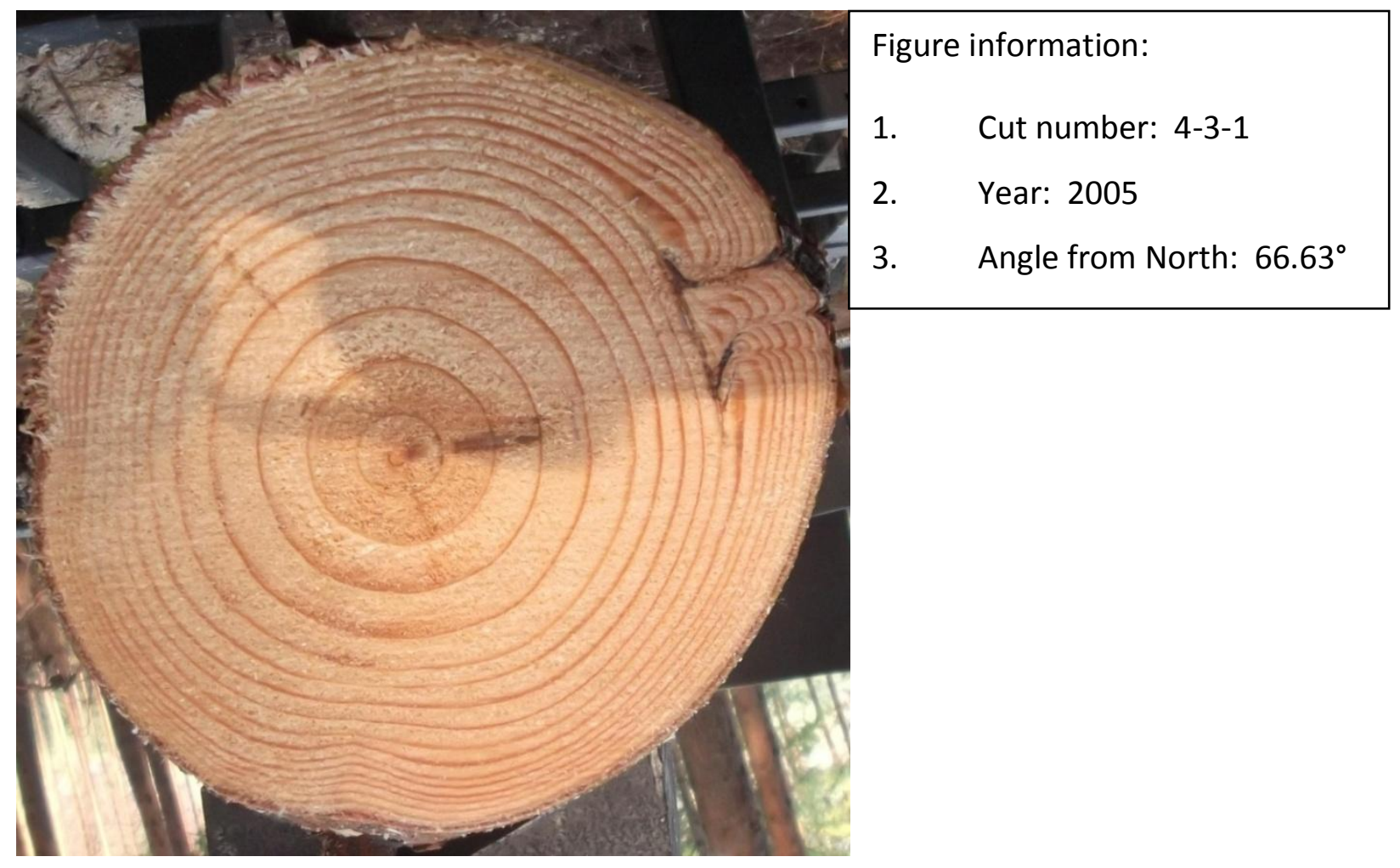

Figure 37: Resin pocket identified from photos.

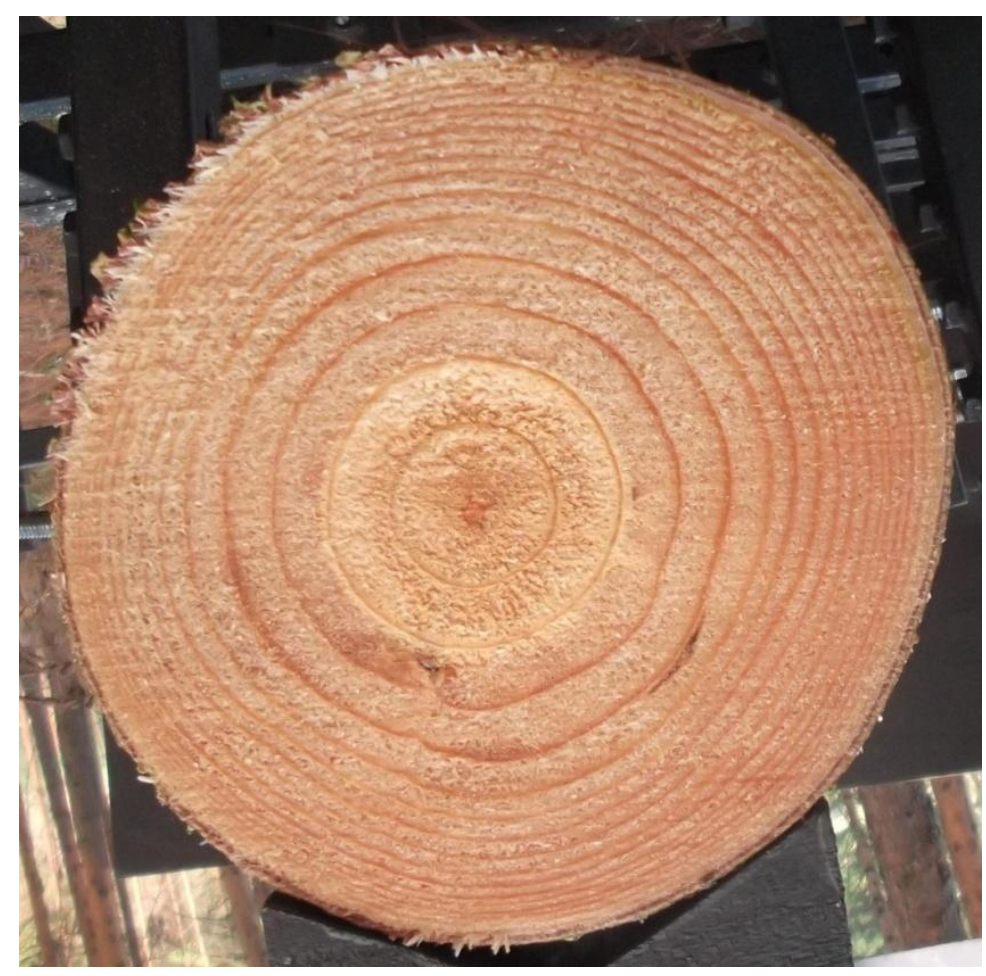

Figure information:

1. Cut number: $4-3-16$

2. Year: 2000

3. Angle from North: $125.54^{\circ}$

Figure 38: Resin pocket identified from photos. 


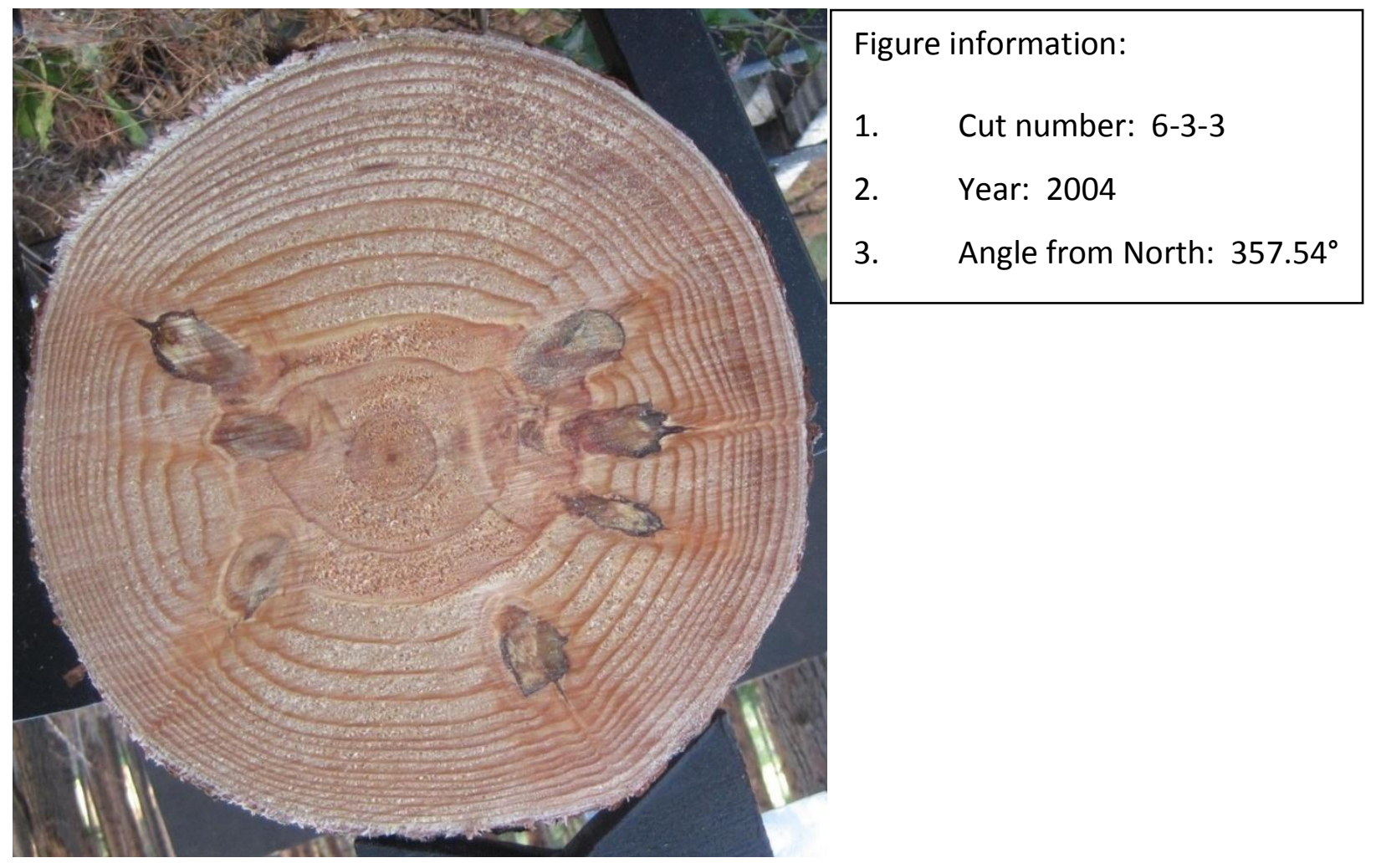

Figure 39: Resin pocket identified from photos.

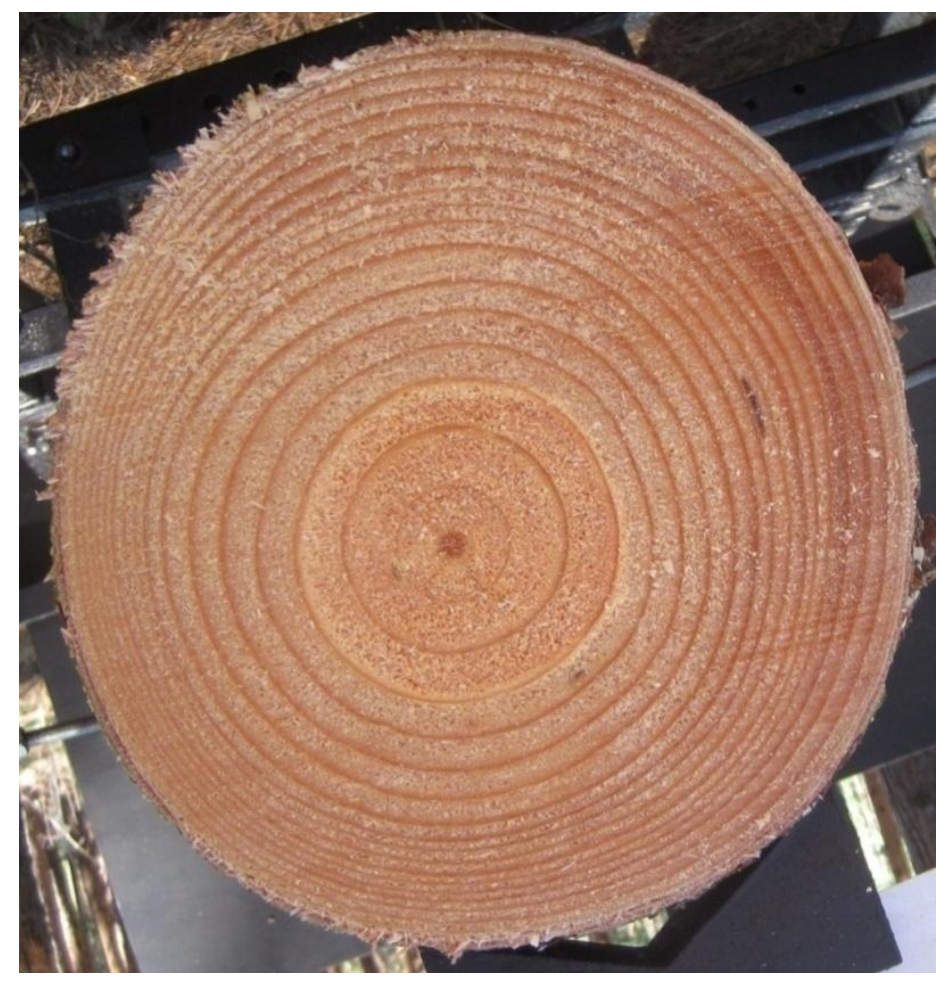

Figure information:

1. Cut number: $6-3-8$

2. Year: 2004

3. Angle from North: $65.44^{\circ}$

Figure 40: Resin pocket identified from photos. 


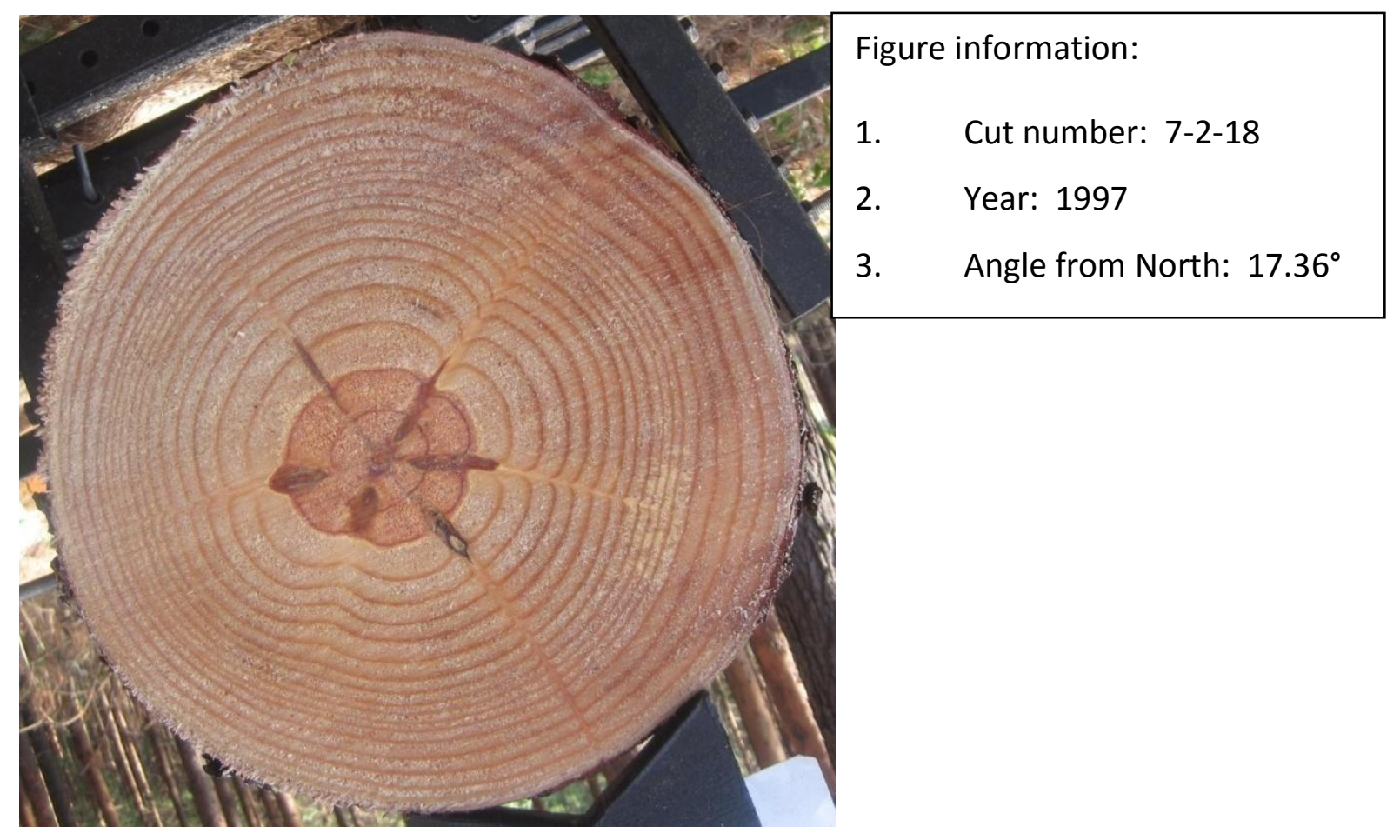

Figure 41: Resin pocket identified from photos.

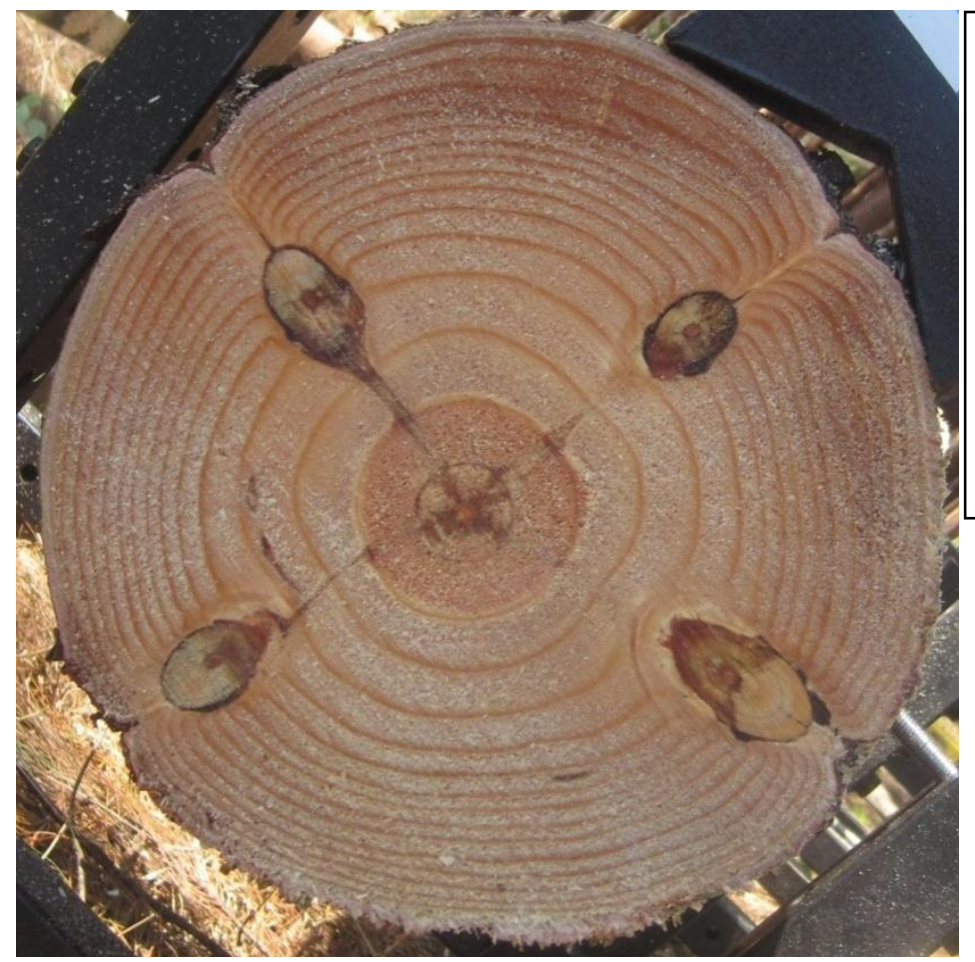

Figure information:

1. Cut number: $7-4-4$

2. Year: 2003

3. Angle from North: $158.04^{\circ}$

4. Year: 2000

5. Angle from North: $256.59^{\circ}$

Figure 42: Resin pocket identified from photos. 


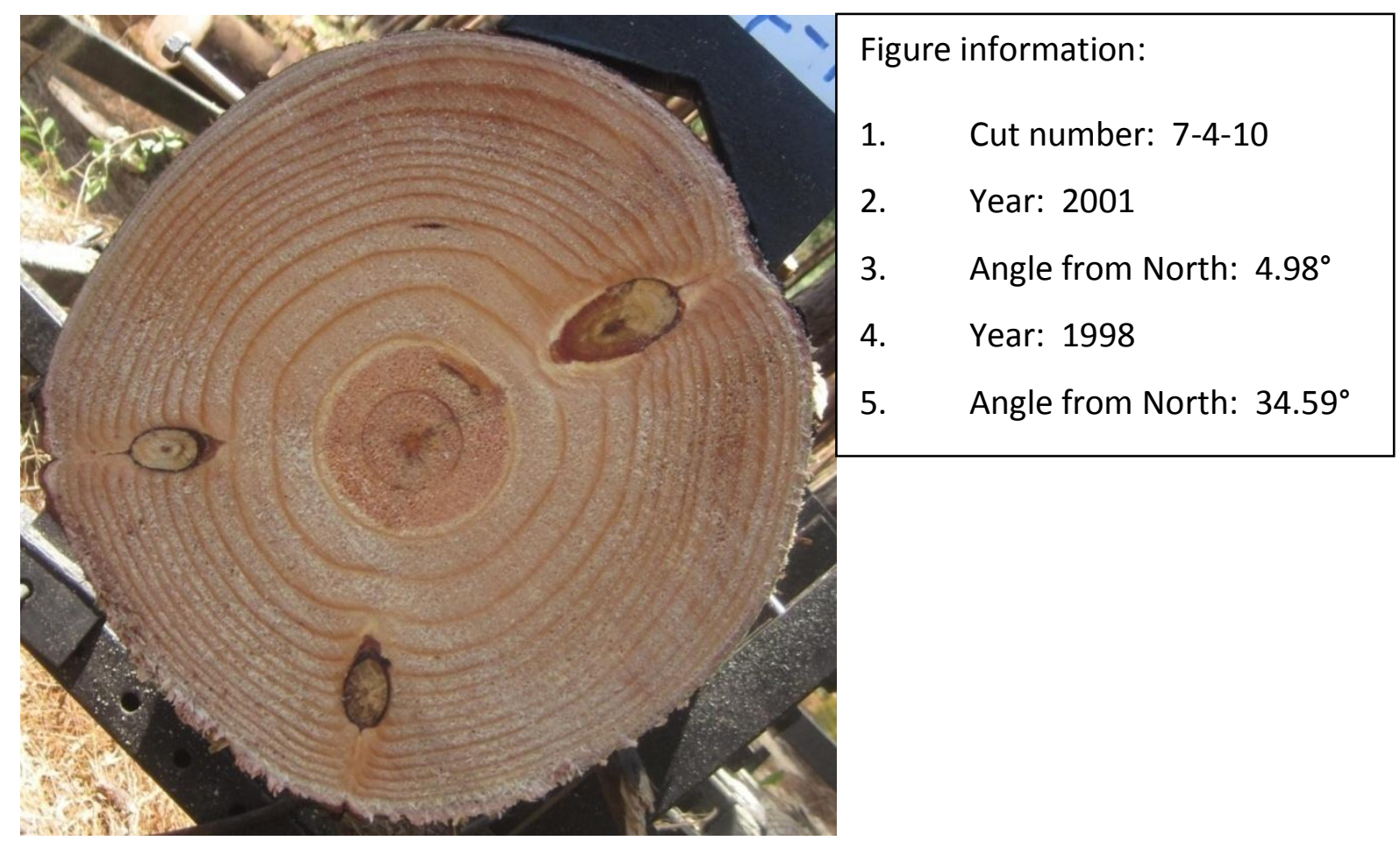

Figure 43: Resin pocket identified from photos.

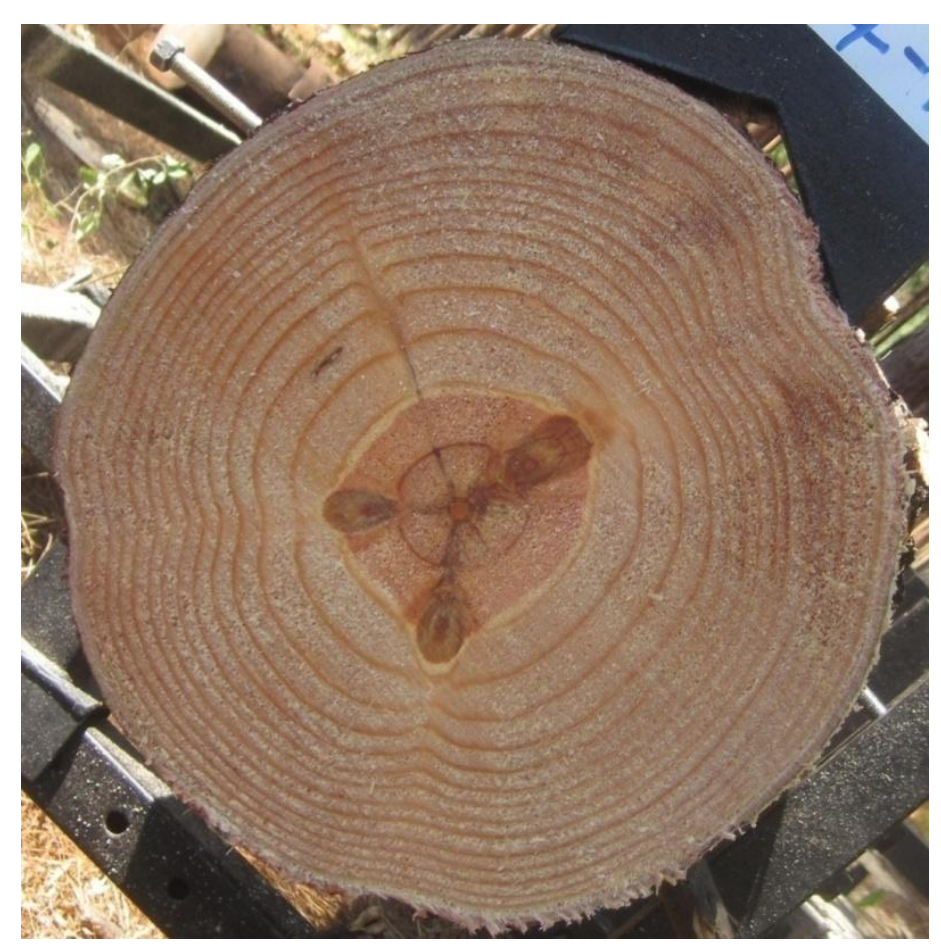

Figure information:

1. Cut number: $7-4-12$

2. Year: 2000

3. Angle from North: $318.8^{\circ}$

Figure 44: Resin pocket identified from photos. 


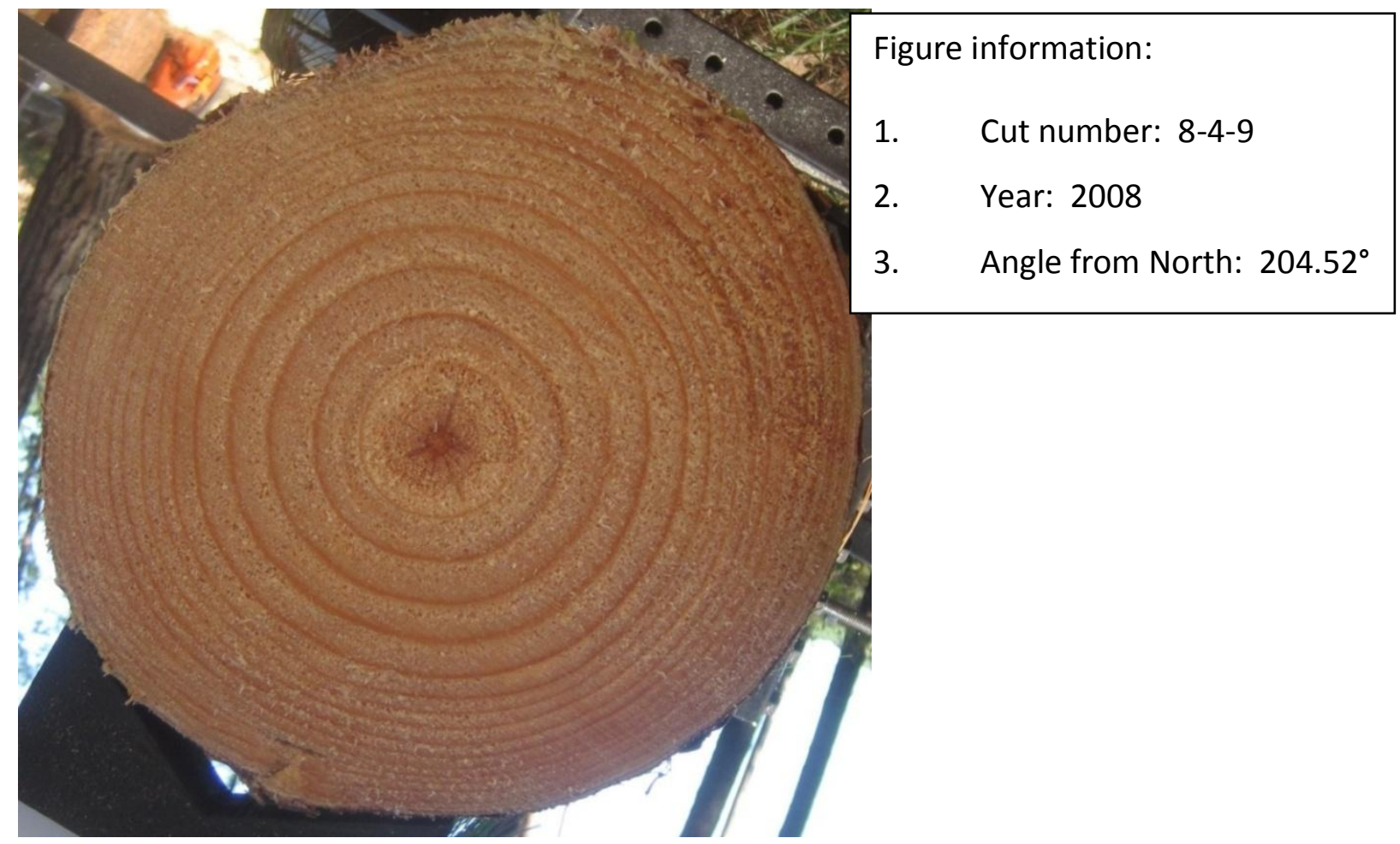

Figure 45: Resin pocket identified from photos.

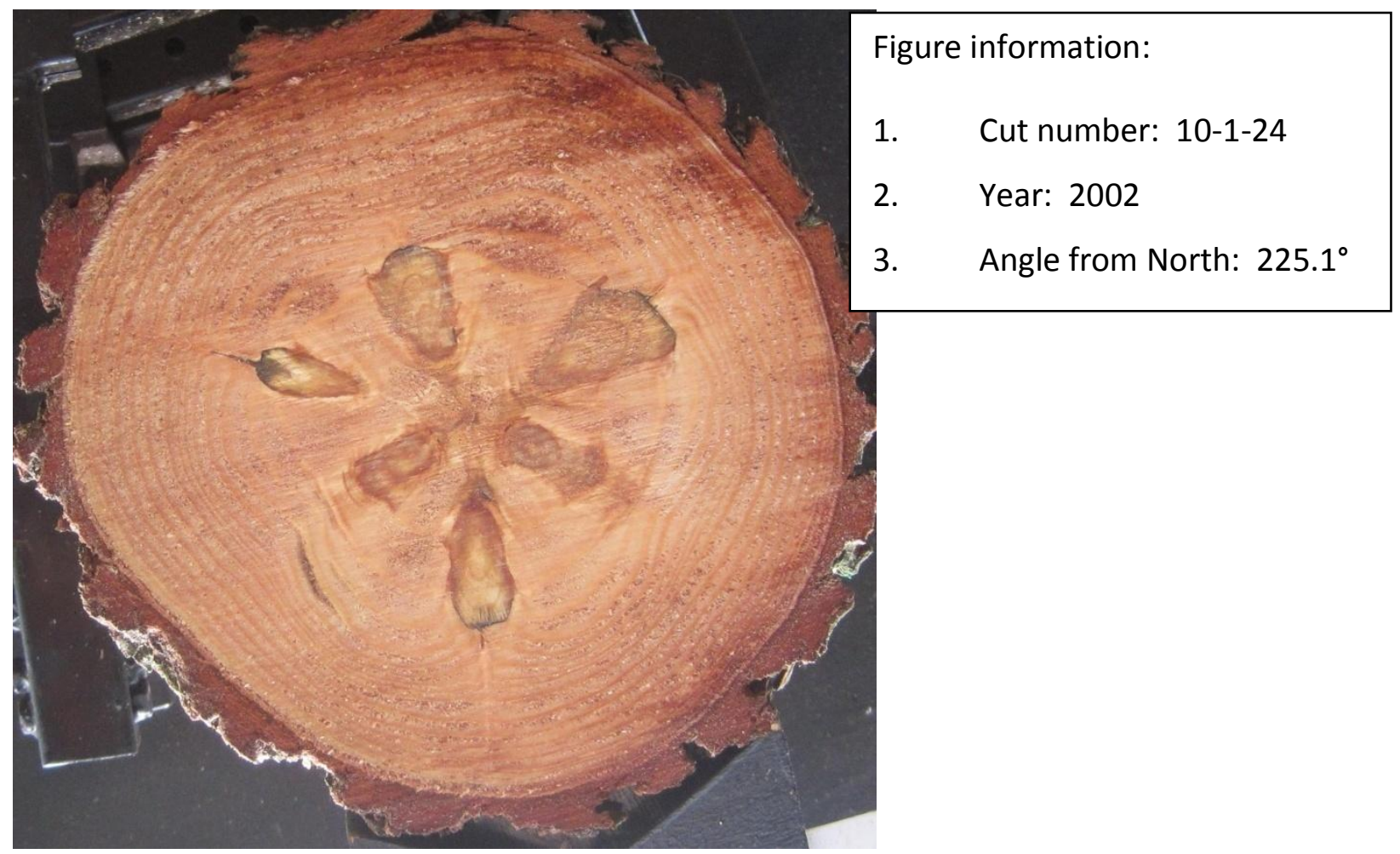

Figure 46: Resin pocket identified from photos. 


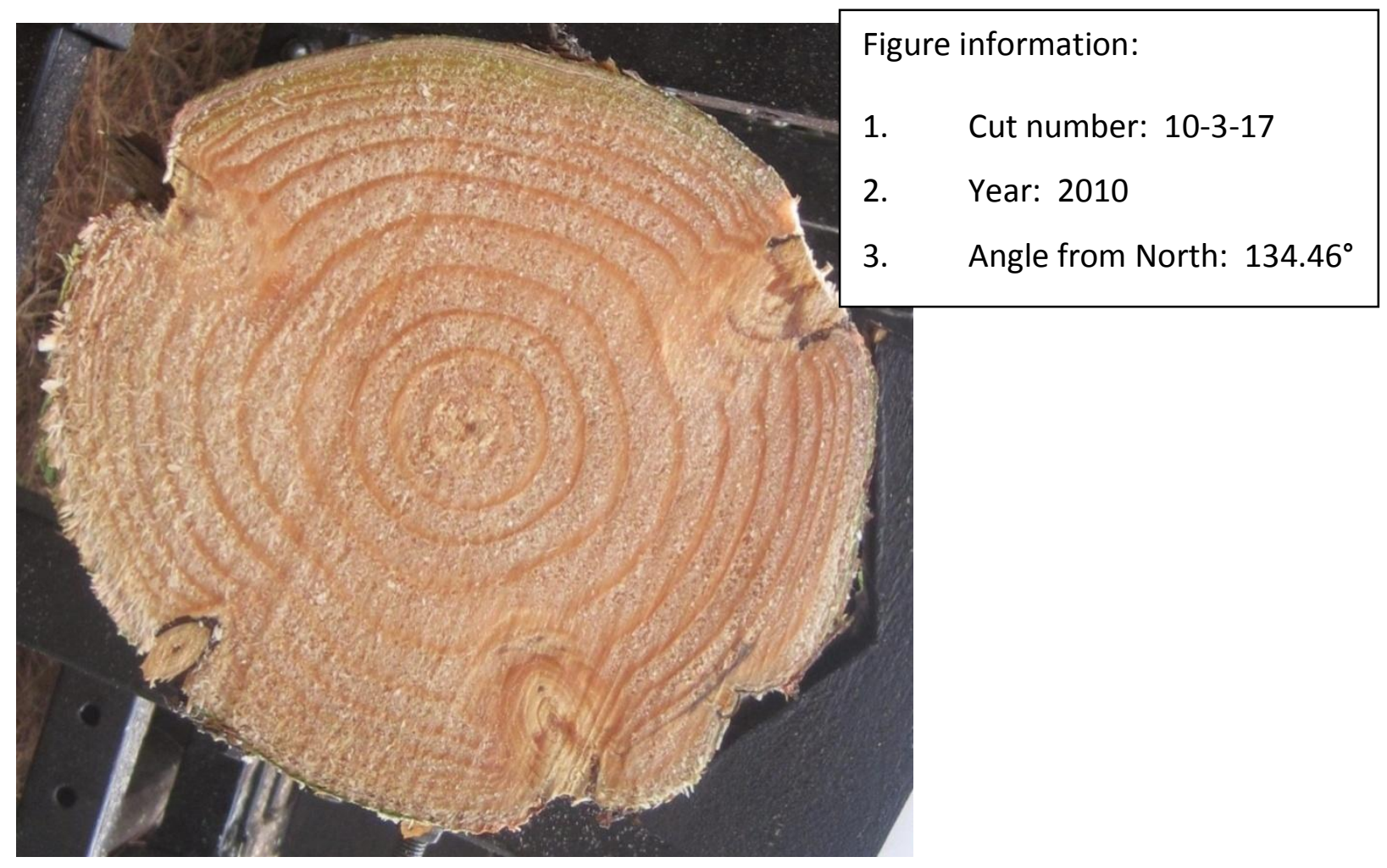

Figure 47: Resin pocket identified from photos.

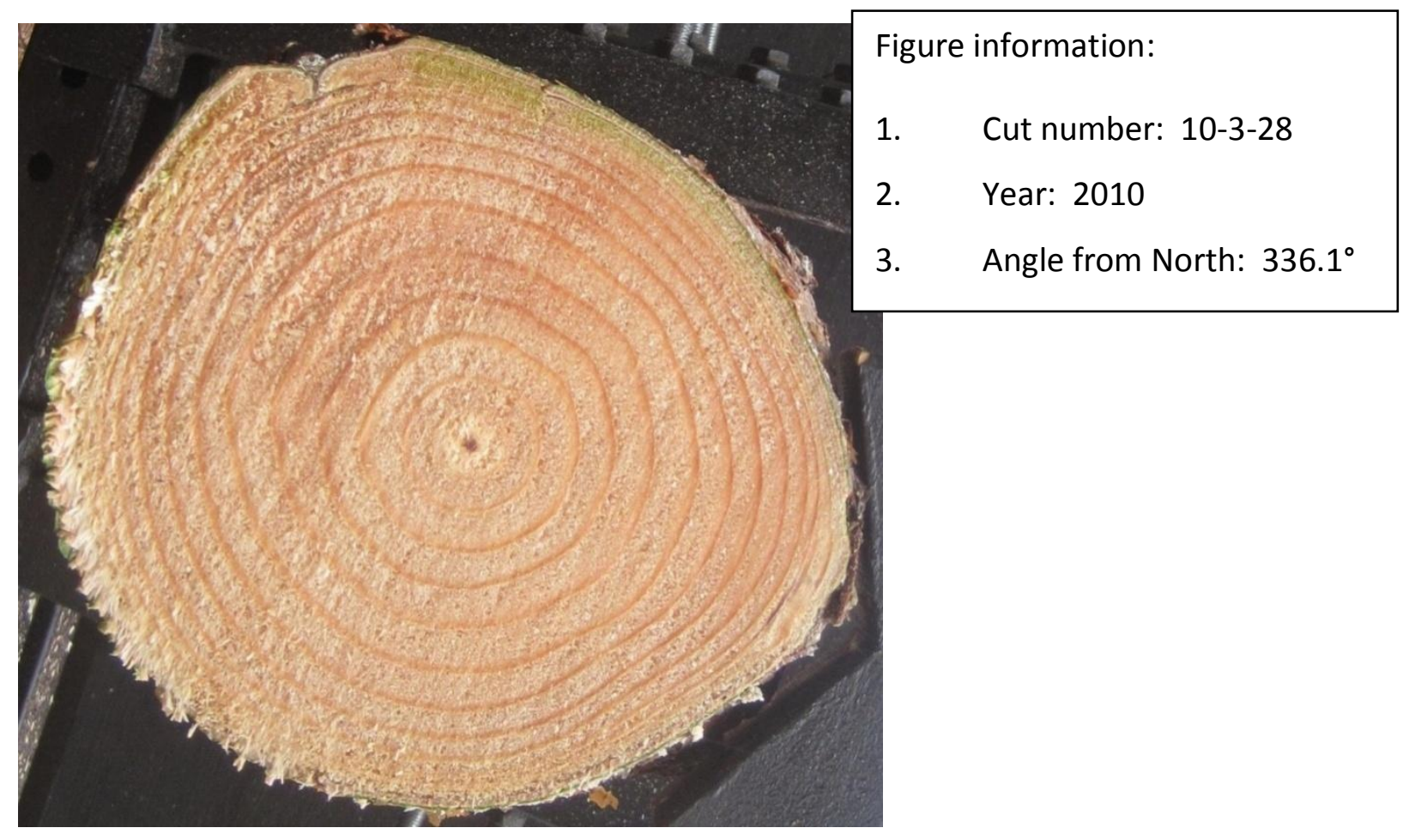

Figure 48: Resin pocket identified from photos. 


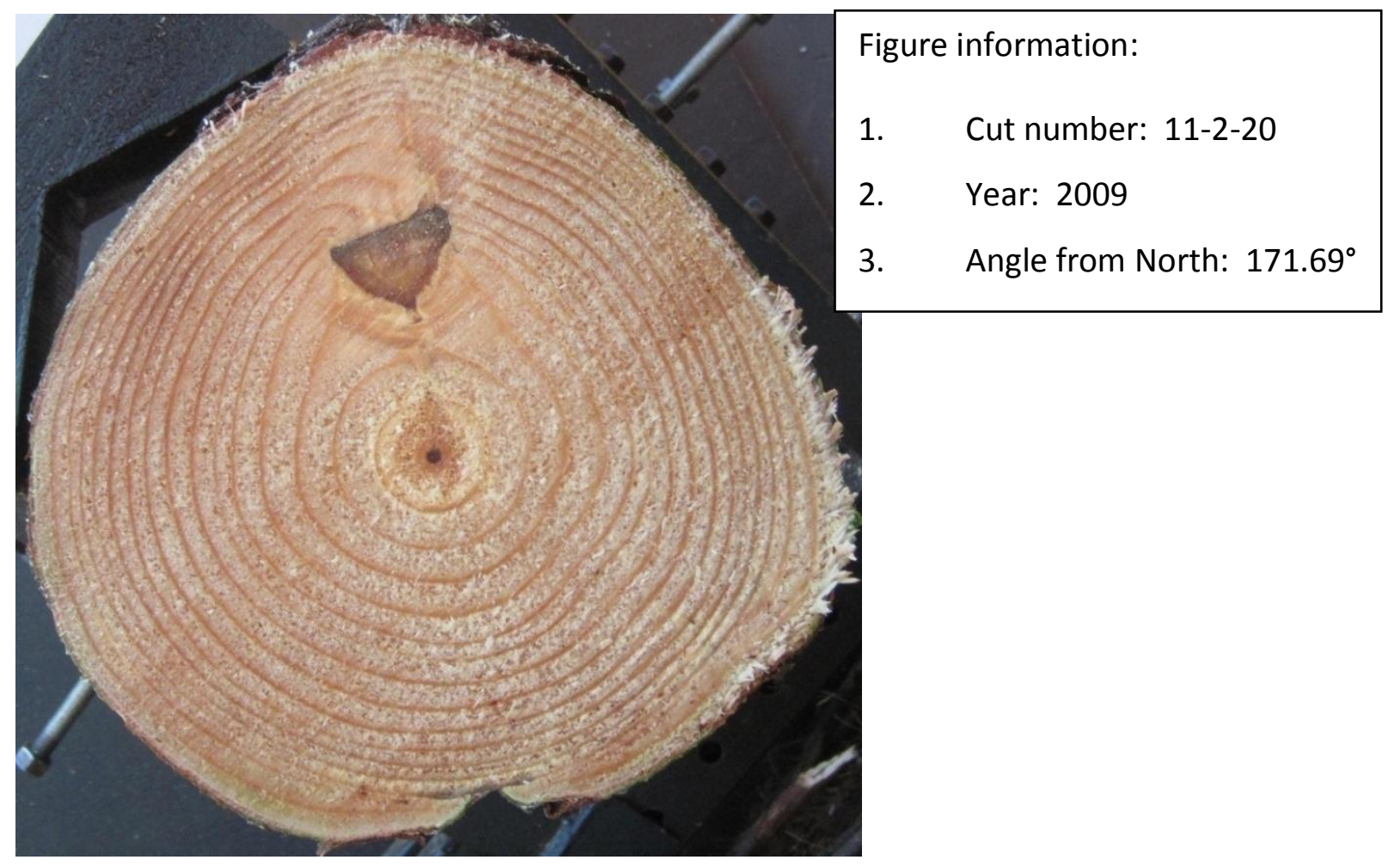

Figure 49: Resin pocket identified from photos.

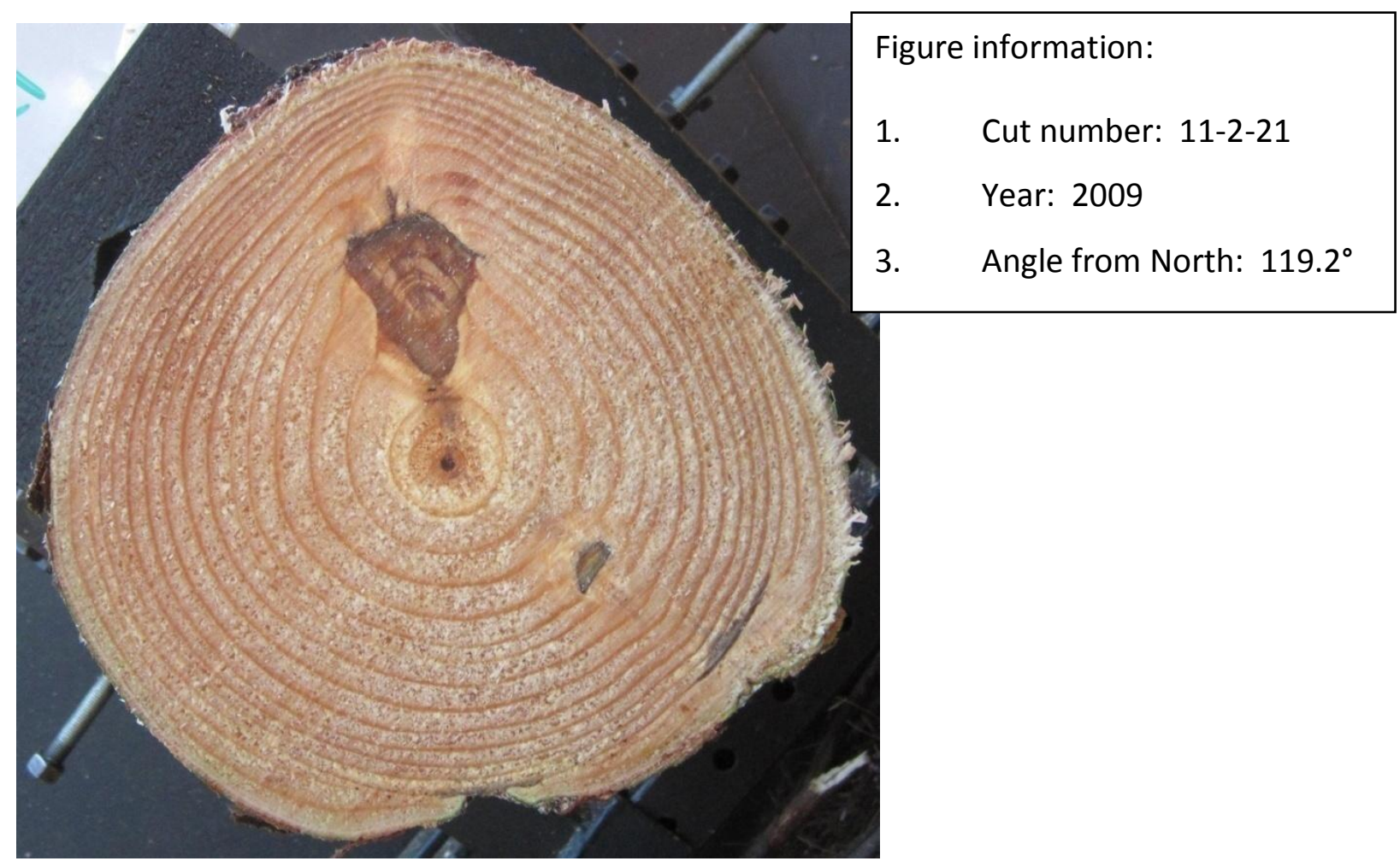

Figure 50: Resin pocket identified from photos. 


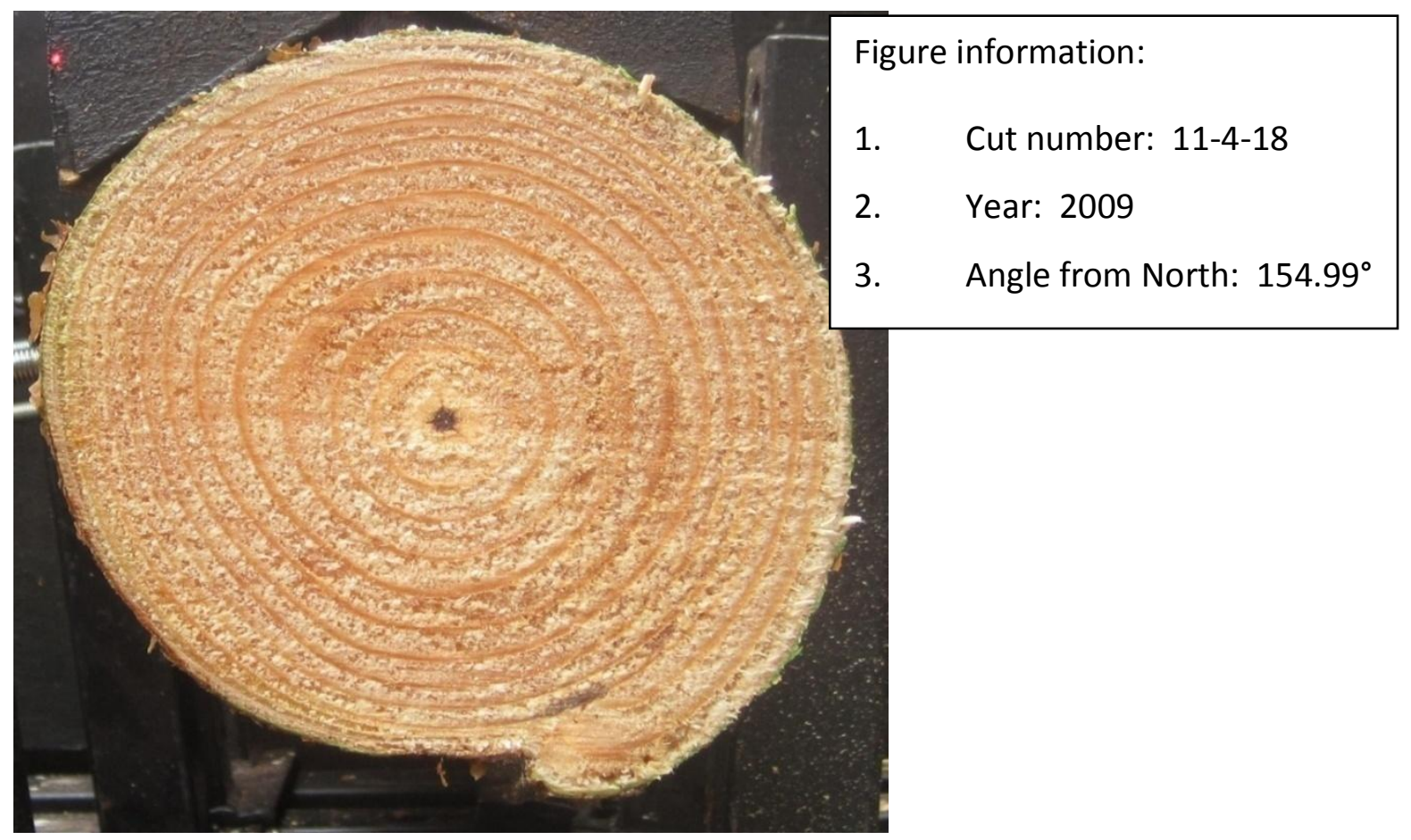

Figure 51: Resin pocket identified from photos.

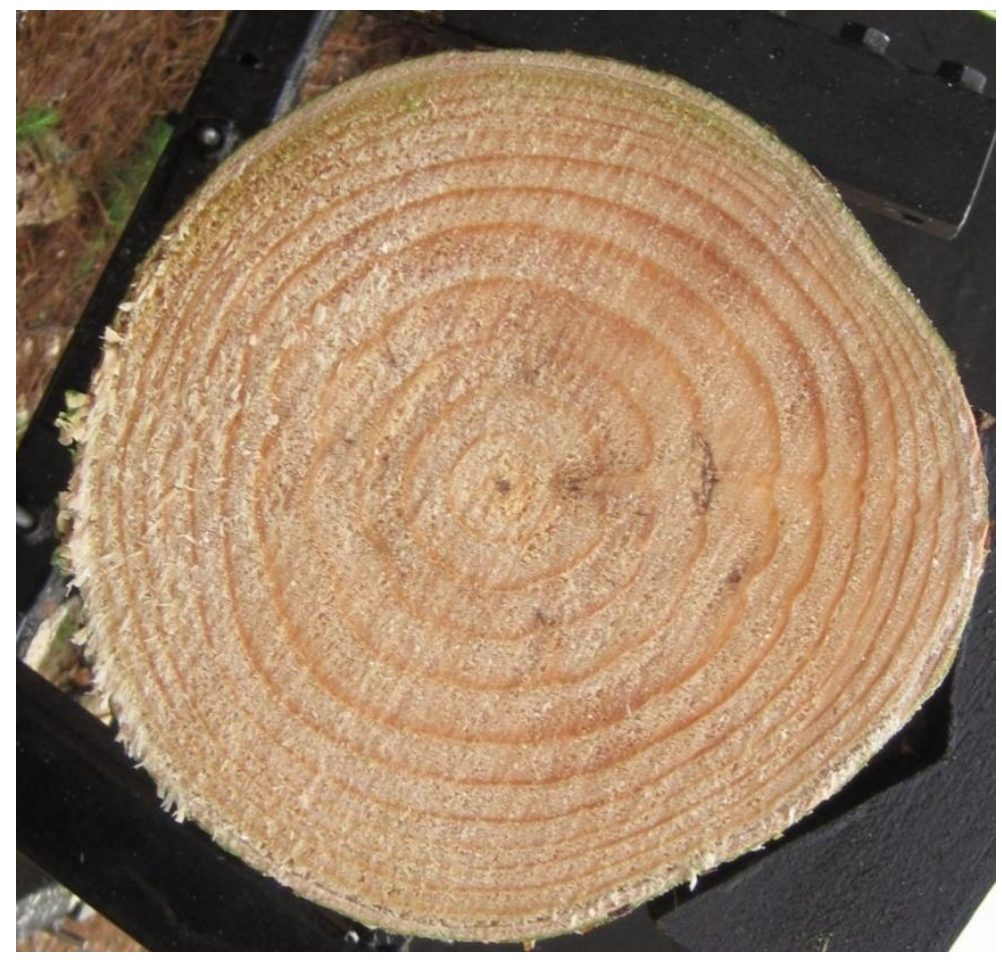

Figure information:

1. Cut number: $12-4-4$

2. Year: 2005

3. Angle from North: $86.64^{\circ}$

Figure 52: Resin pocket identified from photos. 


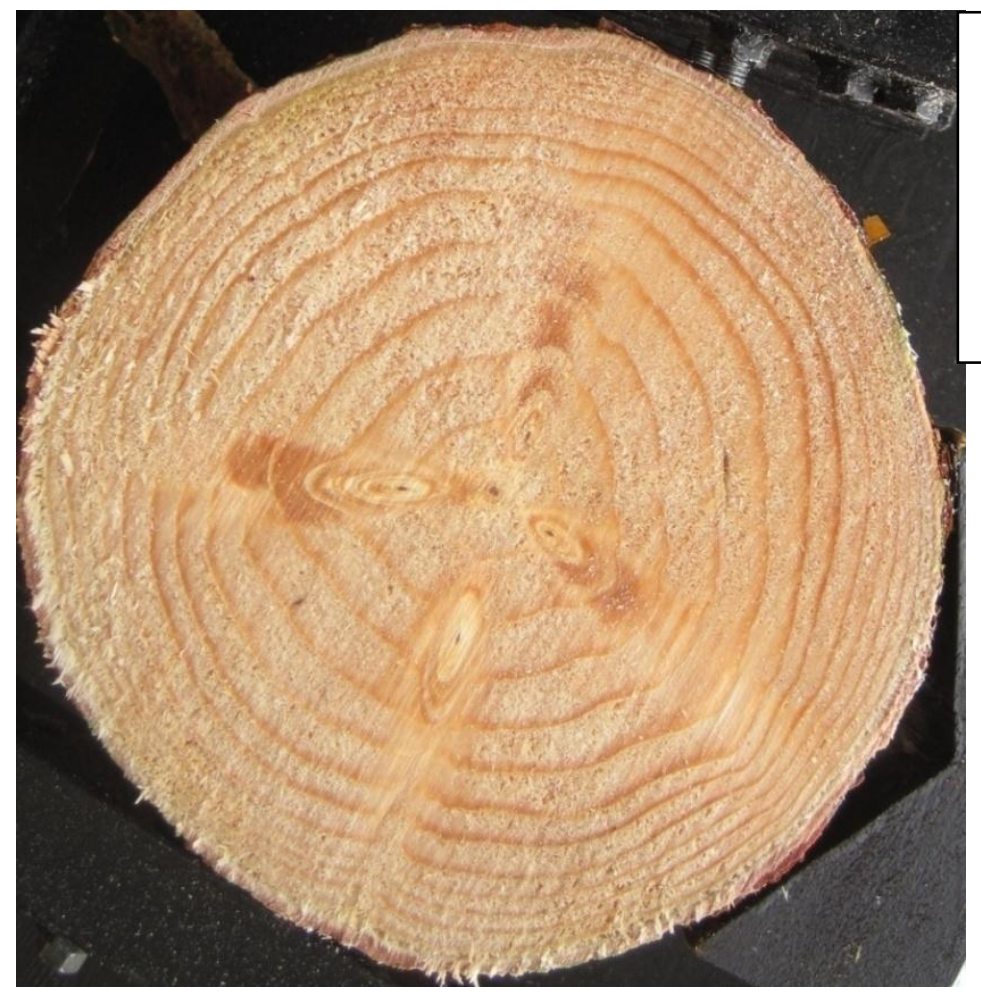

Figure information:

1. Cut number: $12-4-28$

2. Year: 2004

3. Angle from North: $85.43^{\circ}$

Figure 53: Resin pocket identified from photos.

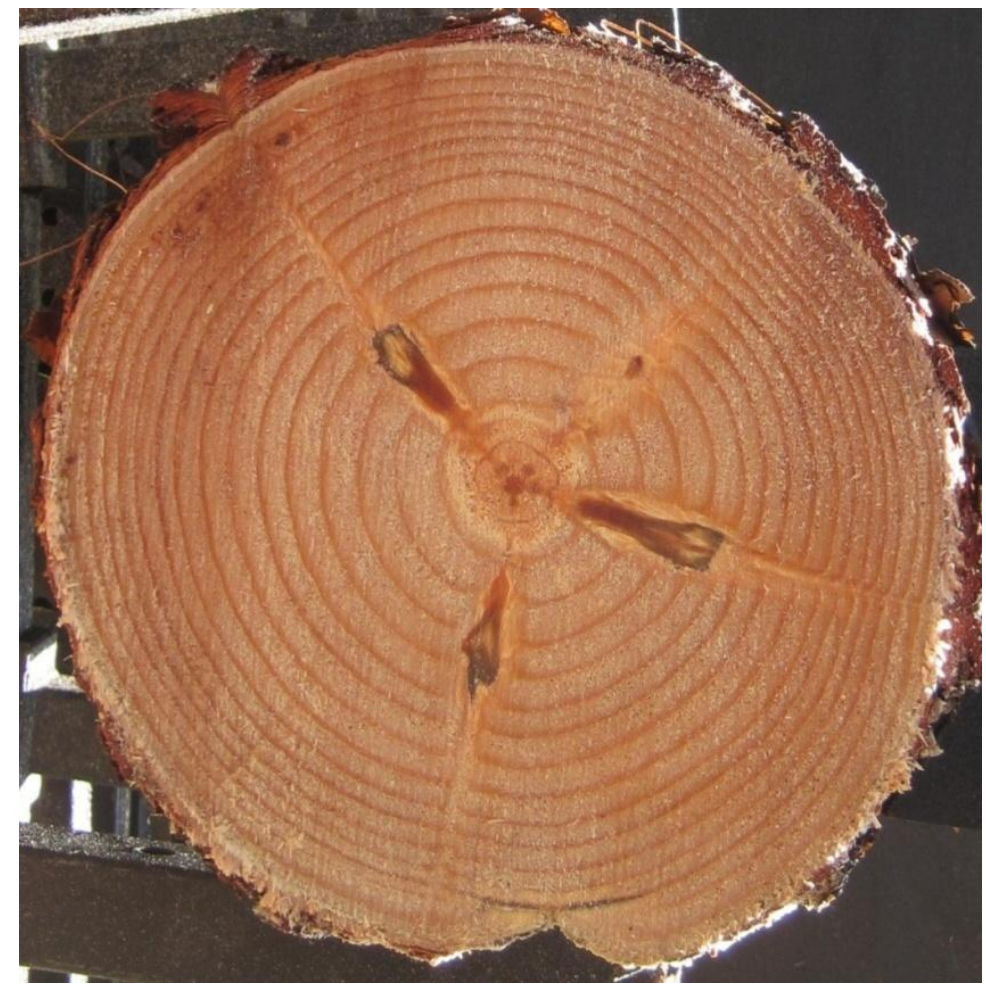

Figure information:

1. Cut number: $15-2-16$

2. Year: 2009

3. Angle from North: $173.76^{\circ}$

Figure 54: Resin pocket identified from photos. 


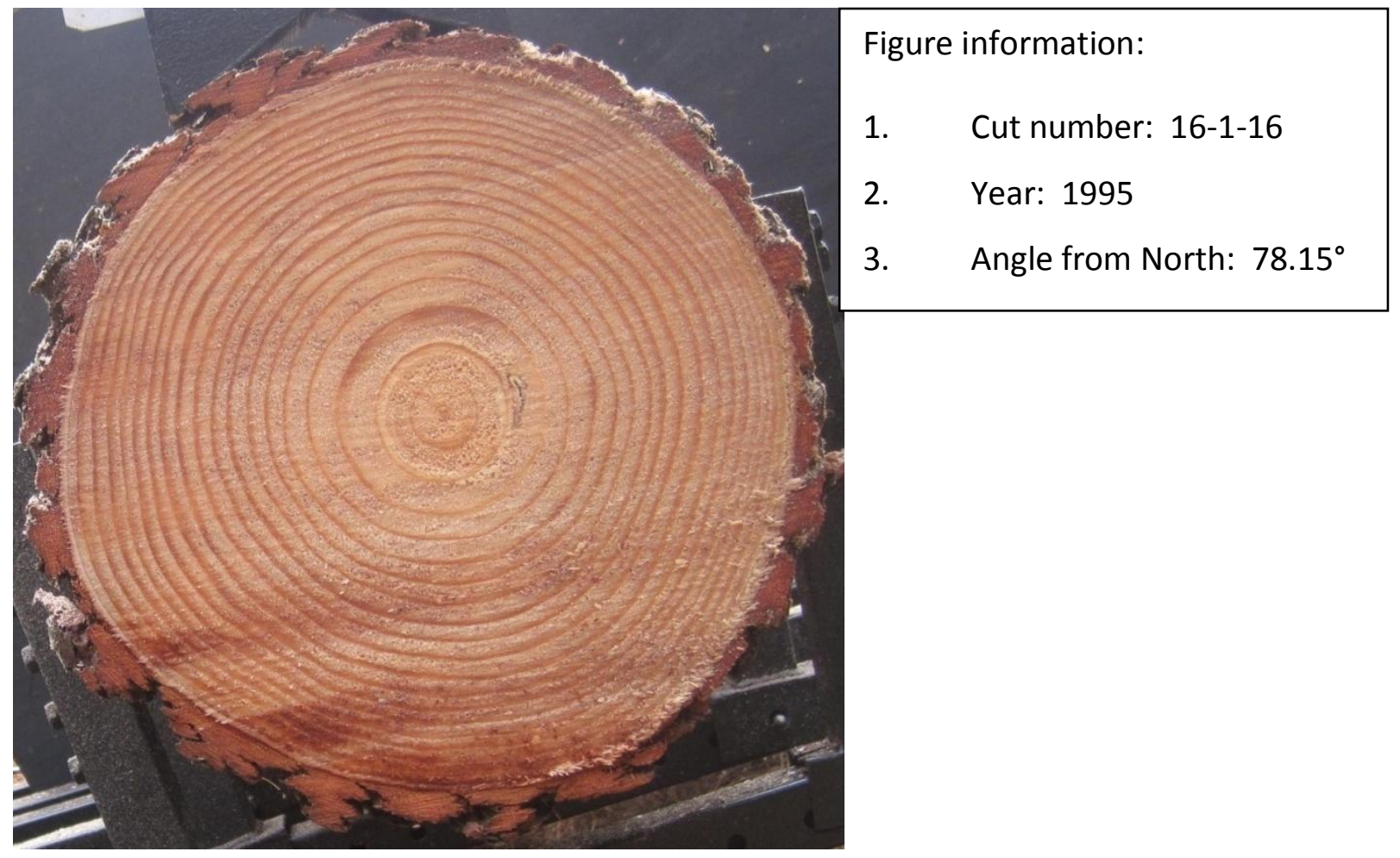

Figure 55: Resin pocket identified from photos.

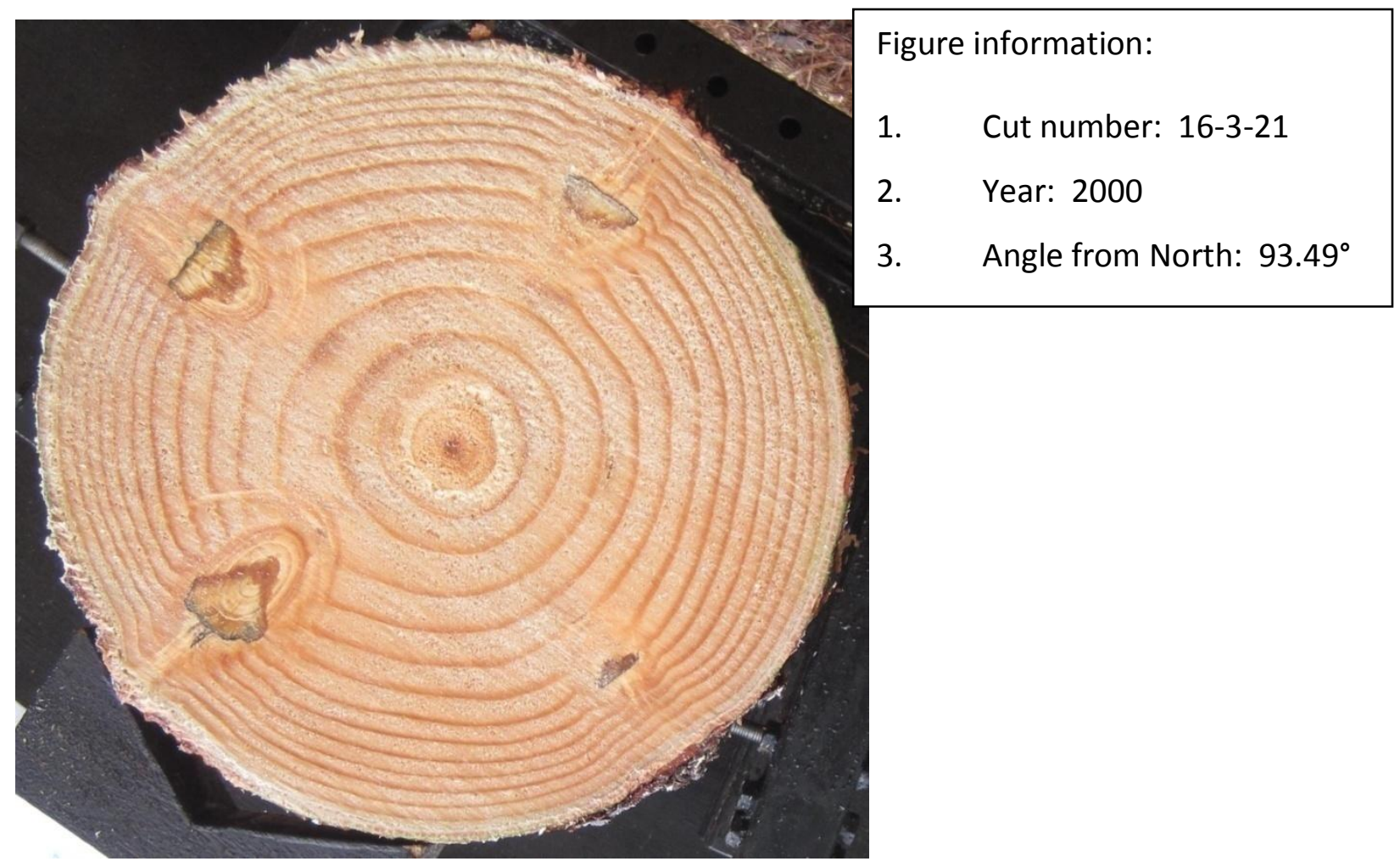

Figure 56: Resin pocket identified from photos. 


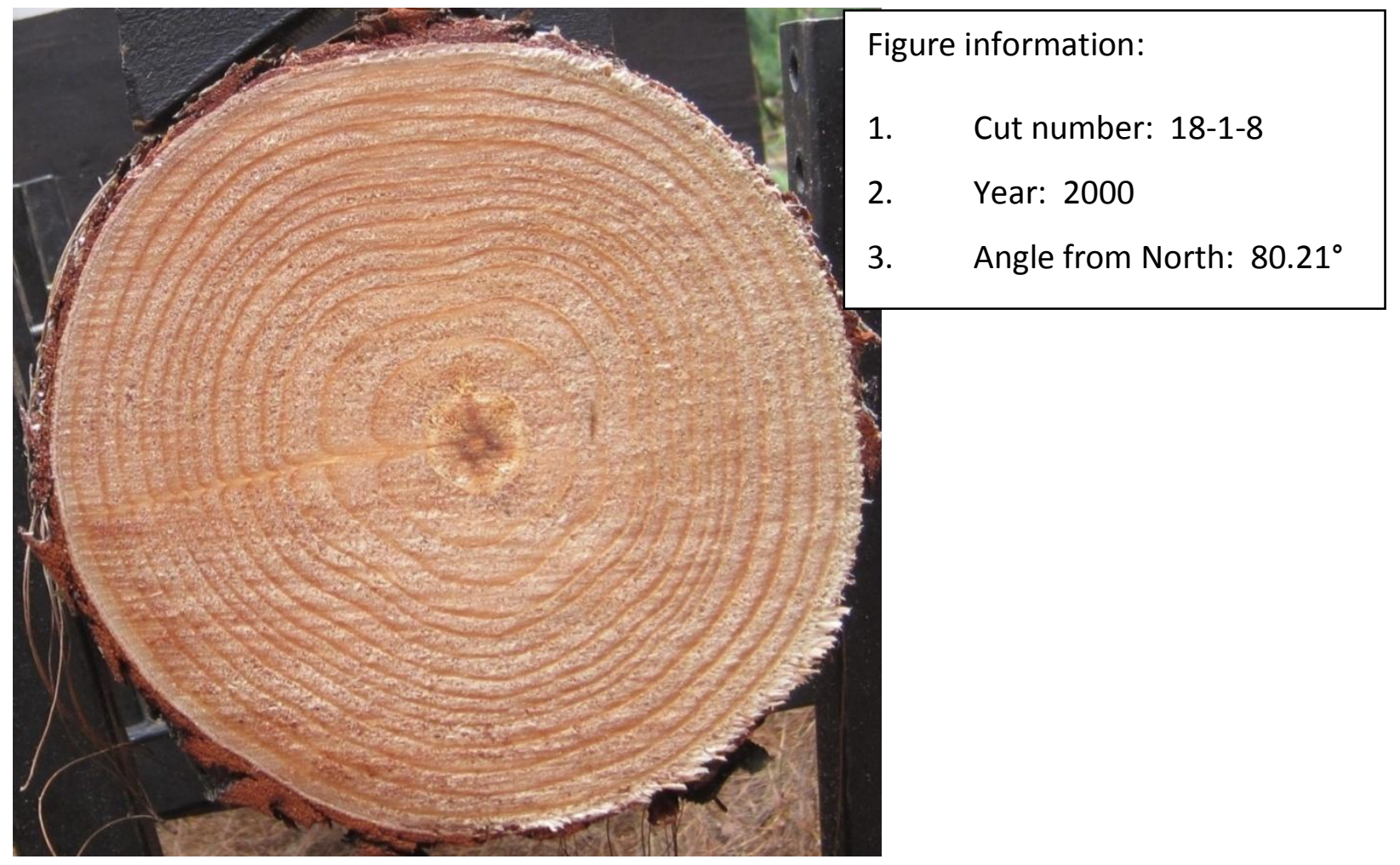

Figure 57: Resin pocket identified from photos.

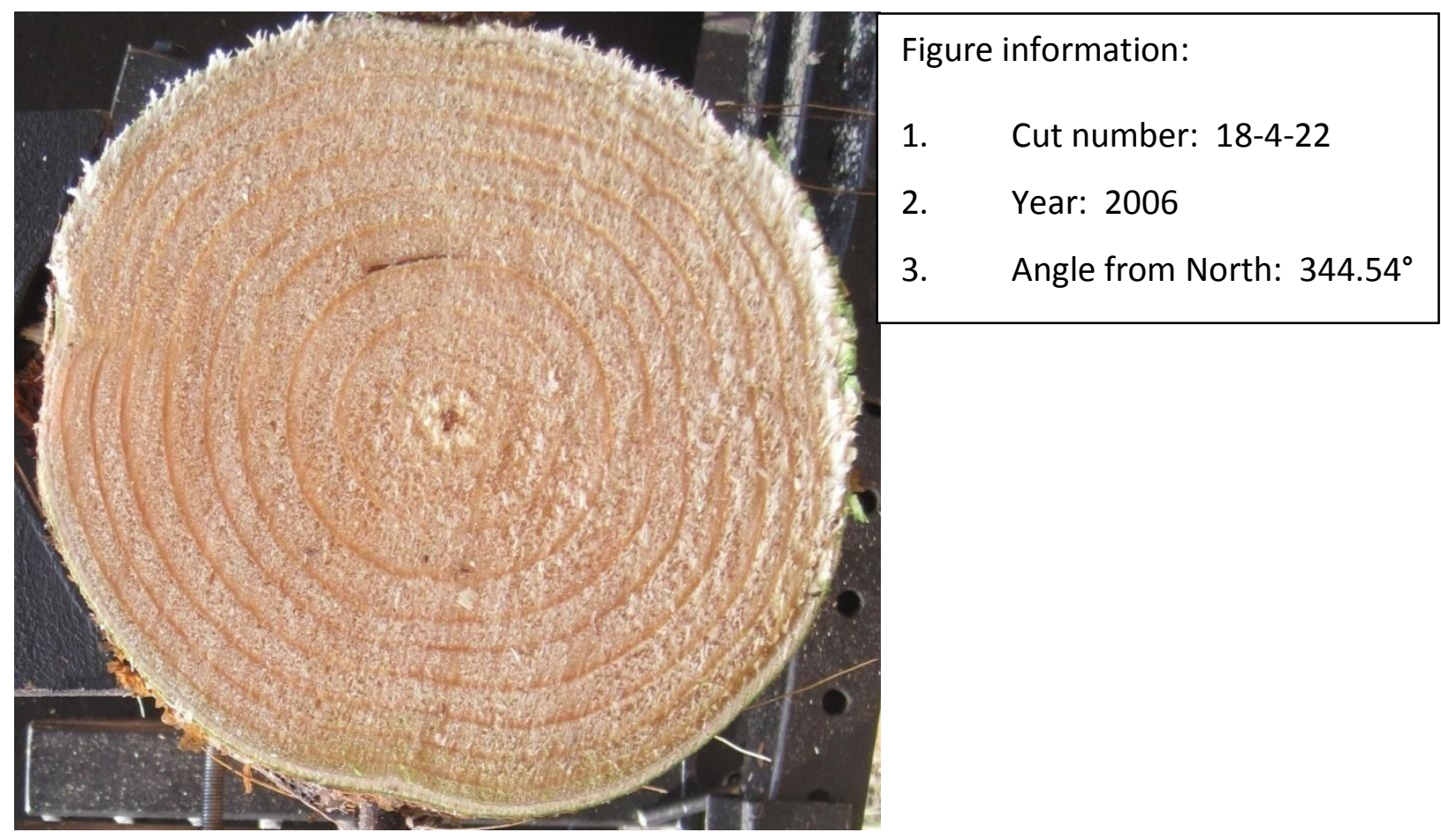

Figure 58: Resin pocket identified from photos. 


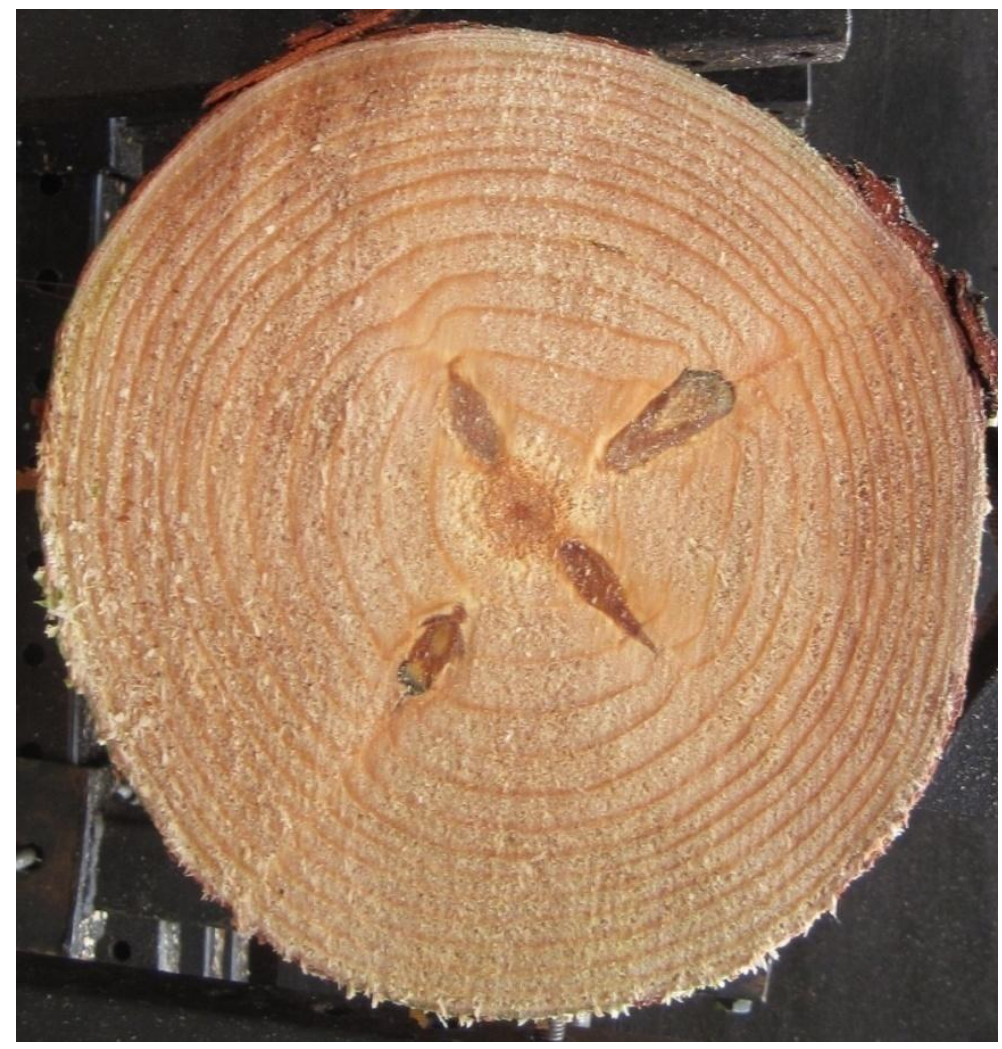

Figure information:

1. Cut number: $21-2-22$

2. Year: 2004

3. Angle from North: $17.49^{\circ}$

Figure 59: Resin pocket identified from photos.

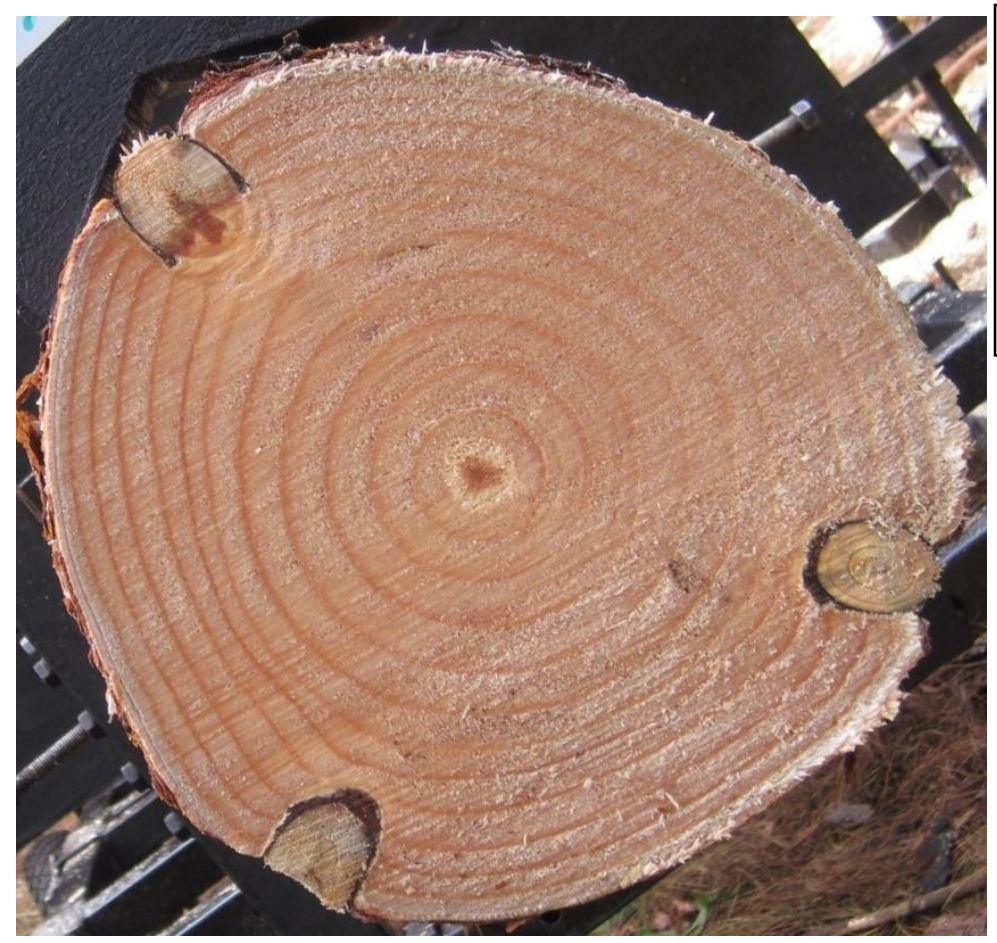

Figure information:

1. Cut number: $22-3-13$

2. Year: 2005

3. Angle from North: $343.76^{\circ}$

Figure 60: Resin pocket identified from photos. 


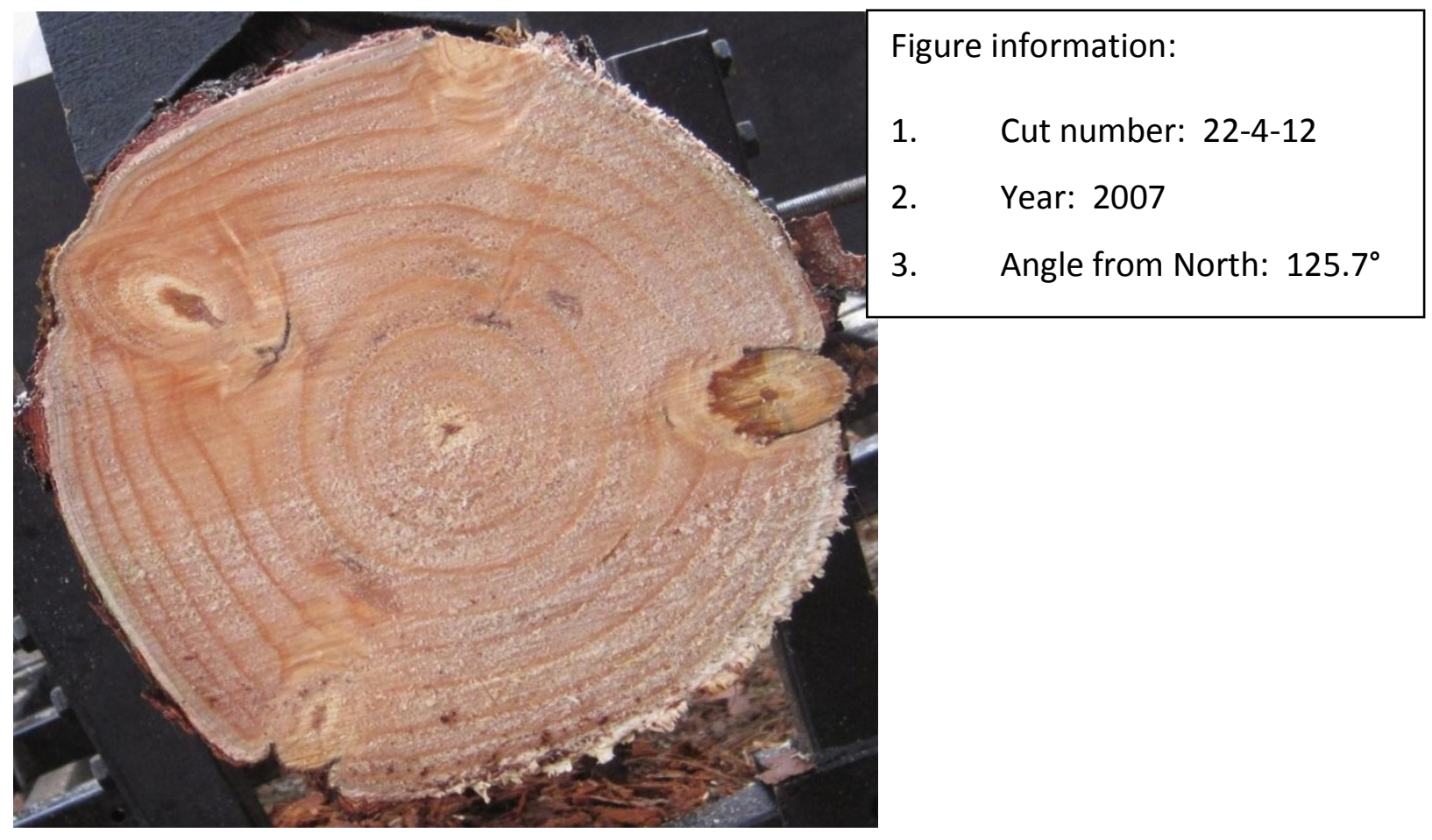

Figure 61: Resin pocket identified from photos. 